\title{
COORDINADORES
}

Adrián Antonio Cisneros Hernández y Livier Olivia Escamilla Galindo
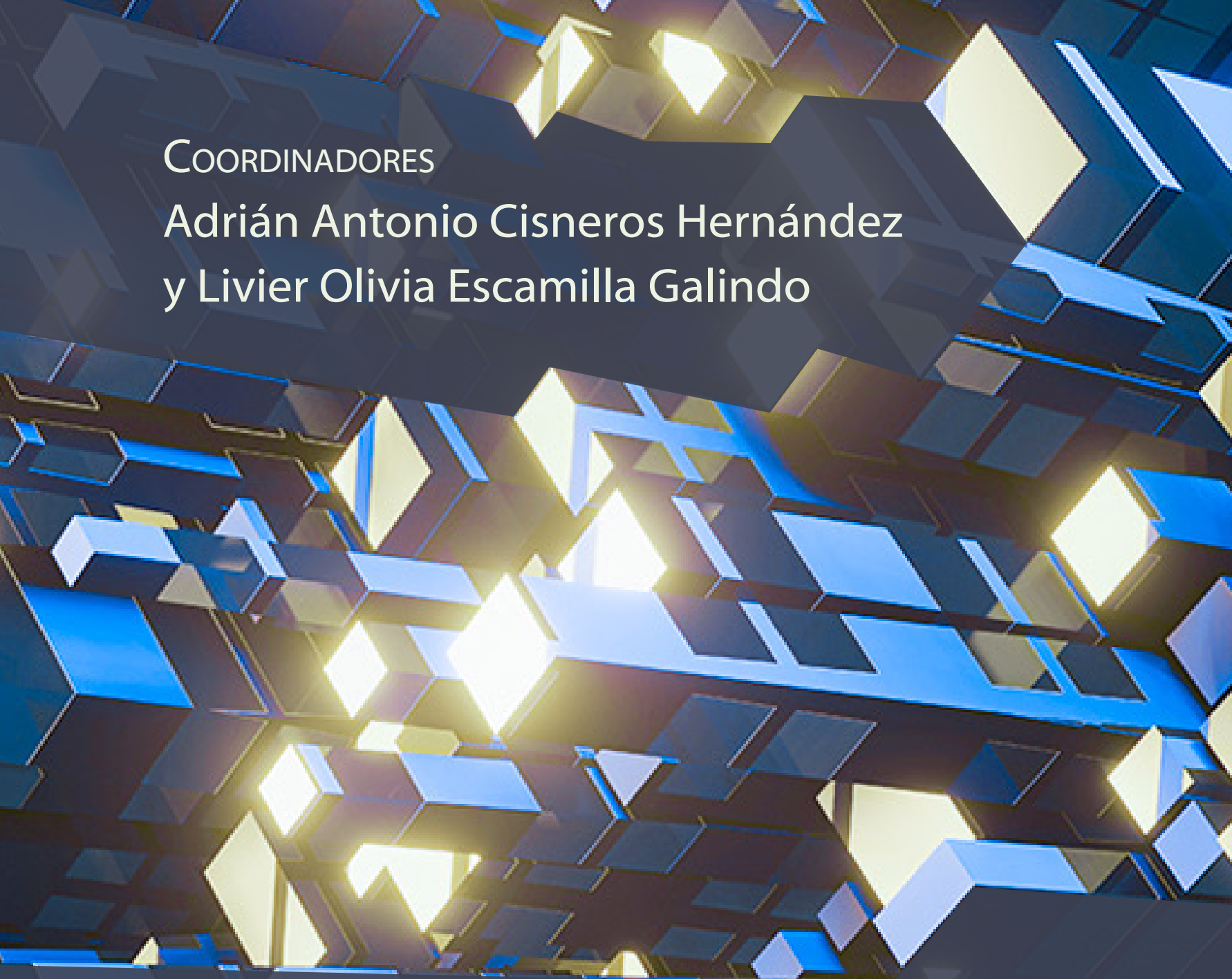

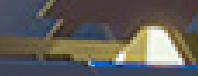

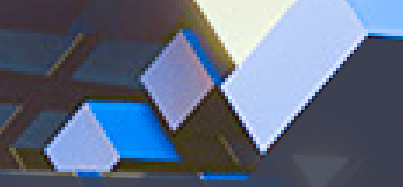

\section{Diseño de información} en escenarios comerciales y sociales

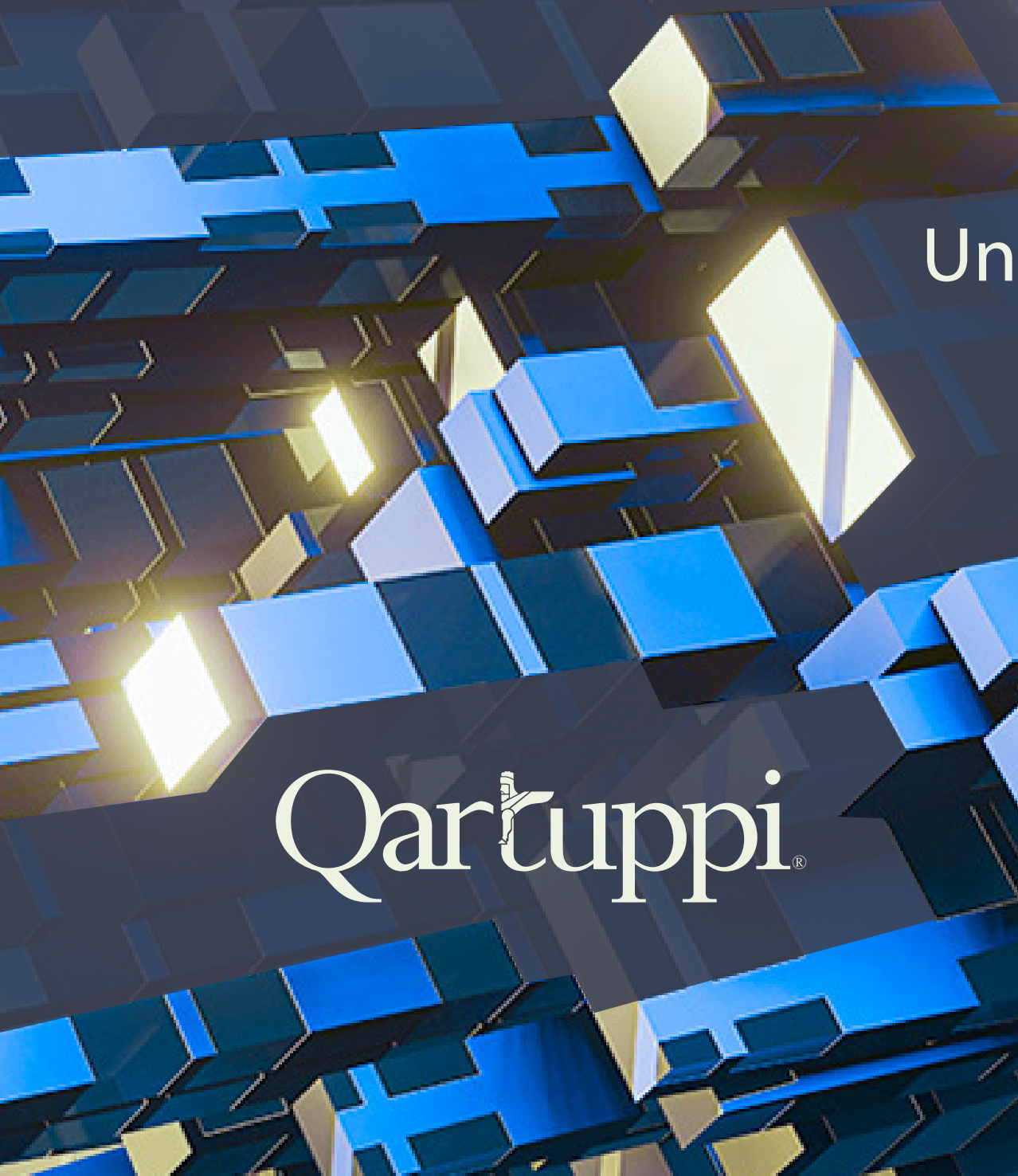
aplicación y análisis 


\section{(c) (i) $\$$}

BY NC SA

Esta obra se edita bajo una Licencia Creative Commons

Atribución-NoComercial-Compartirlgual 4.0 Internacional. 
Coordinadores

Adrián Antonio Cisneros Hernández

y Livier Olivia Escamilla Galindo

\title{
Diseño de información en escenarios comerciales y sociales
}

\author{
Un acercamiento a la teoría, \\ aplicación y análisis
}

Qartuppi 
Esta obra fue dictaminada por pares académicos a través del sistema de evaluación a doble ciego.

Diseño de información en escenarios comerciales y sociales Un acercamiento a la teoría, aplicación y análisis

1era. edición, diciembre 2021

ISBN 978-607-8694-22-8

DOI 10.29410/QTP.21.20

D.R. ๑ 2021. Qartuppi, S. de R.L. de C.V.

Villa Turca 17, Villas del Mediterráneo

Hermosillo, Son. 83220 México

https://qartuppi.com

Edición: Qartuppi, S. de R.L. de C.V.

Diseño editorial: Catalina Guiffo Cardona

Imagen de portada: Unsplash 


\section{Tabla de contenido}

7 Introducción

Adrián Antonio Cisneros Hernández y Livier Olivia Escamilla Galindo

10 Capítulo 1

Diseño de información como transformador social

Orlando Ortiz Márquez y Leonardo Mora Lomelí

17 Capítulo 2

Análisis de la comunicación del riesgo en una infografía sobre un fenómeno hidrometeorológico

Lenin Aceves Díaz, Jorge Campos Sánchez y Eva Guadalupe Osuna Ruiz

$30 \quad$ Capítulo 3

Análisis de la plataforma pictoagenda.com de acuerdo con los lineamientos de diseño de Información

Karla Alejandra Ponce Salinas y Adrián Antonio Cisneros Hernández

$49 \quad$ Capítulo 4

La legibilidad en el diseño de información para los débiles visuales

Elika Hadassa Arellano Chávez, Cynthia Lizette Hurtado Espinosa

y Marcela del Rocío Ramírez Mercado 
$64 \quad$ Capítulo 5

Design thinking para implementar buenas prácticas

en accesibilidad web

Angie Fernández Olimón y Elvia Luz González Muñoz

$82 \quad$ Capítulo 6

El wayfinding y su incidencia en las estrategias de movilidad urbana.

Caso de estudio: ciclovías del centro de Puebla

Mariel García Hernández y Juan Eduardo López Morales

$96 \quad$ Capítulo 7

Tipografías web para uso informativo

Tannia Flores Raffta y Jorge Campos Sánchez

108 Capítulo 8

Las variables visuales como herramienta para la configuración

del mensaje visual de artefactos de diseño de información

Mariel García Hernández y Adrián Antonio Cisneros Hernández 


\section{Introducción}

Adrián Antonio Cisneros Hernández

y Livier Olivia Escamilla Galindo

Diseño de información en escenarios sociales y comerciales. Un acercamiento a la teoría, aplicación y análisis es el resultado de la colaboración de estudiantes y académicos de la Maestría en Diseño de Información y Comunicación Digital. El libro se desarrolla mediante ocho capítulos con una indagación teórica, aplicabilidad y análisis de casos de estudio, con el objetivo de aportar conocimientos en el ámbito del diseño de información, desde diferentes perspectivas de estudio.

Orlando Ortiz Márquez y Leonardo Mora Lomelí presentan, en el capítulo 1, el tema "Diseño de información como transformador social", en el que describen el beneficio de la inferencia del diseño de información en áreas como la educación para la salud, desde la perspectiva preventiva, ante enfermedades no transmisibles y problemas de carácter conductual; lo que posiciona a la creación de contenidos como un actor principal en la intervención de la transformación social, realizada por instituciones en búsqueda de un cambio en la toma de decisiones de la población. Por ello, las acciones de intervención se benefician del trabajo multidisciplinario de expertos de la salud, diseñadores y usuarios, donde los contenidos generados se enfocan en solucionar objetivos específicos, en entornos determinados.

En el capítulo 2, "Análisis de la comunicación del riesgo en una infografía sobre un fenómeno hidrometeorológico", Lenin Aceves Díaz, Jorge Campos Sánchez y Eva Guadalupe Osuna Ruiz exponen una reflexión sobre la comunicación del riesgo, el diseño de información y la tipografía, a partir de un análisis de elementos visuales en un recurso infográfico sobre un fenómeno hidrometeorológico.

Karla Alejandra Ponce Salinas y Adrián Antonio Cisneros Hernández en el capítulo 3, "Análisis de la plataforma pictoagenda.com de acuerdo con los lineamientos de diseño de información", explican cada uno de los criterios y verifican si se cumplen en función de las necesidades de los usuarios (agentes cuidadores o agentes 
educadores junto con los especialistas a cargo de personas con trastorno del espectro autista [TEA]) o se carece de las directrices del diseño de información. Los autores también abordan uno de los métodos de aprendizaje de Picture Exchange Communication System (PECS), que los usuarios utilizan en personas con TEA.

En el capítulo 4, “La legibilidad en el diseño de información para los débiles visuales", Elika Hadassa Arellano Chávez, Cynthia Lizette Hurtado Espinosa y Marcela del Rocío Ramírez Mercado describen las características del diseño de información adaptado a un usuario con deficiencias visuales, en el que no solo se considera la legibilidad, sino también la ley de accesibilidad con respecto a dicha deficiencia.

Angie Fernández Olimón y Elvia Luz González Muñoz presentan, en el capítulo 5, el tema "Design thinking para implementar buenas prácticas en accesibilidad Web", en el que explican que se deben considerar las fases de esta metodología, ya que beneficia el proceso de diseño, mejora la definición de la estructura de la información de un producto y la experiencia de usuario en la interacción con un producto o servicio; además, ofrece flexibilidad para resolver problemas antes de llegar a la fase de producción. En el capítulo también se abordan los roles que desempeñan los profesionales durante el proceso metodológico del design thinking y se propone la mejora de los procesos y los resultados que se obtienen con la implementación de la accesibilidad Web para usuarios con algún tipo de limitación.

En el capítulo 6, "El wayfinding y su incidencia en las estrategias de movilidad urbana: caso de estudio de las ciclovías del centro de Puebla", los autores Mariel García Hernández y Juan Eduardo López Morales exponen que la legibilidad urbana debe ser considerada para desarrollar estrategias de movilidad y establecer bases empáticas con los usuarios de los espacios urbanos y sus expectativas con respecto a estos, a través de un análisis del comportamiento de los usuarios, sus necesidades con respecto al objeto de diseño a desarrollar y su perfil, tanto demográfico como psicográfico, sus deseos y necesidades a cubrir con base en el espacio urbano.

En el capítulo 7, "Tipografías Web para uso informativo", Tannia Edisa Flores Raffta y Jorge Campos Sánchez centran su trabajo en analizar factores formales y criterios de selección y aplicación tipográfica para ocho piezas de información que fueron publicadas en la página Web del Centro Universitario de Arte, Arquitectura y Diseño de la Universidad de Guadalajara. Los autores evidencian la relevancia de la selección tipográfica en el diseño de las piezas de información. 
Finalmente, en el capítulo 8, "Las variables visuales como herramienta para la configuración del mensaje visual de artefactos de diseño de información", Mariel García Hernández y Antonio Adrián Cisneros Hernández describen las variables visuales perceptivas y diferenciales como herramientas que facilitan la configuración del mensaje visual, al permitir una transmisión eficaz de la información y propiciar la fácil comprensión por parte del usuario. Los autores realizan un análisis exploratorio en tres piezas infográficas, en tres niveles de complejidad (bajo, intermedio y alto), que evidencian la aplicación de las variables, al identificar el orden de la información, la agrupación y la jerarquización.

A través de los ocho capítulos se presentan diferentes perspectivas de estudio sobre el diseño de información y se evidencia que su uso permite transmitir, de manera apropiada y accesible, información o conocimiento complejo sobre un tema en particular. El diseño de información ha adquirido un rol importante en los últimos años y en estos escenarios sociales y comerciales ha quedado de manifiesto el aporte significativo desde la teoría, la aplicación y el análisis en los casos de estudio expuestos. 


\section{Capítulo 1}

\section{Diseño de información como transformador social}

Orlando Ortiz Márquez y Leonardo Mora Lomelí

El diseño de información es una herramienta caracterizada por tener la versatilidad de construir proyectos en diferentes áreas de estudio; es utilizado como herramienta auxiliar para facilitar la labor de los profesionales a cargo de ejecutar los proyectos en los cuales están involucrados.

Aunque el diseño de información no proporciona un método exacto para lograr cumplir los objetivos planteados, ofrece una visión completa del panorama donde los usuarios son el eje central de la construcción de mensajes, lo cual facilita que la comunicación sea lo más exitosa posible.

En el presente capítulo se describe el beneficio de la inferencia del diseño de información en áreas como la educación para la salud, desde la perspectiva preventiva ante enfermedades no transmisibles y problemas de carácter conductual; esto posiciona a la creación de contenidos como un actor principal en la intervención de transformación social realizada por instituciones en búsqueda de un cambio en la toma de decisiones de la población.

Por ello, las acciones de intervención se benefician del trabajo multidisciplinario de expertos de la salud, diseñadores y usuarios, donde los contenidos construidos son enfocados en cumplir objetivos específicos en entornos determinados; a continuación, se describe el diseño de información, sus características y cómo actúa como herramienta auxiliar. 


\section{Descripción del diseño de información}

El diseño de información puede ser entendido como una ciencia, arte o herramienta, según como sea empleado; sin embargo, resulta más práctico entenderlo como un proceso para la construcción de mensajes, visualizaciones de datos o contenidos previamente adaptados a usuarios específicos con características particulares.

También el diseño es un proceso multidisciplinario que requiere de la amplia participación de otras ciencias, para las cuales se intenta elaborar contenidos; una de las características más importante que engloba al diseño de información es la construcción de traducciones de datos a contenidos; por lo general, se mantiene la característica de realizar un estudio previo sobre el usuario, escenario o contexto donde se desarrollarán las piezas de diseño y cuál será su interacción con estas.

De acuerdo con Frascara (2011):

El diseño de información tiene como objetivo asegurar la efectividad de las comunicaciones mediante la facilitación de los procesos de percepción, lectura, comprensión, memorización y uso de la información presentada. El diseño de información es necesariamente diseño centrado en el usuario. (p.9)

Lo anterior significaría que es una herramienta útil, en procesos educativos de cualquier índole, para transmitir grandes cantidades de información de la manera más efectiva posible.

Por otro lado, es complicado definir el diseño como una ciencia exacta por ser dependiente de la condición humana, por sus cambios, la temporalidad en la cual se desarrolla y el contexto a su alrededor; por ello, es importante que cada pieza de diseño sea reinventada de manera constante, sobre todo al tratar de influir de manera directa en las decisiones de los usuarios involucrados.

Debe considerarse al diseño de información como una herramienta de elaboración estratégica para traducir situaciones complejas a expresiones simples y entendibles, para facilitar a los usuarios adueñarse de dicho conocimiento en su uso personal o para ser compartido con sus pares. La difusión de contenidos en individuos particulares con intenciones específicas puede repercutir de manera social cuando se aplica a comunidades o grupos. 


\section{Herramienta para generar un cambio}

Muchas de las campañas de diseño, pensadas en la prevención y conservación de la salud, realizadas por organizaciones, empresas o gobiernos, tienen la intención de generar un cambio por medio de la participación de comunidades; esto, a través del cambio de hábitos en los denominados procesos educativos para la salud, donde los individuos requieren ser dueños del conocimiento y aplicarlo durante la toma de decisiones de su vida diaria.

Un ejemplo de intento por mejorar la calidad de vida de las comunidades es el esfuerzo realizado por los gobiernos para tratar de disminuir el contagio de la enfermedad conocida como dengue; en dichas campañas, es posible visualizar la información que trata de prevenir la propagación del mosquito portador, por medio del cambio de hábitos. Ante la creciente ola de casos de dengue en el continente americano, la Organización Panamericana de la Salud (OPS, 2017) emitió una serie de recomendaciones para que cada gobierno implementara acciones capaces de evitar el contagio de la enfermedad causada por el mosquito.

Dentro de las recomendaciones para el control de la enfermedad del dengue en las Américas, se hizo la mención de realizar la difusión de información centrada en las necesidades del usuario. La gestión para la prevención y control del dengue implicaba la toma de decisiones en diferentes niveles, entre ellos, el político:

para definir los papeles y funciones de los sectores e instituciones involucrados en la respuesta de prevención y control del dengue, en base a la información, las necesidades y las recomendaciones elaboradas por la institución líder o rectora, que debe ser salud. (OPS, 2017, p.21)

Por lo tanto, el diseño de información para combatir y prevenir la enfermedad debe considerar la construcción de contenidos para sus usuarios, con la traducción de las recomendaciones complejas a información entendible, por medio de los diferentes organismos y medios de cada país.

En el caso de México, tanto los gobiernos estatales como municipales se encargan de la elaboración de contenidos explicativos sobre qué acciones deben ser realizadas para evitar la propagación del mosquito portador; los contenidos incluyen realizar cambios en hábitos donde se sugiere a los usuarios evitar los criaderos del mosquito que pudieran presentarse por la falta de higiene en el hogar. 
La información suele ser presentada por medios impresos o digitales, con la pauta de transmitir información sobre acciones preventivas, posibles consecuencias, la forma de identificar la enfermedad y qué hacer en caso de estar contagiado.

El diseño de información actúa como una herramienta para influenciar el razonamiento sobre la salud, para que el individuo logre realizar acciones simples como mantener limpio su hogar, lo cual puede mejorar su condición de vida y la de quienes le rodean.

La comunicación en dichos procesos de educación para la salud hace uso del diseño de información como herramienta auxiliar, con la generación de contenidos para traducir las acciones necesarias que los individuos deben llevar a cabo para evitar contagiarse; entonces, resulta importante adaptar los contenidos intervinientes en un grupo determinado de usuarios.

El diseño de información es un proceso que puede facilitar y potencializar los procesos de transmisión de información compleja, dicha adaptación a las necesidades de los involucrados se vuelve un referente cultural cuando es compartida entre los individuos de cada comunidad.

Otro ejemplo, en el que el diseño de información es utilizado como herramienta para generar un cambio, es el problema de carácter conductual en jóvenes de educación primaria y secundaria, donde la falta de empatía por sus pares puede ocasionar disparidades.

Los problemas conductuales pueden ser clasificados en dos tipos, de acuerdo con Briggs-Gowan et al. (2006, como se citó en Gómez et al., 2014): “Las dificultades como la ansiedad, miedos, retraimiento y timidez se encuentran dentro de las dificultades internalizantes, mientras que las externalizantes incluyen agresión, hiperactividad, impulsividad e inatención" (p.177). En ambos casos, los usuarios involucrados encuentran un sesgo en su desarrollo personal y social, lo que puede derivar en futuros problemas al seguir las reglas y leyes de instituciones o estados.

La prevención y solución de problemas conductuales a una temprana edad pudiera verse reflejada en aspectos de convivencia social, educación e incluso seguridad para el caso de actitudes y prácticas antisociales, las cuales ponen en peligro la integridad de los individuos de una comunidad; por lo tanto, el diseño de información juega un papel importante durante la construcción de mensajes y materiales didácticos para solucionar dichas condiciones. 
Para ello, es importante el diseño de materiales educativos centrados en las necesidades y experiencias de los usuarios, ya que facilita el proceso cognitivo de aprendizaje de los contenidos otorgados por cada organización; el diseño de información está totalmente ligado a la creatividad y el manejo de los datos; al respecto, Wurman et al. (1996) indicaron que: "mientras que la información puede ser infinita, las maneras de estructurarla no lo son" (p.40). Cada visualización tendrá como condicionantes las diferentes lecturas de los usuarios y sus contextos específicos, pero las maneras de transmitir los mensajes pueden ser adaptados de maneras infinitas.

Los contenidos a los que cada persona es expuesta continuamente tienen una gran influencia en la toma de decisiones de cada usuario, las elecciones de compra pueden ser influenciadas por la publicidad o por la experiencia compartida por otros individuos; en el caso particular de las decisiones intervinientes en aspectos de índole social, la principal influencia es el conocimiento sobre las situaciones de riesgo o limitantes del desarrollo de las comunidades, porque un grupo de individuos conscientes de sus decisiones pueden llegar a transformar su estilo de vida o entorno.

Por medio de la transmisión de conocimiento para la toma de decisiones, el diseño de información logra realizar un cambio de carácter social reflejado en las condiciones de salud y vivienda de los integrantes de una comunidad, ya que la facilidad de los usuarios para consultar, comprender y adueñarse del conocimiento es un factor decisivo en el futuro de sí mismos y de quienes le rodean.

La construcción exitosa de piezas de diseño de información para generar un cambio de hábitos, por medio de la influencia en las decisiones razonadas de cada usuario, derivará en una transformación social; esto debido a que el conocimiento será transmitido de manera masiva por medios de comunicación o compartido entre los involucrados, para encontrar una fácil solución de conflictos dentro de una comunidad.

Como es mencionado por Smith y Ragan:

debe de existir una congruencia ente las metas, las actividades de aprendizaje y la evaluación. Junto con las características los que aprenderán y el contexto de aprendizaje, las metas del aprendizaje deben ser la fuerza conductora detrás de las actividades y la evaluación. (como se citó en Pettersson et al., 2012, pp.18-19) 
Entonces, será posible generar contenidos educativos óptimos para ser usados en los procesos educativos participativos.

El uso de herramientas auxiliares para facilitar la labor de los profesionales encargados de trabajar en comunidades, con la finalidad de realizar un cambio del entorno social, puede lograr una mejoría en el desarrollo y calidad de vida de los usuarios cuando se cuenta con materiales fáciles de entender y trabajar; estas herramientas, también pueden llegar a ser empleadas para mejorar la accesibilidad de usuarios vulnerables, limitados por sus sentidos o condición física, siempre que se genere material gráfico a consideración y empatía de las necesidades cognitivas y culturales de los individuos.

\section{Conclusiones}

Las herramientas de comunicación pueden ser empleadas en múltiples áreas de intervención social que requieren de potenciar los mensajes transmitidos. El caso de la educación para la salud para prevenir enfermedades es una de las principales áreas donde se construyen mensajes para originar transformaciones sociales, con la consideración a los usuarios y expertos de la salud como actores principales y punto de partida para diseñar; la educación para la salud puede llegar a beneficiarse en el uso de recursos didácticos de fácil implementación, para incrementar el aprovechamiento y rendimiento de los procesos de prevención de enfermedades; esto implica un beneficio en una sociedad educada, que cuenta con un acceso universal al conocimiento.

El diseño de información con características centradas en el usuario, junto con los esfuerzos de alguna organización, podrá repercutir en la interacción del usuario con un referente cultural, para facilitar el entendimiento del mundo a su alrededor, lo que derivará en la toma de decisiones conscientes; además, podrá provocar un cambio colectivo en el entorno social en aspectos como la salud, la educación, el ambiente, el territorio o la sociedad. 


\section{Referencias}

Frascara, J. (2000). Diseño gráfico y comunicación. Infinito.

Gómez, A., Santelices, M., Gómez D., Rivera, C., \& Farkas, C. (2014). Problemas conductuales en preescolares chilenos: Percepción de las madres y del personal educativo. Estudios pedagógicos, 5(40), 175-187. https://doi.org/10.4067/ S0718-07052014000300011

Organización Panamericana de la Salud. (2017). Estrategia de gestión integrada para la prevención y control del dengue en la Región de las Américas. OPS. https://iris.paho.org/bitstream/handle/10665.2/34859/OPSCHA17039_spa. pdf?sequence $=8 \&$ isAllowed $=y$ \&ua $=1$

Pettersson, R. (2012). Information design—It Depends. Rune Pettersson.

Wurman, R., Leifer, L., Sume, D., \& Whitehouse, K. (1996). Information anxiety 2. Que. 


\section{Capítulo 2}

\section{Análisis de la comunicación del riesgo en una infografía sobre un fenómeno hidrometeorológico}

Lenin Aceves Díaz, Jorge Campos Sánchez y Eva Guadalupe Osuna Ruiz

El diseño gráfico es una disciplina que encontró su definición en el siglo XX, sin embargo, a lo largo del desarrollo de la humanidad han existido diversas formas de representar y comunicar las expresiones o manifestaciones de las actividades de la sociedad. Las pinturas rupestres, los papiros, los códices, las hojas volantes y las infografías son algunos ejemplos de recursos de comunicación a lo largo del tiempo. La escritura sienta las bases de la historia documentada, mientras que la caligrafía y la tipografía facilitaron los procesos de impresión, con impacto en la difusión y transmisión del conocimiento y la cultura. Ante una situación de emergencia, resulta conveniente reflexionar sobre la comunicación del riesgo, el diseño de información y la tipografía, a partir de un análisis de elementos visuales en un recurso infográfico sobre un fenómeno hidrometeorológico, para preservar el bienestar de las personas y disminuir los riesgos; de esa forma, contribuir desde la comunicación con la gestión del riesgo.

\section{La comunicación del riesgo}

La comunicación, en sus diversas formas, ha acompañado a la humanidad y existen múltiples evidencias de la necesidad de transmitir un mensaje. Comunicar, en términos generales, es el proceso de transmisión y recepción de ideas, información y mensajes entre dos o más personas, es decir, poner en común un mensaje a través de un código comprensible entre los individuos o participantes. 
Desde la educación básica, las personas se familiarizan con los elementos primordiales del proceso de la comunicación:

el emisor, es decir, la persona que produce un mensaje; el código o conjunto de signos empleados para codificar el mensaje; el mensaje o información que se transmite; el canal o medio por donde viaja el mensaje; y finalmente el receptor, la persona o individuos que reciben el mensaje y lo interpretan. (Aceves, 2020, párr.2)

La disciplina que comunica los aspectos relativos a la prevención de situaciones de peligro se denomina comunicación del riesgo y, para la Organización Mundial de la Salud (OMS, 2018), ocurre cuando los expertos, líderes de comunidades, funcionarios públicos y personas de las comunidades intercambian información, consejos y opiniones, de manera continua y en tiempo real, para que la población adopte aquellas medidas de protección con el propósito de preservar la vida, los bienes, entre otros aspectos.

Este proceso de comunicación facilita a los tomadores de decisiones identificar, escuchar y atender necesidades y aquellas situaciones que preocupan a las personas, reconoce la OMS. Además, los mensajes o consejos que se emiten de las instituciones y dependencias de gobierno contribuyen con la certeza de la población al ser pertinentes o adecuados y con credibilidad.

De acuerdo con este organismo internacional, la comunicación del riesgo es una actividad que se desarrolla en tres momentos: antes, durante y después de una situación de emergencia. Antes, como parte de las actividades de preparación, es decir, en el desarrollo de capacidades para actuar ante una situación de emergencia o desastre; durante y después de una emergencia, en apoyo a las intervenciones de recuperación:

con el fin de asegurar que todas las personas en situación de riesgo puedan adoptar decisiones fundamentadas para protegerse a sí mismas, así como a sus familias y comunidades, contra las amenazas para su supervivencia, su salud y su bienestar. (OMS, 2018, p.1) 
México es una nación que por su dimensión y posición geográfica es susceptible de presentar diversos tipos de desastres, como los asociados a fenómenos de carácter hidrometeorológico, químico, socio-organizativo, geológico y sanitario. En 2019, el Centro Nacional de Prevención de Desastres (CENAPRED, 2020) reportó una erogación de 4 mil 915.8 millones de pesos y la muerte de 616 personas a causa de desastres. De acuerdo con esta dependencia del gobierno federal, el grado de marginación de las poblaciones determina el factor de riesgo para los habitantes y sus bienes.

\section{Modelo de comunicación de riesgos de la OMS}

Entre 2014 y 2017, la OMS actualizó las directrices sobre políticas y prácticas para la comunicación de riesgos en emergencias (CRE), en una primera etapa con una revisión bibliográfica y la integración de un grupo de elaboración de las directrices (GED) con la participación de "expertos en comunicación de riesgos, en preparación y respuesta ante desastres y en emergencias sanitarias" (OMS, 2018, p.4). Posteriormente, las evidencias científicas fueron sintetizadas a partir de una clasificación de la metodología empleada: estudios cuantitativos, cualitativos y mixtos, en los que se establecieron "niveles de confianza y certidumbre/incertidumbre" (OMS, 2018, p.6).

En ese sentido, las recomendaciones que aprobó la OMS (2018) se enmarcan en los siguientes aspectos:

A. Generación de confianza, comunicación de los elementos de incertidumbre y colaboración con las poblaciones afectadas;

B. Integración de la comunicación del riesgo en emergencias (CRE) y respuesta en emergencias, con acciones específicas en materia de gobernanza y liderazgo; la integración de un sistema de información y coordinación; formación de personal y financiamiento;

C. Prácticas de CRE, con acciones que contribuyan a la planificación estratégica de la comunicación; seguimiento y evaluación de CRE; integración a la estrategia de comunicación de las redes sociales virtuales; y la difusión de mensajes sin términos técnicos y entendibles para la población en general.

\section{El diseño de información}

Para Pontis (2011), el diseño de información atiende un problema y brinda una solución; en este caso, se trata de comunicar el riesgo. En este tipo de recursos, la pro- 
puesta estética se desplaza a un lugar secundario, ya que lo fundamental es poner en el lector una solución.

La esencia del diseño de información es analizar, organizar, entender, solucionar y diseñar, y su principal objetivo es la traducción de información compleja, datos no organizados ni estructurados, en información con sentido y de fácil acceso. (Pontis, 2011, párr.4)

Si bien el término diseño de información se gestó en la segunda mitad del siglo XX, existen ejemplos cuyos autores pusieron en práctica el análisis de los datos, su organización, entendieron el problema, propusieron una solución y la diseñaron, tal como sugiere Pontis.

Frascara (2011) señaló que el diseño de información "asegura la efectividad de las comunicaciones mediante la facilitación de los procesos de percepción, lectura, comprensión, memorización y uso de información presentada" (p.9). Además, posee las siguientes características: está centrado en el usuario; es interdisciplinario; ético, ya que reconoce las capacidades y limitaciones del otro y resuelve un problema e implica un esfuerzo cognitivo con mayor o menor eficacia.

En tanto, González (2016) definió el diseño de información como “la transformación de datos complejos en información que permite al usuario entender, generar conocimiento y tomar decisiones para la acción" (p.24). Además, reflexiona sobre las funciones del diseño de información, al crear puentes de comunicación entre usuarios de los artefactos para el entendimiento, la toma de decisiones y facilitar la vida cotidiana.

\section{La tipografía}

La escritura sienta las bases de la historia, ya que los diálogos y las referencias permiten ir hilando y tejiendo los hechos y acontecimientos de las sociedades. La escritura, además, requirió el desarrollo de un sistema de signos, que, en común acuerdo, dieron origen al alfabeto y las palabras. En ese sentido, la caligrafía y, principalmente, el desarrollo de la tipografía, facilitaron los procesos de impresión y, por lo tanto, la difusión y transmisión del conocimiento y la cultura. La Revolución Industrial (1760-1840) hizo posible el desarrollo de las artes gráficas, así como transformaciones culturales e intelectuales de fondo (Gómez, 2020). 
La evolución de las formas tipográficas ha ido de la mano de los avances tecnológicos en los sistemas de reproducción en que han sido utilizadas, desde los tipos de plomo hasta las fuentes digitales variables. En muchas ocasiones, la forma se supedita a la técnica, aunque, de manera más frecuente, las bondades de la tecnología han permitido reproducir formas más intrincadas, en sustratos de mejor calidad o dispositivos de mayor resolución. Sin embargo, aún con los avances técnicos de los últimos años, siguen existiendo consideraciones importantes al momento de elegir tipografía.

Seleccionar una familia tipográfica para un proyecto específico no es tarea sencilla, se tienen que considerar muchos factores, entre los que destacan aspectos conceptuales, técnicos y legales. El diseño de información no es la excepción, pues la palabra escrita es un factor elemental para cumplir con el objetivo de la pieza: comunicar de manera clara una gran cantidad de datos.

Para los fines de este capítulo se analizarán los factores antes mencionados en la pieza de información presentada.

\section{Aspecto conceptual}

La palabra escrita tiene dos funciones: lingüística y formal. La primera se refiere, en estricto sentido, a las palabras formadas por un conjunto de letras que, siguiendo las reglas gramaticales de cada idioma, se colocan una junto a otras para formar unidades de significado. Bajo esta óptica, no importa la plasticidad de estas letras, siempre y cuando cumplan con dichas reglas. La función formal es más complicada; está relacionada con el estilo gráfico de las letras y lo que él dispara en la mente del lector, activando mecanismos de relaciones metafóricas entre diferentes campos semánticos. Lo complicado de esta función es que no todos los lectores tienen las mismas categorías instaladas en sus mentes, por lo que se deben conocer los acuerdos previos, que el público objetivo de una pieza de información tiene en común, para utilizarlos a favor de una traducción conceptual más adecuada.

Al respecto, Pepe (2015) señaló:

La tipografía tomada como elemento identitario básico es una herramienta de fundamental importancia en la tarea profesional del diseñador gráfico y de comunicación. La relación entre la forma y la función de una fuente tipográfica debe ser el resultado de un profundo trabajo de 
análisis y un serio planteo conceptual, en el marco de un método proyectual. Toda tipografía expresa, por medio de su morfología externa, un mensaje particular. Podemos decir, por lo tanto, que el tipo comunica a través de su apariencia. (p.58)

En el caso de la pieza analizada (Figura 1), se observa que se utilizan dos familias tipográficas. Por un lado, la familia GMX, desarrollada por el equipo de la agencia de comunicación Enigma (2021), como parte del sistema de identidad institucional para el Gobierno de México 2018-2024. GMX solo se encuentra presente en los signos identitarios de las instituciones o dependencias de gobierno que avalan la información del recurso gráfico, en este caso, Gobierno de México, Secretaría de Seguridad y Protección Ciudadana (SSPC), Coordinación Nacional de Protección Civil (CNPC) y Centro Nacional de Prevención de Desastres (CENAPRED). Al ser un proyecto tipográfico desarrollado a la medida, la fuente ya fue concebida con ciertos atributos formales para comunicar algunos conceptos, sin embargo, lo que hace que el lector le atribuya confianza a esta fuente, posiblemente, es el hecho de que sea utilizada por el gobierno federal en todas sus comunicaciones. De esta forma, se construyó un acuerdo previo: Tipografía GMX es igual a oficialidad en la comunicación y, por ende, confianza en la información que la pieza contenga.

Por otro lado, el resto del texto en la pieza de información (Figura 1 y Figura 2) se compone con la familia tipográfica Montserrat, desarrollada en 2010 por la diseñadora tipográfica argentina Julieta Ulanovsky y ahora parte de Google Fonts, cuya inspiración fue "la señalización encontrada en un barrio histórico de Buenos Aires" (Kickstarter, 2014). La selección de esta familia no es una arbitrariedad, pues en el Manual de Identidad Gráfica 2018-2024 del Gobierno de México (2021a), se marca como tipografía secundaria para diseñar piezas de comunicación oficial. Se puede considerar como una fuente de formas neutras y que cede el protagonismo al mensaje a comunicar.

\section{Aspecto técnico}

Los sistemas de reproducción, sean físicos o digitales, influyen de manera muy significativa en la forma en que las formas tipográficas se despliegan y son percibidas por los usuarios de una pieza de comunicación. Desde la aparición de la imprenta en el siglo XV hasta la aparición de los primeros sistemas computacionales en el 
siglo XX, se desarrollaron familias tipográficas con un objetivo casi unánime: ser reproducidas en medios impresos. No es sino hasta la década de los ochenta que se comienza a popularizar el diseño de signos tipográficos pensados en su reproducción en pantallas digitales. Este cambio de paradigma ha bifurcado el camino del diseño de tipos, pues cada uno de estos entornos implica consideraciones técnicas especiales. Mientras que en la impresión, la ganancia de punto de los papeles juega un rol importante en los ajustes ópticos a algunos signos, en la reproducción digital, la adaptación de las formas a una cuadrícula de pixeles que se prenden o apagan es vital, sobre todo, cuando la resolución de los dispositivos no es la mejor o cuando los textos se deben desplegar en tamaños muy pequeños, como es el caso de los teléfonos móviles y las tabletas digitales; dos de los dispositivos más comunes para acceder a la red hoy en día y en donde es muy posible que los usuarios de las piezas de comunicación las consuman.

En este apartado, solamente se analizará la fuente Montserrat, pues es la que se utiliza en escenarios que presentan un mayor reto, como las cajas de texto amplias o cuerpos tipográficos pequeños. Montserrat tiene tres características que le ayudan a funcionar de una forma más o menos eficiente en pantallas digitales: carece de remates y ornamentos; tiene una modulación muy baja entre trazos finos y gruesos en su estructura y tiene contraformas amplias, sobre todo, en sus pesos más ligeros. Estos aspectos hacen que se pueda adaptar mejor a la retícula cuadrada de los pixeles y que resista mejor en tamaños pequeños. Sin embargo, sus formas tan redondas hacen que, en algunos escenarios su reproducción no sea tan eficiente.

\section{Aspecto legal}

Es muy importante comprender que las fuentes tipográficas son pequeños programas de cómputo, que se instalan en los equipos para desplegar las formas tipográficas en el momento en que el usuario presiona las teclas; por lo tanto, se encuentran bajo el esquema de licencias de uso. La gran mayoría de las familias tipográficas digitales que se encuentran de manera comercial, se encuentran protegidas ante las instancias internacionales correspondientes. Es de suma importancia que los usuarios cuenten con una licencia de uso de la fuente para evitar problemas legales. Esto no quiere decir que todas las fuentes tengan un costo monetario para el usuario final. Existen muchos tipos de licencias y modelos de distribución en el mercado, algunos de paga y otros de acceso gratuito. 
En la pieza de comunicación analizada, la familia GMX, al ser una familia a la medida, desarrollada por encargo del gobierno federal, se cuenta con la licencia de uso libre para las entidades de gobierno correspondientes, por lo que no existe conflicto legal para su uso en las piezas de comunicación oficiales, como es el caso de estudio. Por otro lado, la familia Montserrat, es parte de la compañía Google, quien la ha puesto a disposición del público de manera gratuita y bajo un esquema de licencia Open Font License, a través de su sitio Google Fonts. Esto permite que pueda ser utilizada de manera libre para proyectos impresos o digitales y con fines comerciales o de otro tipo, por lo que no existe conflicto en su uso para las piezas de comunicación del gobierno federal.

\section{Análisis de elementos visuales en un recurso infográfico}

EI CENAPRED es un órgano administrativo desconcentrado de la Secretaría de Seguridad y Protección Ciudadana (SSPC) del Gobierno Federal, que apoya con requerimientos técnicos y científicos al Sistema Nacional de Protección Civil (SINAPROC). Se creó en 1988 y hasta 2018 estuvo subordinado a la Secretaría de Gobernación.

Realiza actividades de investigación, capacitación, instrumentación y difusión acerca de fenómenos naturales y antropogénicos que pueden originar situaciones de desastre, así como acciones para reducir y mitigar los efectos negativos de tales fenómenos, para coadyuvar a una mejor preparación de la población para enfrentarlos. (Gobierno de México, 2021b, párr.1)

En el sitio web de CENAPRED, es posible tener acceso a una serie de recursos informativos de carácter preventivo. En el apartado de publicaciones, se encuentran recursos organizados por riesgos geológicos, riesgos hidrometeorológicos, riesgos químicos y sanitarios, prevención/preparación; series especiales e institucionales.

Para este caso de análisis, se eligió la infografía Ciclón acercándose, del apartado riesgos hidrometeorológicos, compuesta de dos secciones, como se muestra en la Figura 1 y la Figura 2. Una infografía es un recurso gráfico cuyo objetivo es "convertir lo complejo en sencillo y explicar lo difícil de la forma más clara posible" (Gamonal, 2013, p.335). 
En ese sentido, la infografía analizada (Figura 1) explica los cinco niveles del Sistema de Alerta Temprana de Ciclones Tropicales (SIAT-CT), a partir de un semáforo que busca informar sobre los riesgos de un fenómeno hidrometeorológico, sobre su proximidad. El color azul indica peligro mínimo; el verde, peligro bajo; el amarillo, peligro moderado; el naranja, peligro alto; y el rojo, peligro máximo. Este sistema de color incluye números y podría confundirse con la escala Saffir-Simpson, que mide la intensidad de los vientos de un ciclón tropical y determina su peligrosidad también con una escala de cinco niveles.

\section{Figura 1}

Infografía Ciclón acercándose

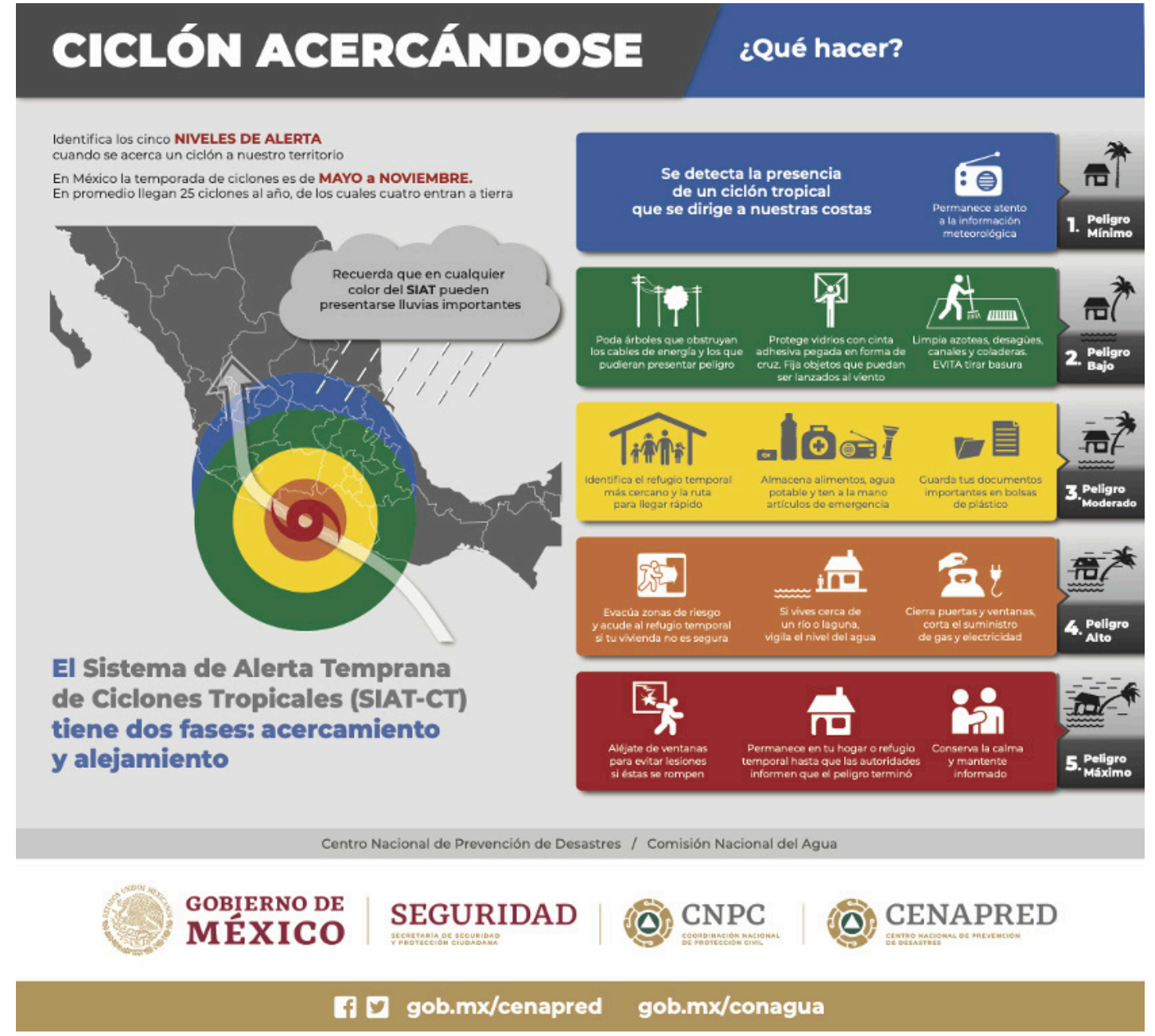

Nota. Tomado de CENAPRED, 2021.

Sin embargo, la Figura 1 brinda también información sobre las medidas de protección y las acciones que la población debe considerar, a partir de la proximidad de un fenómeno hidrometeorológico; es decir, busca transmitir confianza y certidumbre sobre las medidas de prevención, como lo aconseja la OMS (2018) en sus recomendaciones para comunicar los riesgos. 
La Figura 2 de este recurso describe los ciclones tropicales, su origen, la escala que los mide (Saffir-Simpson) y los efectos que podría ocasionar; en este sentido, esta sección de la infografía comunica una serie de elementos de incertidumbre con la intención de generar conciencia sobre la peligrosidad de este tipo de fenómenos. La integración de los mensajes es en menor medida con términos técnicos $y$, por el contrario, utiliza metáforas para esclarecer el concepto. Por ejemplo, para explicar un sistema atmosférico, emplea la frase "se asemeja a motores gigantes" (CENAPRED, 2021).

Los mensajes que se incluyen en la infografía que se analiza son breves, claros y certeros, ya que la Figura 1 del recurso se limita a frases con menos de 20 palabras, utiliza un lenguaje sencillo y común. La estructura gramatical enfatiza el verbo al inicio de la mayoría de las oraciones, con la intención de informar y llamar a la acción por parte del lector del recurso.

\section{Figura 2}

Infografía Ciclones tropicales

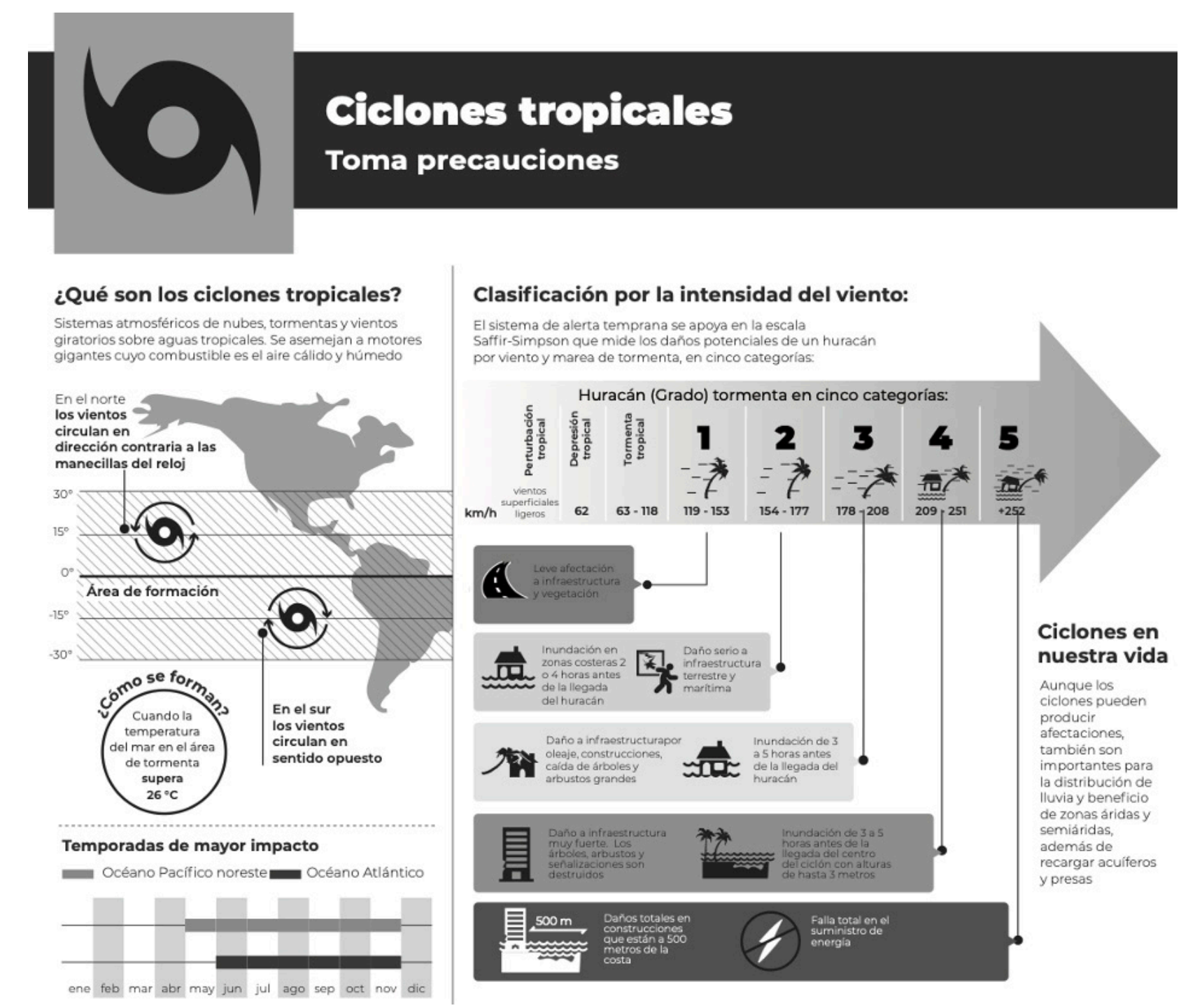

Nota. Tomado de CENAPRED, 2021. 
En cuanto al diseño de información, la Figura 1 tiene una estructura definida: un título que aclara el tema que aborda, un subtítulo que define el Sistema de Alerta Temprana de Ciclones Tropicales (SIAT-CT) y las recomendaciones. La información se presenta a manera de díptico: el elemento izquierdo describe el SIAT-CT, la temporada en la que se presentan dichos fenómenos, una representación de un ciclón y los niveles del SIAT. En esta sección, el titular sobre el SIAT-CT cumpliría mejor su función al estar posicionado en la parte superior izquierda. El elemento derecho describe los cinco niveles de la alerta y los posibles efectos del fenómeno hidrometeorológico.

La Figura 2, al carecer de color y presentar la información en tonos de gris, es menos atractiva visualmente, pero es informativa; otorga datos precisos, de interés para los lectores y con fines educativos. Su estructura es clara, ofrece un título y precisa el contenido, centrado mayormente en la descripción de los efectos de un ciclón tropical. En segundo término, se pueden conocer más detalles sobre qué son y cómo se forman estos fenómenos hidrometeorológicos, así como la temporada de mayor impacto en el territorio nacional.

Respecto a la composición tipográfica, una situación es la selección de un sistema tipográfico para una pieza de comunicación y otra es componer dicha pieza con él. En el caso analizado, se ha utilizado la familia Montserrat, en algunas de sus variantes, para crear jerarquías a través del peso visual; usando versiones más gruesas (bold) para titulares y otras más delgadas (light) para el cuerpo de texto, lo que facilita la lectura fragmentaria de la información.

Sin embargo, el hecho de que se utilicen versiones muy delgadas en color blanco, sobre los fondos de color utilizados para seccionar la información por bloques, hace complicada su lectura, sobre todo, en escenarios en donde el tamaño de la letra o la resolución del dispositivo no sean los más adecuados. De la misma forma, en la Figura 2, diseñada únicamente en escala de grises, el contraste en algunos de los apartados es bajo, lo que dificulta el reconocimiento de los signos y, por ende, la lectura de la pieza en general.

\section{Conclusiones}

Si bien, las recomendaciones sobre comunicación del riesgo de la OMS contemplan otros aspectos como la gobernanza y el liderazgo, la integración de un sistema de información y coordinación, la formación de personal y el financiamiento, es posi- 
ble identificar el cumplimiento de los aspectos relacionados con la generación de confianza, comunicación de los elementos de incertidumbre y colaboración con las poblaciones afectadas; así como la planificación estratégica de la comunicación y la difusión de mensajes, sin términos técnicos y con textos entendibles para la población en general, que contribuyan con la toma de decisiones de los lectores.

La selección tipográfica juega un papel sumamente importante en el diseño de información, pues puede facilitar el proceso de lectura y la comprensión del mensaje o, por el contario, provocar que el usuario se canse de sobremanera y abandone la lectura.

Conocer los escenarios de reproducción de cada pieza de información es de vital importancia para la selección tipográfica y las decisiones de diseño. Pareciera que la pieza analizada fue diseñada, en un principio, para ser impresa y que, con el paso del tiempo, se comenzó a compartir a través de medios digitales. El tamaño de las letras en proporción a la pieza en general es muy pequeño y dificulta su lectura.

Los productos de comunicación del riesgo, con criterios de diseño de información y la aplicación de una tipografía adecuada contribuyen con la creación de capacidades y el fortalecimiento de la toma de decisiones de la población ante una emergencia. 


\section{Referencias}

Aceves, L. (2020). La comunicación ante una pandemia. La gaceta del sur. http:// gaceta.cusur.udg.mx/la-comunicacion-ante-una-pandemia/

Centro Nacional de Prevención de Desastres. (2020). Impacto Socioeconómico de los Principales Desastres Ocurridos en México en el Año 2019. CENAPRED. http://www.cenapred.unam.mx/es/Publicaciones/archivos/429RESUMENEJECUTIVOIMPACTO2019.PDF

Centro Nacional de Prevención de Desastres. (2021). Búsqueda de publicaciones. Riesgos hidrometeorológicos Ciclones Tropicales. http://www.cenapred.unam. $\mathrm{mx} /$ PublicacionesWebGobMX/buscar_buscaSubcategoria

Enigma. (2021). Proyectos. https://enigma.mx/proyectos/gmx/

Frascara, J. (2011). ¿Qué es el diseño de información? Infinito.

Gamonal, A. R. (2013). Infografía: Etapas históricas y desarrollo de la gráfica informativa. Historiay Comunicación Social, 18, 335-347.http://wdg.biblio.udg.mx:2048/ login?url=https://www.proquest.com/scholarly-journals/infografía-etapashistóricas-y-desarrollo-de-la/docview/1508553595/se-2?accountid=28915

Gobierno de México. (2021a). Manual de Identidad Gráfica 2018-2024. https://www. gob.mx/wikiguias/articulos/manual-de-identidad-grafica-2018-2024

Gobierno de México. (2021b). Instituciones. CENAPRED. https://datos.gob.mx/busca/ organization/about/cenapred

González, M. (2016). Diseño de Información y vida cotidiana. Editorial Designio.

Gómez, R. G. (2020). Diseño, tipografía y comunicación visual. Ahora todo vale. Cuadernos del Centro de Estudios en Diseño y Comunicación, 25(120), 83-100. https://fido.palermo.edu/servicios_dyc/publicacionesdc/cuadernos/detalle_ articulo.php?id_libro $=850 \&$ id_articulo $=17452$

Kickstarter. (2014). The Montserrat Typeface. https://www.kickstarter.com/projects/ julietaulanovsky/the-montserrat-typeface

Organización Mundial de la Salud. (2018). Comunicación de riesgos en emergencias de salud pública: directrices de la OMS sobre políticas y prácticas para la comunicación de riesgos en emergencias (CRE). OMS.

Pepe, E. G. (2015). Diseño tipográfico e identidad. Revista Bold, 2(2), 56-66. http:// sedici.unlp.edu.ar/bitstream/handle/10915/53704/Documento_completo. pdf-PDFA.pdf? sequence $=1$ \&isAllowed $=\mathrm{y}$

Pontis, S. (2011). ¿Qué es el diseño de información? ForoAlfa. https://foroalfa.org/ articulos/que-es-el-diseno-de-informacion 


\section{Capítulo 3}

\section{Análisis de la plataforma pictoagenda.com de acuerdo con los lineamientos de diseño de información}

Karla Alejandra Ponce Salinas y Adrián Antonio Cisneros Hernández

El método de aprendizaje Picture Exchange Communication System (PECS) es abordado en el presente capítulo; este es utilizado por agentes cuidadores o educadores para que las personas con trastorno del espectro autista (TEA), a través de imágenes, aprendan a comunicarse y a desarrollar distintas habilidades. Según el grado del trastorno, las personas con TEA pueden aprender a hablar, leer o escribir; aunque esto también dependerá de distintos factores en su entorno.

También se aborda el tema de las Tecnologías de Información y Comunicación (TIC), las cuales han tenido un gran desarrollo durante los últimos años, logrando desempeñar un papel fundamental en la enseñanza; no solo como apoyo para todos los niveles educativos, sino también en el ámbito de la educación especial. Actualmente, es posible encontrar distintas plataformas en la web y aplicaciones móviles que potencian y mejoran la comunicación de personas con TEA.

Sin embargo, la efectividad de este tipo de plataformas o aplicaciones está condicionada por su diseño y estructura para un mejor manejo y comprensión; en este sentido, el diseño de información es esencial para que la experiencia del usuario sea óptima, sin condicionar su desempeño.

La experiencia que brinde la interfaz dependerá del diseño y comunicación de la información, la cual debe ser clara, sencilla y eficiente. Esto ayudará no solo en el aprendizaje, sino también para empezar a desarrollar distintas habilidades; desde aquellas esenciales del día a día hasta aquellas más complejas (e. g., desarrollar 
técnicas del habla y la comunicación), que se verán beneficiadas a partir un buen diseño, para que los usuarios (en este caso, los agentes cuidadores o educadores y especialistas) puedan navegar y hacer las cosas de manera independiente sin necesidad de apoyo externo; sin embargo, se deben cumplir algunas directrices para que este sea efectivo y se pueda considerar como un buen diseño de información (DI).

Para este proyecto, se hará un análisis exploratorio del uso de la plataforma pictoagenda.com; se explicarán cada uno de los puntos con los que cumple acorde al diseño de información y se dará a conocer si realmente genera la experiencia esperada como herramienta de apoyo para la comunicación de las personas con TEA.

\section{Lineamientos de diseño de información en la plataforma pictoagenda.com}

La forma en la que una persona se comunica se debe estrictamente a la manera en la que se nos enseñó en su momento, a través de acciones o palabras, para facilitar la comprensión; esto es de suma importancia al momento de desarrollar una capacidad de comunicación entre iguales o cualquier persona con la que se desea entablar una conversación o diálogo.

Se puede decir que la forma en la que un escolar empieza a reconocer la información es a través de la mímica e imitación; los infantes utilizan esta técnica para relacionar una figura con el significado que se le está proporcionando. Un claro ejemplo es al momento de empezar a leer y escribir, cuando se pone a los niños a copiar la forma gráfica de las letras, apoyándose de la fonética para enfatizar el sonido de esta y para que ellos sean capaces de repetir y relacionar no solo el gráfico, sino también el sonido.

De acuerdo con estudios y pruebas realizadas por Montessori (1918), se ha visto que la facilidad de un niño para aprender y reforzar algunos de los conocimientos que se le imparten, es con el apoyo de cierto tipo de materiales a los que se llamaron didácticos, que ayudan a reforzar o transmitir de una manera lúdica la información que se quiere enseñar, donde el niño interactúa de manera directa con su entorno a modo de juego o actividad. Rodríguez y García (2020) indicaron la importancia del método:

En los colegios Montessori que hemos visitado, hemos podido observar cómo los niños se pelean su propia fruta, deciden ellos mismos a qué hora le apetece comer etc. Por ello queremos destacar una frase que un 
maestro de una de las escuelas que visitamos nos dijo: "El mayor logro que puede sentir un profesor es que no te necesitan en tu aula. Si eso se cumple, lo estás consiguiendo." Esto refleja la esencia de lo que busca este método [...] (p.122)

La mayoría de este material, a pesar de ser de apoyo, comúnmente está acompañado de dinámicas relacionadas a un tema a tratar, ya sea de aprendizaje o de contenido. Un claro ejemplo serían las canciones del abecedario o gráficos que relacionan figura-forma de objetos con colores o cantidades. En muchas ocasiones, este material didáctico es de madera, plástico o cartón para ser manipulado fácilmente por los niños.

Piaget (1980) indicó que el aprendizaje nos lleva a realizar acciones por las cuales se aprende y se adquieren ciertos conocimientos, teniendo como resultado un conocimiento empírico. Por lo que el material didáctico se convierte en parte esencial en el aula y el aprendizaje mismo; siendo un gran aliado en la enseñanza, para que el niño absorba la información de una manera divertida y didáctica.

Se han realizado distintos métodos de enseñanza a lo largo de la historia de la educación, aunque muchas de estas prácticas se basan solamente en el uso de la memoria, haciendo que el escolar no emplee su creatividad y solo memorice la información que se le va dando, sin necesidad de entender o comprender lo que está haciendo; por lo tanto, la información no se retiene y se desecha a las pocas horas si no se vuelve a repasar el contenido.

Esto ha llevado a la educación a pasar de materiales físicos a herramientas digitales orientadas a la educación, abriendo un amplio abanico de posibilidades para poder hacer del aprendizaje un proceso más dinámico y divertido, dejando atrás las viejas prácticas donde el único material de aprendizaje eran los libros y cuadernos. Hoy en día, se puede contar con una tableta, un teléfono inteligente o incluso una SmartTV como herramientas para el aprendizaje de los niños.

Un claro ejemplo han sido las distintas aplicaciones y páginas de apoyo que se han generado no solamente como herramientas, sino también como programas de soporte para un mejor aprendizaje; incluso se puede decir que varias de estas herramientas son consideradas esenciales; según Torres (2021), el tipo de aprendizaje por imitación es fundamental durante el proceso global de aprendizaje, incluso se ha demostrado que es esencial para los niños con TEA, ya que el proceso se facilita 
por la repetición y engloba por lo menos tres sentidos, convirtiendo el proceso en un ejercicio completamente sensorial. Por lo tanto, se refuerza la hipótesis de que el aprendizaje lúdico y didáctico tiene más fuerza de aprendizaje que el simple hecho de leer y releer el contenido o la información.

Ahora bien, este tipo de tecnologías han sido de gran apoyo para este tipo de niños, que cuentan con ciertas características, las cuales se pueden identificar como síntomas y comportamientos visibles o identificables. Según Wing (1979) son los siguientes: (1) trastorno cualitativo de relación que remite básicamente en la reciprocidad socioemocional; (2) alteraciones de la comunicación y el lenguaje donde afecta principalmente a la comunicación no verbal y desarrollo junto con el mantenimiento y comprensión de relaciones; y (3) falta de flexibilidad mental y comportamental.

Afortunadamente, en la actualidad, el material didáctico con el que se cuenta, no solo para la educación en todos los niveles, sino para la educación especial, ya no se limita al material didáctico convencional; se ha evolucionado junto con la era digital y se han convertido en plataformas de aprendizaje, aplicaciones para equipos móviles o incluso se pueden apoyar en otras plataformas de streaming o programas televisivos. Por lo tanto, las TIC tienen un papel fundamental en la educación.

De acuerdo con Cuesta (1997) y Rivière (1997), las TIC han demostrado ser un gran apoyo para las personas con TEA, para promover y desarrollar cierto grado de autonomía y destreza cognitiva para la interacción con otras personas y, a su vez, con su entorno. Son de gran utilidad para que estos desarrollen un sentido de espacio-temporal a través de una rutina u horario, para cumplir con determinadas actividades, acorde a una serie de pasos y actividades marcadas de manera visual; a través de cronogramas ayudan a tener cierto sentido de comunicación y acción; por medio de pictogramas regulan su comunicación y facilitan la elección y toma de decisiones, logrando en gran parte la autonomía que se plantea desde un inicio con este método.

El método de aprendizaje Picture Exchange Communication System (PECS) Sistema de Comunicación por Imágenes, traducido al español- es un método creado por Andy Bondy y Lori Frost en 1985, cuyo proceso tiene seis etapas; va desde el reconocimiento de palabras por objetos acorde a las tarjetas que se indican y señalando a la otra persona qué necesita o a qué se refiere con esa tarjeta, escalando la dificultad de su uso y acorde con el avance del proceso, de igual forma se avanza de 
nivel para usar las tarjetas, incluso para formar oraciones o frases, incluyendo la estructura de una oración donde se señala el sujeto, el verbo y la preposición (Bondy \& Frost, 1985).

En la actualidad, las herramientas digitales han tomado un papel fundamental en la educación, modificando de manera radical la forma en la que esta es impartida; sobre todo, en los últimos dos años. Al respecto, Tonucci mencionó que:

La contradicción que yo encuentro es que la escuela quiere demostrar que se puede seguir como antes y sigue siendo una institución de clases y deberes, donde lo único que se modificó fue el medio: en lugar de ser presencial, se hace de forma virtual. (Belleli, 2020, párr.7)

Por lo tanto, la educación ya no solamente se limita a un espacio (en este caso el aula), sino que se ha pasado al ambiente entero del escolar.

Sin embargo, se pueden encontrar muchas herramientas o material de apoyo para el desarrollo del niño con TEA. Según la página web Educación 3.0 (2021) es posible encontrar diversos recursos para que los agentes cuidadores trabajen desde casa el TEA, en sus diferentes grados y niveles. Entre estos recursos, indican los siguientes: (1) Smile and Learn: hace uso de juegos interactivos que ayudan a trabajar la atención, la memoria, el cálculo o el lenguaje; (2) José Aprende: es una serie de cuentos visuales que enseña a los niños cómo aprender rutinas, cómo se manifiestan las emociones, además de autocuidados; (3) See.Touch.Learn: utiliza el formato de tarjetas con ilustraciones para realizar actividades de emparejamiento, identificación y lenguaje; (4) Appyautism: ofrece aplicaciones destinadas a ordenadores Mac y Windows, así como para dispositivos móviles Android, Windows Phone e iOS; y (5) Proyect@Emociones Software: enfocada a trabajar las emociones básicas de los estudiantes tanto en el aula como en el hogar, a través de pictogramas, imágenes reales, ejercicios entre la situación y la emoción, y ejercicios sobre la relación establecida entre las creencias y las emociones.

Una de las plataformas que han llamado la atención por el uso de sus pictogramas, es la plataforma pictoagenda.com; esta es una herramienta de apoyo a los agentes cuidadores o educadores de personas con TEA, que permite generar una pictoagenda, para ayudar a estos a realizar las rutinas diarias o, por lo menos, para reforzar las acciones que se tienen que hacer, a través de pictogramas que se em- 
plean en las tarjetas o páginas. Esta plataforma utiliza los pictogramas de Carmen Basil llamados sistemas aumentativos y alternativos de comunicación (ARASAAC) (Basil, 2007), esta consta de una serie de pictogramas que muestran una serie de gestos, acciones y objetos. Son fundamentales para hacer las pictoagendas con las rutinas del día a día o como apoyo para personas que presentan un severo grado de dificultad para comunicarse o con alguna diversidad funcional (autismo, discapacidad intelectual, afasia, entre otros).

Esta plataforma cuenta con diferentes elementos de distintas situaciones, las cuales abarcan actividades como la alimentación, el ocio, la educación, la comunicación, las tareas escolares, entre otras. Ayuda a generar no solo rutinas específicas, sino que también sirven de apoyo para crear un canal de comunicación para aquellas personas que cuentan con una condición atípica y tengan una dificultad para comunicarse de una manera verbal. Tomando en cuenta el método PECS y su implemento de imágenes como medio de comunicación, algunos de los especialistas o agentes cuidadores a cargo de los niños con TEA han demostrado que su función es de gran apoyo, puesto que la literalidad de estos niños propicia la mímica, para así llevar a cabo ciertas acciones que requiere para realizar ciertas tareas. Esto fortalece la habilidad para llevar a cabo la acción en futuras ocasiones o para hacer uso de este método para tener una mejor comunicación.

Por lo tanto, esta plataforma no solo ayuda en el proceso de aprendizaje, sino que aporta una experiencia que permite elegir las actividades, la cantidad de estas o qué tan específico se quiere ser al momento de hacer las agendas. Es práctica, accesible y fácil de usar. Pero ¿qué tan bien está diseñada? ¿Cumple con el fin por el cual está hecha? ¿Es fácil de entender?

Para este punto, se debe aclarar las funciones que el diseño de informació deberá cumplir, con cierto rubros o especificaciones. De acuerdo con Sánchez y Sánchez (2018), desde el punto de vista gráfico y estético, para la funcionalidad y usabilidad de los datos o el sitio en general, la visualización debe "cumplir con los criterios de jerarquía y organización visual, contraste, legibilidad, o correcto uso de elementos gráficos y tipográficos, entre otros" (p.22).

\section{Lineamientos de diseño de Información para la web}

Según Pontis (2019), el diseño de información es el campo que facilita el entendimiento para ayudar a la gente a lograr sus metas, gracias a la traducción de la 
información cruda y desorganizada a una forma en la que pueda ser percibida de manera rápida, entendible, procesada y usada. No importa el medio de transmisión de la información, ya sea en papel o digital, la meta es que el usuario o cliente sea capaz de realizar la acción que se tenía planeada.

Si el diseño de la estructura y la manera en la que se presenta la información cumplen con lo anteriormente mencionado, lo más probable es que el usuario o las personas que la usen entiendan perfectamente el contenido. Para poder lograrlo, el diseñador deberá darle sentido a la estructura y flujo, para que así el usuario logre su objetivo y entienda toda la información. Durante este proceso, se deben entablar actividades cognitivas tales como la memoria, la percepción y el proceso visual, donde se irá de lo general a lo particular, dando un recorrido y filtrando la información de manera que los usuarios tengan la oportunidad de interpretar y darle sentido a la información, dependiendo de la experiencia que estén teniendo acerca de una situación específica. Si esta información es efectiva, logrará que el cerebro la procese de mejor manera.

Para lograr un buen desarrollo en el diseño de la información, Pontis (2019) señaló que se debe considerar lo siguiente:

- Problema: a lo que se enfrenta la audiencia.

- Gente: la audiencia a la que va dirigida.

- Contexto: cómo, dónde y cuándo la audiencia tiene acceso a la información.

- Contenido: lo que necesita ser comunicado.

De acuerdo con Hassan (2015), la arquitectura de información es: “El arte, la ciencia y la práctica de diseñar espacios interactivos comprensibles, que ofrezcan una experiencia de uso satisfactoria facilitando el encuentro entre las necesidades de los usuarios y los contenidos y/o funcionalidades del producto" (p.14).

Las estructuras de las páginas web deben cumplir ciertos criterios para que la experiencia del usuario, con respecto a la interfaz, tenga un correcto uso y se logre el objetivo por el cual la persona entró inicialmente a la página. Por ello, es importante realizar una auditoría del diseño, para revisar que se cumplan los requisitos de accesibilidad, continuidad de los componentes y unidad de diseño; según Silverira (2021), al hacerlo se pueden identificar problemas previamente dentro de los diseños. Algunos problemas comunes son los siguientes: (a) falta de imágenes como alternativa del texto omitido; (b) inconsistencia del tipo de fuente tipográfica y ta- 
maño a través del sitio web; (c) falta de enlaces de navegación; (d) contenido desactualizado; (e) uso incorrecto de componentes y patrones; (f) uso de colores que no son parte de la marca y no cumplen con los estándares de accesibilidad; y (g) no se usa un diseño y hace que los componentes se vean desordenados.

Con base en lo anterior, se deben tener en cuenta ciertos lineamientos o aspectos al diseñar una interfaz de una página web o cualquier plataforma digital; por ejemplo, la clasificación, el color, la eficiencia, el error humano, la estética, las fotografías e imágenes, los íconos, la jerarquía visual, la legibilidad e inteligibilidad, el mapeo natural, el orden, la relevancia, la taxonomía, la visibilidad y la retroalimentación. Cada uno de estos puntos tiene relación con la forma en la que el usuario verá e interactuará con la interfaz; por ello, a partir de estos, se realizará el análisis para saber si se siguen los lineamientos o tiene un área de mejora.

A continuación, se explicará brevemente cada uno de estos puntos acorde a la interfaz del sitio:

- Clasificación. Describe el tipo de necesidades acerca de la información que busca o necesita el usuario. Haasan (2015) indicó que existen tres tipos de clasificaciones: (a) clasificación orientada a la tarea, (b) clasificación orientada a la audiencia y (c) clasificación temática. En este caso, la página indica que está orientada a una tarea en específico, por lo tanto, tiene una "clasificación orientada a la tarea".

- Color. Este es un recurso visual, que permite la identificación entre elementos y genera un contraste. Según Natoli (2019), el buen uso del color maximiza la lectura y minimiza la fatiga ocular, le proporciona un significado simbólico que apoya y realza la experiencia visual en el diseño, complace al ojo y mantiene el interés visual. Además, incita al usuario a interactuar con la interfaz de manera más orgánica. En este caso, la plataforma no muestra un buen uso del color, ya que el contraste no se ve en ningún lado. Solo las flechas hacen contraste y muestran un claro call to action para realizar las tareas que se necesitan.

- Eficiencia. Aspecto relacionado con la precisión e integridad de los objetivos alcanzados por el usuario en la interfaz con respecto a su tarea (Stone et al., 2005). Este aspecto también se mide en cuanto al tiempo que le lleve al usuario realizar su tarea; entre más rápido se realice la tarea, es seguro que el usuario se sienta más satisfecho con el sitio. ¿La plataforma cumple con este punto? No, ya que no hay un elemento que indique cómo hacer uso de la interfaz. 
- Error humano. Es el resultado de un diseño mal ejecutado. Cuando los usuarios hacen mal uso o cometen un error cuando se interactúa con la interfaz, los diseñadores interceden comentando que el usuario hace mal uso de esta. Culpar al usuario no resolverá el problema, es probable que este error sea repetido por otros usuarios; entre mayor sea la complejidad de los diseños, estos deberán tener ciertas instrucciones que ayuden al usuario a saber qué se espera que hagan; sin esto, claramente van a cometer errores y se confundirán en el proceso (Munot, 2017). Al no haber indicaciones claras en la plataforma, es predecible que se cometan errores sin realmente saberlo.

- Fotografías o imágenes. Una forma que tiene el ser humano de aprender del entorno que lo rodea es por medio de relaciones mentales, que se logran mediante las semejanzas. Según Esqueda (2009), las imágenes cognitivas aportan un entendimiento claro de las personas con respecto a las acciones que deben realizar, ya que relacionan con más facilidad las acciones con ciertas imágenes o íconos, cuando los persuaden a hacer dicha acción por imitación. En este caso, se utilizan los pictogramas de ARASAAC, así que la plataforma cuenta con este punto.

- Íconos. De acuerdo con Hassan (2015), son aquellos elementos que pueden facilitar el uso y comprensión del producto si están bien ideados y diseñados. Estos pueden ser planos (2D) o volumétricos (3D). Según Frascara (2011), el tamaño debe ser en relación con el puntaje del texto, para que haya una proporción entre estos dos elementos; esto se determinará cuando se haga una prueba a un modelo a escala real, colocados en el sitio de uso. A pesar de que la plataforma cuenta con íconos, estos no son claros; algunos cumplen su función, pero son confusos.

- Jerarquía visual. Según Nielson (2021), es la forma en la que un diseñador organiza una página; esta tiene un rol importante que determinará la experiencia del usuario. Una buena organización creará un flujo que facilite su uso. El arreglo de los elementos en el diseño es sumamente importante; la información más relevante debe estar al principio, siguiendo por lo menos importante; esto hará la página más fluida, mientras el usuario desciende por la página. En este caso, se resalta desde un inicio que la principal tarea es la creación de la pictoagenda, sin embargo, deja de lado las acciones secundarias o incluso las anula por completo. 
- Legibilidad e inteligibilidad. Se refiere a resaltar la obviedad de la esencia en el diseño de información (Frascara, 2011); su propósito es lograr una lectura sostenida y clara, ya que se basa en una coherencia de estilo y peso tonal en toda la tipografía utilizada, siendo las letras distinguibles entre sí; la selección debe basarse en la claridad, altura, ancho, grosor de trazo y programa de espaciado con el que cuenta la tipografía, junto con el puntaje acorde a las necesidades de los elementos tipográficos de la página. En este caso, si bien la tipografía no es la adecuada, cuenta con un buen contraste con el fondo, pero al momento de reducir el puntaje, esta pierde toda claridad y se vuelve ilegible, perdiendo por completo la función de este punto.

- Mapeo natural. Según Norman (2004), es la relación entre un elemento interactivo y sus acciones; es más fácil de entender si existe un mapeo natural o relación constante y previsible entre elementos interactivos, acciones y resultados. Por su parte, Hassan (2015) lo interpretó como la capacidad del usuario para predecir la función de cada uno de los elementos de la página, a través de la intuición y las metáforas cognitivas. Esqueda (2009) indicó que es una operación que asocia cada elemento de un conjunto o dominio con uno o más elementos de otro. En este caso, aun cuando se tiene clara la acción, el mapeo de la plataforma cuando el usuario hace uso de ella, es bastante irregular y atípica, por el acomodo de los elementos con los que cuenta, haciendo un poco difícil el uso de la plataforma en general.

- Orden. De acuerdo con Natoli (2019), balancear el contenido de los layouts ayudará a tener un área ordenada para que ninguna de las zonas o secciones donde estén los elementos se sobrepongan entre sí. Hassan (2015) reconoció que la facilidad con la que se localice el contenido de la información resultará en el éxito del usuario para poder realizar la acción por la cual entró al sitio, dándole importancia a los elementos que ayuden al usuario a llevar a cabo su tarea. En este caso, el orden es bastante atípico a lo que el usuario está acostumbrado en una interfaz, pareciera que la acción es la única tarea con la que cuenta la plataforma.

- Relevancia. Con esta se determina el acomodo apropiado en los niveles con los que los elementos se van a visualizar, puesto que se van a empezar a ordenar acorde a la relevancia que estos tengan; esto incluye agrupar los componentes según su significado y categorías distintivas (Morville \& Rosenfeld, 2007). 
Esto permitirá que el usuario consiga sus objetivos, lo que se determina según su prioridad visual para aquellos contenidos de mayor interés.

- Taxonomía. Se refiere a la clasificación por categorías; se define como la estructura de organización de la información, a partir de categorías. Según Hassan (2015), la taxonomía puede ser: (a) plana, cuando se trata de un conjunto de categorías que se encuentran en un mismo nivel; (b) jerárquica, donde hay subcategorías; (c) relacional, cuando las categorías además de vincularse a una categoría superior y a subcategorías, también se vinculan a otras ramas del árbol jerárquico; y (d) facetada, la cual permite una navegación por filtrado. En el caso de esta plataforma no hay subcategorías, y si las hay, no son lo bastante claras para definirlas en este punto como tal.

- Visibilidad y retroalimentación. Este punto es algo que usualmente se ha dejado de lado en algunos sitios, pero en las aplicaciones móviles se ha vuelto algo esencial, puesto que en muchos casos son pop ups que salen al dar o introducir información importante. Como indicó Hassan (2015), ayuda al usuario a saber el estado en el que se encuentra según la acción que está realizando. En este caso, este punto está completamente ausente en la plataforma, ya que en ningún momento se muestra algún tipo de retroalimentación o no se muestra algún tipo de aviso que indique las acciones que estás realizando, dejando a oscuras al usuario, sin saber qué es lo que sigue en el proceso de la creación de su pictoagenda.

\section{El análisis de la pictoagenda}

Para hacer el análisis, es importante considerar el tipo de clasificación que se tomará como guía; en este caso, es una clasificación orientada a la tarea. A pesar de que podría considerase del tipo orientada a la audiencia (personas con TEA), esta plataforma está estrictamente diseñada para realizar un producto viable mínimo (MVP, por sus siglas en inglés), es decir, un producto más valioso, lo cual indica que el fin último de la página es generar pictoagendas, las cuales son desarrolladas por los agentes educadores, cuidadores o los especialistas que las utilizan como herramientas de apoyo para las personas con TEA; por esta razón, es que la estructura de la interfaz es de esa manera. Por lo tanto, se determinó que el tipo de análisis es exploratorio, es decir, a través de su uso se conocerá la manera en la que se genera la experiencia del usuario. 
Una buena estructuración de la información y accesibilidad a la navegación es fundamental para propiciar la participación del usuario (Sánchez \& Sánchez, 2018); tomando en cuenta los elementos de la plataforma: al inicio de la página nos presenta simplemente una pantalla con el título de "Pictoagenda", bajo este se logra ver una flecha roja en un recuadro señalando en dirección abajo, la cual indica otro recuadro donde se encuentra un pictograma de ARASAAC con la descripción de "tu texto" y a unos cuantos centímetros hay una serie de íconos en color blanco, todo esto sobre un fondo color beige con textura (Figura 1).

\section{Figura 1}

Pantalla inicio plataforma pictoagenda.com

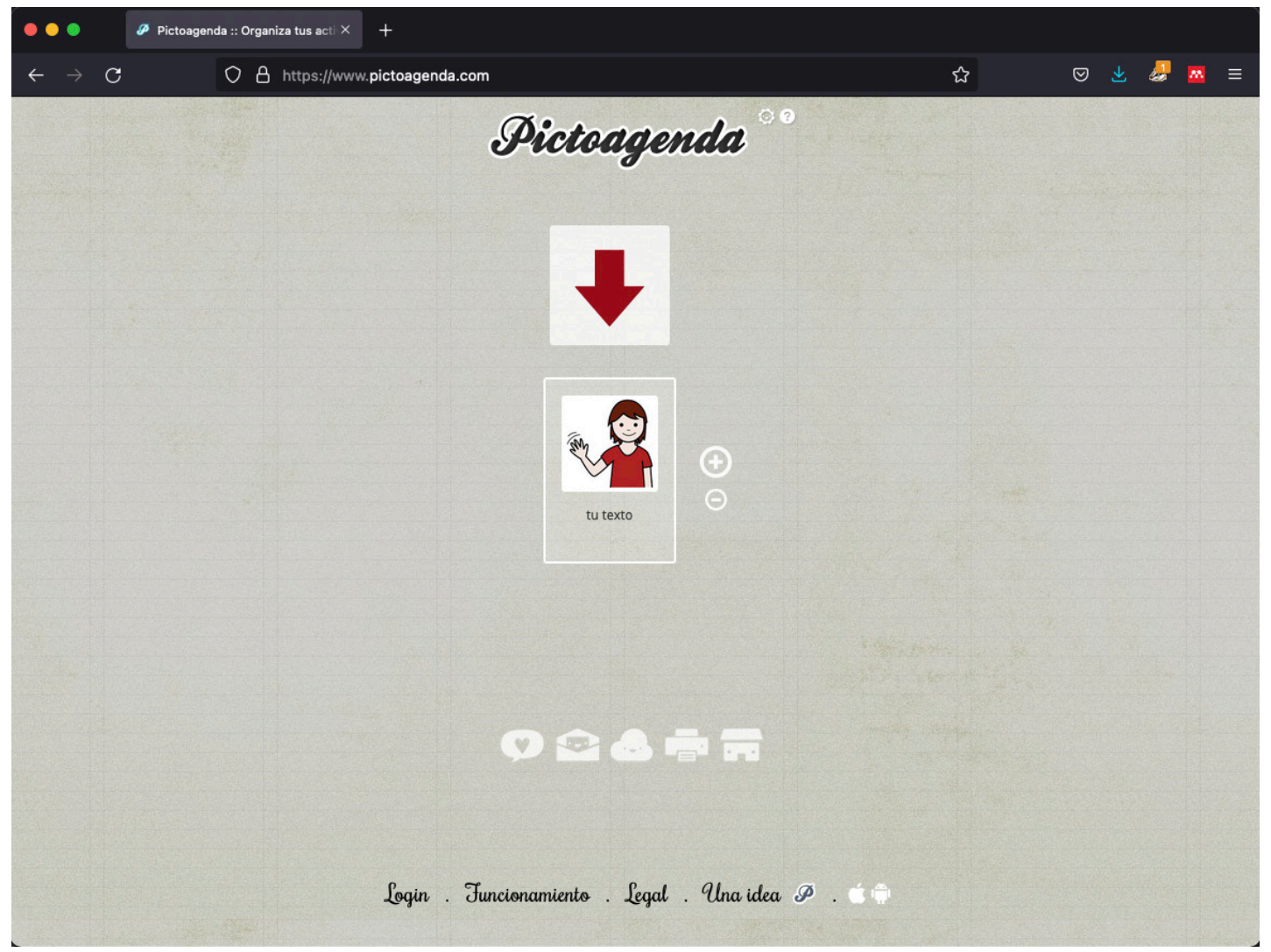

Si analizamos la pantalla inicial (Figura 1), con los lineamientos anteriormente mencionados, se pude destacar lo siguiente:

- La tipografía que se utiliza en el título es legible, sin embargo, cuando se usa en los botones inferiores, al ser de menor puntaje y la tipografía bold o condensada, se pierde; a eso le suma que el script la hace poco legible para aquellos que cuentan con baja agudeza visual. Aun cuando es congruente con el formato entre textos, no es una buena elección de tipografía. 
- El contraste que hay entre elementos es muy baja; si bien el fondo de color claro contrasta perfectamente con el color del texto, no es el mismo caso con los íconos de las acciones (de izquierda a derecha) de "favoritos", "enviar por mail", "compartir en redes sociales", "imprimir" y "volver", que están en color blanco, haciendo un bajo contraste entre sí y dificultando la visibilidad de estos.

- La localización de los elementos no concuerda con el mapeo natural del usuario promedio, ya que la estructura de una página tiene como elemento principal una flecha roja que indica al usuario la acción que debe de hacer; a pesar de que es el punto principal por la cual el usuario entró a la página, los botones de la parte inferior regularmente están ordenado de distinta manera, siendo estos el menú encabezado, como lo son la acción de Login o "iniciar sesión" junto con funcionamiento, ya que son acciones que el usuario realiza de primera instancia; sin embargo, el botón de "Legal”, “Una idea” y los íconos de tiendas de aplicaciones, usualmente van en la parte inferior junto con los datos de la empresa o compañía que generó la página.

Ya en la pantalla donde se generó una rutina con determinado número de acciones (Figura 2), las que comúnmente son entre 15-20 acciones dependiendo de qué tan detallada sea la rutina, si se quiere poner por horarios específicos con intervalos de 30 minutos entre sí, o simplemente señalar las acciones que se quieren realizar durante todo el día. Se señala con una flecha roja sobre el primer pictograma el inicio de la rutina y se va agregando con el botón de "+" cada acción, o si se quiere eliminar una casilla solo se oprime el botón de "-"; a pesar de ser acciones contrarias, no se hace o marca una diferencia para que se pueda realmente identificar cada una de las acciones, si bien no está mal el uso de los botones, no es completamente correcta con base en los lineamientos previamente mencionados.

En la Figura 2, se puede entender claramente la tarea que se tiene que realizar; sin embargo, la manera en la que se estructura no puede ser tan fácil de entender, o por lo menos, se sabe qué se tiene que hacer, pero no se tiene claro cómo se tiene que realizar la tarea. Esto deja claro que el flujo de la acción es poner los pictogramas secuencialmente para ir armando la pictoagenda, la cual será utilizada por la persona con TEA en sus rutinas del día a día. En el análisis se evidenció qué:

- El área de trabajo, si bien es bastante espacioso, se va organizando por tres elementos, que son: (1) el título de la página; (2) las casillas donde se ponen 


\section{Figura 2}

Pantalla inicio plataforma pictoagenda.com

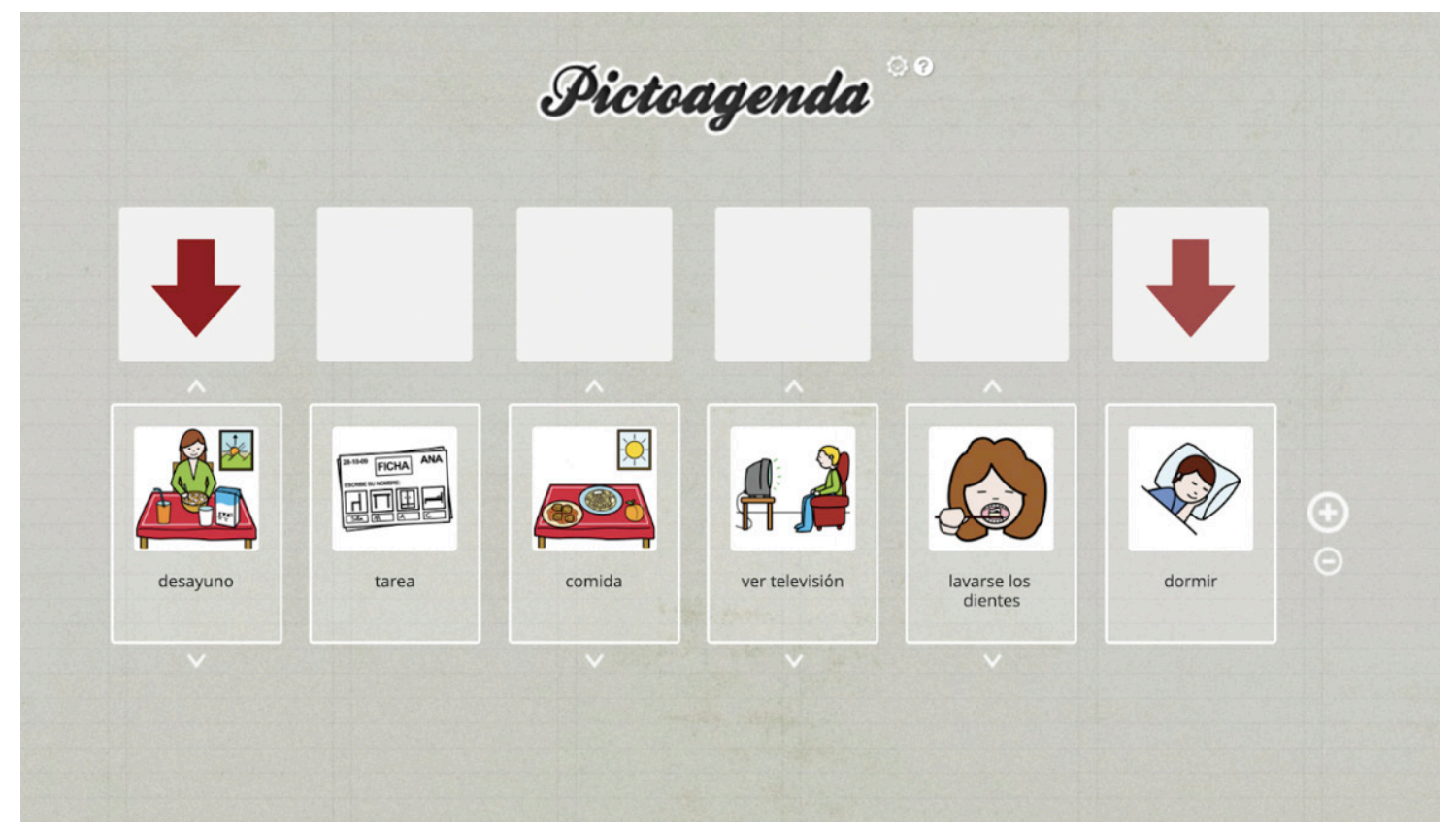

elementos como flechas rojas, cruces verdes o rojas; (3) los recuadros en blanco donde van los elementos anteriores; (4) el recuadro donde va el pictograma señalando la acción a realizar y, debajo de este, está la palabra descriptiva de la acción, además, arriba y abajo del recuadro cuenta con flechas para cambiar las opciones; y (5) los íconos de "+" y "-" para añadir o quitar recuadros para la pictoagenda.

- El texto que indica la palabra descriptiva de la acción cuenta con un puntaje bastante reducido, por lo tanto, se llega a perder entre las dimensiones de los demás elementos; esto hace un poco difícil diferenciar la acción en cuestión. La mala proporción entre los elementos provoca incongruencia en la jerarquía visual. En general, deja claro la relevancia de los pictogramas, pero la armonía entre elementos no encaja en el buen diseño de información con el que debería de contar.

- El color de los elementos no ayuda a resaltar las acciones, ya que el contraste entre los íconos de "+" y "-" con respecto al fondo no les genera la visibilidad que deberían de tener; al no contar con ese contraste pierden la intención de la acción, ya que es un poco difícil encontrar el siguiente paso en el flujo para crear la pictoagenda.

- Ya que el uso de elementos está en todo el flujo para el proceso de generar la pictoagenda, estos deberían de contar con algunos de los puntos para el 
diseño de información. Algunos elementos no deberían de estar en la retícula de la interfaz, ya que generan ruido y llegan a confundir al usuario, quien se pregunta: "¿qué hace ese cuadro?" o "¿qué debe ponerse en este cuadro", ya que cada una de las casillas que contiene un pictograma tiene uno por encima y que está vacío. No queda claro cuál es su función.

- Por último, no hay una clara función que te diga qué sigue cuando se haya terminado el flujo de la tarea, o qué se tiene que hacer para generar la pictoagenda y descargarla. No hay retroalimentación que ayude al usuario a saber qué tiene que hacer para imprimir, descargar o visualizar la agenda de otro modo, dejándolo a oscuras en el flujo de la tarea y término de la acción.

Con esto, se puede ver que el flujo no está claro o bien estructurado, ya que, de principio a fin, las acciones a realizar no son claras y el poco uso de los puntos del diseño de información no ayuda al usuario a realizar las acciones de la tarea en cuestión. Sin embargo, el usuario usualmente cuenta con un sentido de la intuición, o mapeo natural, que le ayuda a realizar algunas de las acciones, pero tampoco ayuda el que la jerarquía visual no sea clara, o que el contraste de los colores no aporte a los call to action que se requieren; esto genera una pobre visibilidad y legibilidad de los elementos para las acciones y hace a la plataforma poco eficaz en ese aspecto.

Una de las ventajas es que puedes elegir entre una variedad de 2-3 pictogramas para cada acción, si se selecciona alguna de las flechas que están debajo o arriba de la casilla del pictograma, personalizando la agenda según los gustos del usuario; sin embargo, la condición de las personas con la condición de TEA son demasiado literales $y$, tal cual vean la acción en la agenda, es casi seguro que la imiten al pie de la letra; si el pictograma marca que el dibujo de la persona usa un cepillo dental verde, esa persona es casi seguro que quiera lavarse los dientes con un cepillo dental verde. Por eso, la plataforma te brinda una opción para personalizar los pictogramas agregando fotos o imágenes de tu escritorio o que tengas almacenadas en un dispositivo drive.

En la Tabla 1, se muestra una recapitulación del análisis, indicando con cuales lineamientos cumple y de cuales carece la plataforma.

Durante el análisis exploratorio, se puede puntualizar que, con base a los lineamientos, la plataforma tiene: 


\section{Tabla 1}

Cumplimiento de lineamientos de pictoagenda.com

\begin{tabular}{|c|c|c|c|c|c|c|c|}
\hline Cumplimiento & Clasificación & Color & Eficiencia & Estética & Gráficos & Jerarquía visual & Legibilidad \\
\hline Sí & $x$ & & & & $x$ & & \\
\hline No & & $x$ & $x$ & $x$ & & $x$ & $x$ \\
\hline
\end{tabular}

- Una clasificación orientada a la tarea. Las categorías están orientadas a la acción (call to action), así que por esa misma razón la clasificación con la que cuenta la plataforma está orientada específicamente a realizar una tarea, que, en este caso, es la de generar la pictoagenda para la rutina del día a día.

- Un uso del color ineficiente. El contraste que se realiza para este punto no es el correcto, es muy poco o casi nulo. El color entre los elementos no tiene un uso de la teoría del color que inciten al usuario a realizar ciertas acciones acorde a lo que se supone simbolizan los elementos, incluso se podría decir que su uso es poco efectivo, lo cual genera un bajo nivel de contraste; al hacer uso de tonos demasiado tenues y similares hace la lectura de la plataforma en general muy pesada y fatiga a la vista del usuario.

- Poca eficiencia. Es complicado realizar bien la tarea de principio a fin; es difícil manejar la plataforma si se entra por primera vez, esta es confusa y poco clara, aun sabiendo cuál es la tarea por realizar.

- Nivel estético bajo. Tiene un aire monocromático, lo cual genera un ambiente monótono y poco atractivo; la estructura de la plataforma es plana; la tipografía es muy sencilla.

- Uso de gráficos de manera correcta. Muestra los pictogramas como elementos principales y da a entender la relevancia que tienen para realizar las acciones que necesita la tarea final, pero cuando se trata de los íconos, estos no ayudan mucho a las metáforas cognitivas que tendría el usuario, ya que su empleo no es demasiado claro, sobre todo, por el color que se usa en estos.

- Jerarquía visual desordenada. No se ve con claridad cuáles son las acciones que deben predominar, por lo tanto, en primera instancia lo que se ve al inicio es el título de "Pictoagenda", seguido de la herramienta que genera la secuencia de la rutina del día a día, por lo que deja de lado todas las demás funciones y elementos de la plataforma. 
- Legibilidad contradictoria. Se entiende claramente la naturaleza del texto y de los elementos, pero es difícil comprender las tareas que realizan cada uno de estos; es comprensible su función, pero no es legible para todos los usuarios, dificultando su uso.

La página es útil para aquellos usuarios que necesiten este tipo de herramienta para utilizarla con las personas con TEA. ¿Logra su función? Sí. ¿Es fácil de utilizar? Sí, cuando ya se hizo una exploración previa, pero si no se tiene conocimiento es poco intuitiva y es más laboriosa de lo que se plantea en un inicio. Es recomendable usarla, pero no es una de las mejores experiencias de usuario.

\section{Conclusiones}

A partir de este estudio exploratorio se sugiere abordar, en estudios posteriores, la ejecución de un rediseño de este portal, considerando los lineamientos de diseño de información; esto podría brindar no solo una mejora visual de la interfaz, sino una mejor experiencia para el usuario.

¿La página sigue los lineamientos del diseño de información? No, pero cumple con la función por la cual fue creada. No se tiene un claro esquema sobre el mapeo de la página, carece de un diseño estético y de un correcto uso de funciones y call to actions; su diseño es arcaico y se podría decir que tiene una clara estructura de un blog de a principios del milenio. Sin embargo, no deja de cumplir su función acerca de crear pictoagendas como apoyo de la rutina del día a día para las personas con trastorno del espectro autista.

El uso del espacio no es el mejor, ya que hay demasiado espacio negativo rodeando los elementos; en lugar de acomodar los elementos por categorías, lo dejaron demasiado simple, lo cual estéticamente no es favorable, ya que no hay armonía entre los elementos entre sí, ni por el estilo ni por el color. Esto dificulta la intuición del usuario, ya que los limitados call to action que presenta no son claros ni hay conexión entre sí, lo cual genera un recorrido atípico en la página. En general, la página es confusa, se necesitan demasiados pasos y se pierde mucho tiempo para generar la tarea de principio a fin.

Se puede ver que la acción principal, que en este caso sería el MVP de la plataforma, es generar una serie de casillas, que con base a palabras clave de las acciones se van agregando en la agenda de la rutina para el día a día. Sin embargo, 
los elementos de la página no son tan claros como alguno de los botones que comúnmente se ven en las páginas. Cuando se utilizó por primera vez para conocer su efectividad, fue difícil entender dónde se tenían que realizar las acciones para hacer la agenda y saber qué era cada elemento, debido a que los menús no son claros.

La plataforma pictoagenda.com es una herramienta útil, pero debe considerarse realizar mejoras para cumplir con los lineamientos del diseño de información, que ayuden a un mejor manejo y uso de los usuarios; esto permitirá una mejor experiencia del sitio.

\section{Referencias}

Bellelli. (2020). Cuarentena y Derechos de las niñas y los niños. https://www. bellellieducacion.com/blog/2020/4/26/cuarentena-y-los-derechos-de-losnios

Cuesta, J. L. (1997). Intervención educativa en alumnos con autismo. En J. L. Cuesta, F. J. Mendizábal, \& C. Gárate (Comps.), El autismo, hoy. Centro de Profesores y Recursos.

Educación 3.0 (2021). Recursos para alumnos con el Trastorno del Espectro del Autismo (TEA). https://www.educaciontrespuntocero.com/recursos/recursostrastorno-espectro-autismo-tea/

Hassan, Y. (2015). Experiencia de Usuario: Principios y Métodos. Publicación independiente.

Montessori, M. (1918). El método de la pedagogía científica: Aplicado a la educación de la infancia. Biblioteca Nueva.

Munot, S. (2017). Human Error or Design Error? https://uxplanet.org/human-error-ordesign-error-23facef8f36e

Natoli, J. (2019). Using Color and Contrast appropriately. Udemy.

Nielson, Z. (2021). Principles of Design. https://xd.adobe.com/ideas/process/uidesign/5-principles-design/

Piaget, J. (1980). Psicología y Pedagogía. https://www.uv.mx/rmipe/files/2017/02/ Psicologia-y-Pedagogia.PDF

Pontis, S. (2019). Making Sense of Field Research: A Practical Guide For Information Designers. Routledge.

Rivière, A. (1997). El tratamiento del autismo como trastorno del desarrollo: principios generales. Ministerio de Trabajo y Asuntos Sociales. 
Rodríguez, R., \& García, M. (2020). Método Montessori: la historia en primaria a través de la metodología Montessori. En M. E. Cambil, A. R. Fernández, G. Romero, \& A. J. Rui (Eds.), Nuevas tendencias en investigación e innovación en didáctica de la historia, patrimonio culrural y memoria. Proyección educativa. Universidad de Granada.

Sánchez, H. M., \& Sánchez, M. (20118). Análisis de. La funcionalidad y usabilidad de las visualizaciones de información online de Politibot. ICONO 14, 16(2), 14-38. https://icono14.net/ojs/index.php/icono14/article/view/1192/1301

Silveira, D. (2021). What is a UX Design Audit? https://xd.adobe.com/ideas/process/ information-architecture/ux-design-audit-templates/

Stone, D., Jarrett, C., Woodroffe, M., \& Minocha, S. (2005). User Interface Design and Evaluation. Morgan Kaufmann Publishers. 


\section{Capítulo 4}

\section{La legibilidad en el diseño de información para los débiles visuales}

Elika Hadassa Arellano Chávez, Cynthia Lizette Hurtado Espinosa

y Marcela del Rocío Ramírez Mercado

La legibilidad es un aspecto esencial cuando se habla de percepción visual y gráfica, este concepto se toma como un indicador para medir la comunicación efectiva en el diseño de información y facilitar la comprensión de aspectos visuales, tipográficos o espaciales adaptados para el usuario con debilidad visual.

En este capítulo se describirán los conceptos de legibilidad y diseño de información y cómo estos deberán tomar en cuenta las necesidades de un usuario con debilidad ocular. Se consideran las posturas de varios autores donde definen a la legibilidad y su relación con la percepción visual; es importante aclarar que, en algunos puntos, la legibilidad engloba otros factores que no se relacionan solo con el sentido de la vista, sino con aspectos de comprensión e interpretación de información; en este sentido, se mencionará la lecturabilidad como consecuencia de este proceso mental de lectocomprensión.

El desarrollo de este trabajo se enfoca en las características del diseño de información adaptado a un usuario con deficiencias visuales. Se considera que cuando se trata de un diseño exclusivo para usuarios con problemas de percepción visual se toman en cuenta no solo la legibilidad, sino también la ley de accesibilidad con respecto a deficiencias visuales, ya estandarizadas mundialmente. 


\section{Débiles visuales}

Como el diseño de información se centra en el usuario, se tienen que aclarar algunos factores del usuario débil visual, quien tiene deficiencias en su percepción, es decir, que no alcanza el grado de lo que se considera normal. De acuerdo con el Consejo Nacional para el Fomento Educativo (CONAFE, 2010), en su guía didáctica para la inclusión:

La discapacidad visual se define con base en la agudeza visual y el campo visual. Se habla de discapacidad visual cuando existe una disminución significativa de la agudeza visual aún con el uso de lentes, o bien, una disminución significativa del campo visual. (pp.16-17)

Es decir, que la discapacidad visual depende de la agudeza con que se percibe; por lo tanto, un usuario con debilidad visual es aquel que ha perdido la agudeza visual y su percepción es parcial. Con respecto a la agudeza, el CONAFE (2010) la define como "la capacidad de un sujeto para percibir con claridad y nitidez la forma y la figura de los objetos a determinada distancia" (p.17).

De acuerdo con el Centro Estatal de Vigilancia Epidemiológica y Control de Enfermedades (CEVECE, 2020), existen alrededor de 700000 personas en México con discapacidad ocular, como ceguera o debilidad, adquirida por enfermedad, accidente o de forma congénita; según datos del Instituto Nacional de Estadística y Geografía (INEGI, 2010), la deficiencia visual ocupa el segundo lugar en el país como problemática que impide la movilidad.

La deficiencia visual ocupa estadísticamente más del $20 \%$ de la población mexicana; al respecto, el diseño, en muchas ocasiones, no está pensado para este tipo de usuario y no se consideran aspectos importantes que se relacionan con la percepción visual deficiente como, por ejemplo, mejorar la legibilidad y la accesibilidad en materiales de lectura o información.

\section{Legibilidad en el diseño de información}

Se define a la legibilidad como la facilidad para leer o comprender un texto, el cual contiene aspectos lingüísticos y tipográficos. Los lingüísticos se relacionan con la sintaxis o el uso del lenguaje y los tipográficos consideran aspectos de forma, tamaño, ancho de línea, medida de un párrafo, entre otros. Tanto la forma como 
el contenido se analizan de manera constante en este capítulo, para entender el concepto y adaptarlo a los usuarios con una deficiencia visual.

La legibilidad no solo considera aspectos de forma o figura, sino también factores de comprensión en donde infieren procesos de carácter mental y de interpretación del lector; en muchos casos, se le ha asignado el nombre de lecturabilidad. Es importante señalar que para que un texto se torne legible no solo debe ser perceptible visualmente sino también comprendido.

Entonces, la legibilidad es la "cualidad de ser legible" según lo que define la Real Academia Española (RAE, 2020); el texto es legible si sus aspectos lingüísticos y sintácticos son entendibles o si sus factores de forma son claros y perceptibles en cuestión de tamaño y de estilo. Por lo tanto, se tendría que considerar todo lo que influye cuando se realiza una lectura, así como los elementos que incluyen aspectos de accesibilidad en un diseño de información para un deficiente visual.

Para facilitar la comprensión del concepto de legibilidad se distinguen sus elementos tipográficos y lingüísticos. Los tipográficos serán todos los relacionados con aspectos visuales del texto y los lingüísticos los aspectos verbales. En la siguiente lista de siete puntos se describen los aspectos visuales de diferentes autores. Es importante mencionar que los primeros tres puntos se refieren a la taxonomía de la tipografía, que es más apropiada para ser leída en el diseño de información.

Aceituno (2010), en su Seminario de Producción Multimedia, mencionó aspectos de estilo y forma como un factor importante para la legibilidad de un texto; por ejemplo, elegir la tipografía adecuada para cada tipo de usuario o contenido. Cuando se trate de un texto extenso e impreso se recomienda que la letra tenga remates, que son esos trazos finales que proporcionan continuidad armoniosa a la hora de percibir los caracteres y facilita la identificación de estos. Cuando se trate de la lectura a través de una pantalla, la tipografía tendrá que ser regular y sin serifas, porque esas formas se adaptan mejor a los pixeles.

Existen elementos que hay que considerar al momento de hacer uso de tipografías en pantalla. De acuerdo con Lupton (2014), las fuentes PostScript permiten al sistema operativo traducir los contornos vectoriales de un carácter a la retícula rasterizada de la pantalla, haciendo que se vean bien en cualquier sistema.

Entonces, cuando se trate de la elección de una tipografía para lectura en pantalla, se deben considerar aspectos de diseño, la modalidad de reproducción y su codificación; por ello, es recomendable una PostScript, que fue creada para profe- 
sionales de lo digital y que en su codificación trae contenido de un mayor número de mapa de bits y también es compatible para impresión.

Para continuar con el siguiente punto, será necesario aclarar a qué se refiere el término "redondas" que acuñó Kane (2012):

Es el estilo básico de las letras y también se les denomina "romanas" porque las letras en caja alta derivan de las inscripciones en los monumentos romanos. Cuando se utiliza para describir el estilo de un tipo, el término "redonda" siempre hace referencia a la caja baja. (p.8)

Y cuando se trata de los términos de letra condensada se refiere a la modificación de los espacios del propio caracter o tipo. "Tal como su nombre lo indica, es una versión estrecha de la letra redonda. Los estilos muy estrechos también suelen llamarse letras compactas" (Kane, 2012, p.8).

Por lo tanto, en cuestión de legibilidad, se recomiendan las formas abiertas y redondas en las letras con serifas o sin ellas, que permiten mejor legibilidad que las condensadas. Esto se debe a las características de la estructura del carácter en sí, aspectos de forma interior y exterior.

Las formas abiertas son más perceptibles visualmente hablando que una con estrechez en su composición, como se muestra en la Figura 1. El ejemplo va en sentido de ser un texto para la lectura y, por lo tanto, no es conveniente usar tipografías condensadas para una caja de texto extensa, porque si se observa es más perceptible la redonda; sin embargo, hay otras consideraciones que dan pie al siguiente punto, como considerar su forma externa y su extensión.

\section{Figura 1}

Ejemplo de dos fuentes tipográficas del mismo tamaño y grosor, una con formas redondas y otra con formas condensadas

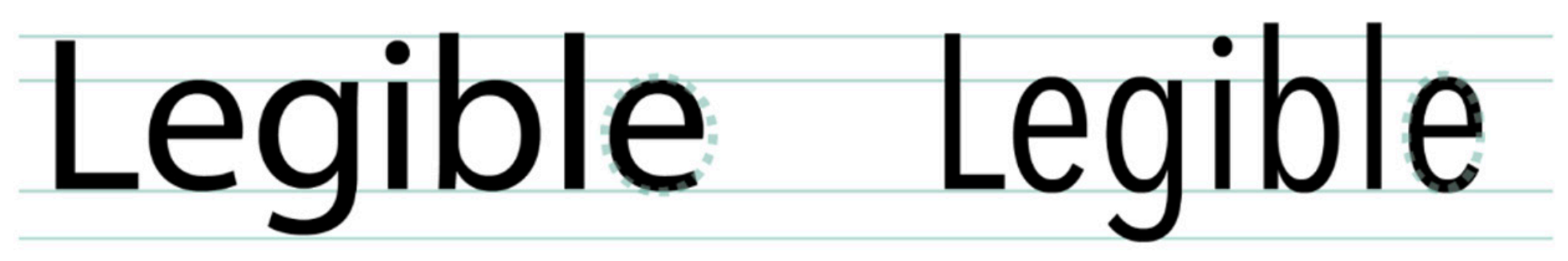


En lugar de un buen tamaño de letra, habría que considerar antes la altura de esta; este aspecto es de suma importancia porque la altura de la tipografía hace la diferencia entre las descendentes y ascendentes del alfabeto; si la altura de la $\mathrm{X}$ es demasiado pequeña puede llegar a confundirse e imposibilitar la lectura, aunque se tenga un tamaño grande (Figura 2).

En este punto, se interpretan las leyes del kerning -concepto que se traduce como interletrado-, que de acuerdo con Adobe (2021) en su guía de usuario, lo define como "el proceso de adición o eliminación de espacio entre pares de caracteres concretos" (párr.1). Este concepto puede medirse de forma métrica u óptica automáticamente.

\section{Figura 2}

Ejemplo de dos fuentes tipográficas del mismo tamaño, pero la segunda con una altura de x más pequeña que la primera

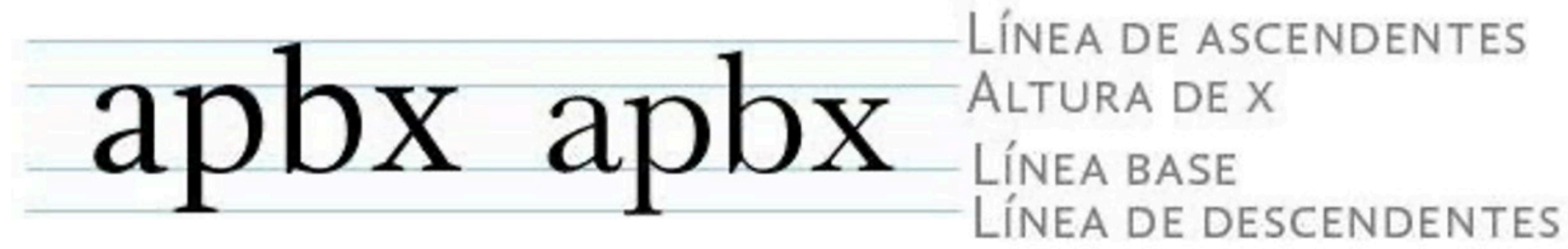

Lo ideal para el interlineado e interletrado es no modificar las proporciones estándar recomendadas. Para una tipografía de tamaño doce, el interlineado debe ser proporcional al $120 \%$ del tamaño de la fuente o dos puntos más, es decir, 14 puntos de interlineado para que los aspectos descendentes y ascendentes no se comprometan.

Cuando se trata del espacio entre letra y letra, el diseñador tiene que mantener un espacio ideal para que cada letra sea distinguible y no provocar que sus elementos se encimen. Esto quiere decir que, para que una fuente o tipografía sea legible, se tienen que considerar los espacios que hay entre ellas, sea cual sea el estilo o forma de la letra, para que se lea o se identifique correctamente.

Según de Buen (2008), para la longitud de línea existen diversos criterios a considerar, dependiendo si el texto es para bajos o altos lectores, los cuales se pueden dividir para un mínimo, óptimo y máximo de caracteres por línea (Tabla 1). 


\section{Tabla 1}

Número de caracteres por línea para bajos y altos lectores

\begin{tabular}{|c|c|c|}
\hline caracteres por renglón & bajos lectores & altos lectores \\
\hline mínimmo & 34 & 45 \\
\hline óptimo & 45 & 60 \\
\hline máximo & 60 & 80 \\
\hline
\end{tabular}

Con respecto al color de letra o su fondo, Borràs et al. (2016) analizaron los efectos de contraste y el color de fondo a la hora de leer un texto.

Blanco y negro

Es la combinación más conocida y utilizada por los textos largos. Además, es la que mejor se lee en visión cercana, ya que el mensaje se transmite de manera más clara y directa gracias al contraste [...] Sin embargo, al realizar el negativo de esta composición, es decir, un blanco sobre fondo negro, los textos se leen peor. (Borràs et al., 2016, p.18)

Al usar colores contrastados entre fondo y figura, la mejor legibilidad en un texto extenso se produce con tipos negros sobre fondo blanco.

Según Rodríguez (2015), para que un texto sea legible se debe mantener una buena jerarquía visual:

La jerarquía visual del texto en una página. Por lo común la gente toma en cuenta que el título principal en un texto es más prominente que un título secundario o subtítulo, el cual es, a su vez, más prominente que el texto del cuerpo. Los mismos principios se deben tomar en cuenta en un diseño de documento escrito. Todos los tamaños de fuente deben derivarse del cuerpo del texto, ya que esto es lo que se va a leer más en cada página.

Cuerpo del texto: Aumentar o disminuir el tamaño del texto hasta que sea cómodo para leer. Por ejemplo: 
Título primario: $180-200 \%$ del cuerpo del texto, entre $40-44 p t$

Título secundario: 130-150\% del cuerpo del texto, entre 29-33pt

Título terciario: $100-125 \%$ del cuerpo del texto, entre 22-28pt

Pequeño texto / subtítulos: $70-75 \%$ del cuerpo del texto, entre $15-17 \mathrm{pt}$ (Rodríguez, 2015, párr.3)

Entonces, el tamaño o jerarquía de todos los elementos dependen del tamaño de cuerpo de texto (caja de texto de mayor extensión) y de ahí se parte para considerar el tamaño de los demás elementos como el título, subtítulo o nota al pie. Esta recomendación hace posible la descripción del último punto de esta lista que considera los porcentajes para crear una buena jerarquía visual.

Mantener una jerarquía adecuada en todos los elementos del texto es lo ideal; por ejemplo, el título deberá mantenerse un $180 \%$ más grande que el cuerpo de texto, el subtítulo un $130 \%$ más grande, y los textos más pequeños que el cuerpo normal deberá mantener la disminución a un $75 \%$.

En cuanto a la legibilidad tipográfica del diseño de información para los débiles visuales, el Instituto Nacional para Ciegos de Colombia $(\mathrm{INCl}, 2018)$ recomendó que para que un material sea accesible para usuarios con discapacidad visual debe tener las siguientes características:

- Fuentes Arial o Verdana: estas dos fuentes tienen trazos redondeados y curvas suaves que permiten mayor legibilidad.

- Tamaño 14 o mayor.

- Dibujos o representaciones gráficas con mayor sencillez y contraste; esto se refiere a mantener un contraste adecuado para que los elementos en la imagen sean percibidos con facilidad. El uso de degradados o colores similares superpuestos imposibilita la legibilidad en estos usuarios.

Es importante mencionar que estas características son previas a trabajar con el software Word y son adecuadas para los sistemas especializados de impresión en Braille.

En cuanto a la información sobre la accesibilidad a la información en canales o medios de comunicación existen varias referencias que se describen en el tema de accesibilidad y diseño de información que se atenderá a continuación. 


\section{Accesibilidad y diseño de información}

Cuando se habla de accesibilidad es pertinente mencionar algunas directrices que existen en las leyes del diseño en general, como algunas pautas consideradas en sitios interactivos y contenido Web llamadas WCAG (Web Content Accessibility Guidelines), enfocadas para webmasters y diseñadores. Las directrices de accesibilidad WCAG 2.1 indican que el contenido visual debe contener alternativas de texto y contenido alternativo al audio o video, además, debe de ser distinguible, legible y compatible.

Maciá (2021) enlistó directrices para que un diseño sea accesible; este debe ofrecer alternativas de texto como el apoyo visual de gráficos, el tamaño de letra extragrande, lenguaje de signos, braille o texto hablado para generalizar y facilitar la percepción de los usuarios con deficiencias visuales o auditivas. En el caso de la presentación del contenido, este debe de ofrecer alternativas al audio o video, como crear subtítulos o una descripción de la imagen u opciones multi-idioma.

En la Figura 3 se observa un ejemplo de cómo un diseño puede ofrecer alternativas de texto, al aumentar el tamaño de la letra o activar la compatibilidad con braille.

\section{Figura 3}

Alternativas de texto en un diseño accesible

\section{Ajustes de accesibilidad}

Activar la compatibilidad con lectores de pantalla

Necesario para la compatibilidad con braille y los anuncios de colaboradores?

Activar la compatibilidad con braille

Funciona con hardware de braille de terceros

Activar las notificaciones de colaborador

Averigua cuándo acceden los usuarios a tus archivos o salen de ellos

Activar la compatibilidad con la lupa

Funciona con software de lupa de terceros ??

Más información

Cancelar

Aceptar 
El contenido debe ser adaptable para todo tipo de plataforma, considerando que el diseño deberá tener un buen contraste de color sin usar algunos muy brillantes que puedan ocasionar los efectos de flash o lastimar la retina.

También la iniciativa W3C (2021), en su apartado "Cómo hacer que el contenido sea utilizable para personas con discapacidades cognitivas y de aprendizaje" enumera los siguientes lineamientos:

1. Ayude a los usuarios a comprender qué son las cosas y cómo usarlas. Utilice iconos, símbolos, términos y patrones de diseño que ya sean familiares para los usuarios para que no tengan que aprender otros nuevos. Las personas con discapacidades cognitivas y de aprendizaje a menudo necesitan patrones de diseño y comportamiento comunes. Por ejemplo, utilice la configuración estándar de color para los hipervínculos (subrayados en azul los no visitados; violeta para los ya visitados).

2. Ayude a los usuarios a encontrar lo que necesitan. Facilite la navegación por el sistema. Utilice un diseño claro y fácil de seguir con señales visuales, como iconos. Los encabezados, los límites y las regiones claras también ayudan a las personas a comprender el diseño de la página.

3. Utilice contenido claro (texto, imágenes y medios). Esto incluye palabras sencillas, oraciones cortas y bloques de texto, imágenes claras y videos fáciles de entender.

4. Ayude a los usuarios a evitar errores. Un buen diseño hace que los errores sean menos probables. ¡Pregunte al usuario solo lo que necesita! Cuando se produzcan errores, facilítele al usuario la tarea de corregirlos.

5. Evite distraer al usuario de sus tareas. Si el usuario se distrae, los encabezados y las rutas de navegación pueden ayudar a orientar al usuario y ayudarlo a restaurar el contexto cuando se pierde. Proporcionar rutas de navegación vinculadas puede ayudar al usuario a deshacer los errores.

6. Asegúrese de que los procesos no dependan de la memoria. Las barreras de la memoria impiden que las personas con discapacidades cognitivas utilicen el contenido. Esto incluye contraseñas largas para iniciar sesión y menús de voz que implican recordar un número o término específico. Asegúrese de que haya una opción más sencilla para las personas que la necesiten.

7. Brinde ayuda y apoyo. Esto incluye: facilitar la obtención de ayuda humana. Si los usuarios tienen dificultades para enviar comentarios, nunca sabrá si pue- 
den usar el contenido o cuándo tienen problemas. Además, permita diferentes formas de entender el contenido. Los gráficos, los resúmenes de documentos extensos, la adición de iconos a los encabezados y enlaces y las alternativas de números son ejemplos de ayuda y apoyo adicionales.

8. Apoye la adaptación y personalización. Las personas con discapacidades cognitivas y de aprendizaje a menudo usan complementos o extensiones como tecnología de asistencia. A veces, el soporte adicional requiere un esfuerzo mínimo por parte del usuario a través de la personalización que le permite seleccionar las opciones preferidas de un conjunto de alternativas. Apoye la personalización cuando pueda. ¡No desactive los complementos y extensiones! A veces, los usuarios pueden recibir asistencia adicional mediante la personalización.

9. ¡Prueba con usuarios reales! Involucra a personas con discapacidades cognitivas y de aprendizaje en el proceso de investigación, diseño y desarrollo. Son expertos en lo que les funciona. Esto incluye involucrar a personas con discapacidades cognitivas y de aprendizaje en:

- grupos focales,

- pruebas de usabilidad, y

- el equipo de diseño e investigación.

Sin duda, considerar todos estos consejos en un diseño de información, propiciará que el diseño sea inclusivo y apropiado para un mayor número de personas.

\section{Legibilidad lingüística en el diseño de información}

Anteriormente, se definieron los aspectos visuales y tipográficos de la legibilidad e incluso su relación con la accesibilidad, pero el aspecto lingüístico se describe en este apartado, para eso es necesario definir lo que es la legibilidad lingüística que, según Ballesteros y Fernández (2013), se define de la siguiente manera:

La legibilidad lingüística ("legibility", también denominada comprensibilidad, perspicuidad o lecturabilidad) se refiere a la facilidad que ofrecen los textos para ser comprendidos sin necesidad de realizar grandes esfuerzos. Un texto puede ser más o menos fácil de comprender en función de la complejidad gramatical de la construcción del mensaje (tamaño y 
número de palabras y frases, promedio de sílabas por palabra, palabras por frase...) y de factores personales del lector (nivel cultural e intelectual, interés por el tema). (p.398)

Existen ciertas fórmulas para medir la legibilidad de acuerdo con el idioma del texto a evaluar. Para el español, se usa el software INFLESZ, que evalúa la facilidad para leer un texto de acuerdo con su construcción gramatical; se basa en una escala que va desde muy difícil, algo difícil, normal, bastante fácil hasta muy fácil; analiza el número de sílabas (S), la cantidad de palabras $(\mathrm{P})$ y el número de frases (F). Para entender un poco sobre cómo se calcula, se ingresará un texto de este capítulo al analizador de legibilidad que se encuentra en el sitio web https://legible.es/y es el siguiente:

La legibilidad es un aspecto esencial cuando se habla de percepción visual y gráfica, este concepto se toma como un indicador que medirá la comunicación efectiva en el diseño de información y que facilite la comprensión como los aspectos visuales, tipográficos o espaciales adaptados para el usuario con debilidad visual.

El fragmento fue sometido a seis fórmulas identificadas como: (a) escala de lecturabilidad de José Hernández Huerta conocida como "la legibilidad lingüística del texto, es decir, si es fácil o difícil de entender" (Legible, 2016-2018a); (b) comprensibilidad de Gutiérrez de Polini (Legible, 2016-2018b); (c) comprensibilidad de Alan Crawford, que ayuda a definir "los años de escolaridad necesarios para entender un texto" (Legible, 2016-2018c); (d) nivel de perspicuidad de Francisco Szigriszt-Pazos, que mide "la legibilidad o facilidad de comprensión lectora del texto [...] escrito con estilo inteligible (que puede ser entendido)" (Legible, 2016-2018d); (e) escala INFLESZ de Inés María Barrio Cantalejo, que "se ha empleado [...] para evaluar la legibilidad del consentimiento informado, los prospectos y materiales para la Educación para la salud. No obstante, se puede aplicar a cualquier tema que no tenga nada que ver con cantidad" (Legible, 2016-2018e); y (f) legibilidad $\mu$ de Miguel Muñoz Baquedano y José Muñoz Urra, que calcula "el grado de facilidad [de lectura] de cualquier texto" (Legible, 2016-2018f). Cada uno tiene una escala que se puede observar en la Figura 4. 
Figura 4

Valores y significado que se presentan en algunas fórmulas validadas para el español

\begin{tabular}{|c|c|c|}
\hline \multicolumn{3}{|c|}{ Escala de lecturabilidad (L) } \\
\hline L & nivel & grado escolar \\
\hline $90-100$ & muy fácil & $4^{\circ}$ grado \\
\hline $80-90$ & fácil & $5^{\circ}$ grado \\
\hline $70-80$ & algo fácil & $6^{\circ}$ grado \\
\hline $60-70$ & normal (para adulto) & $7^{\circ}$ u $8^{\circ}$ grado \\
\hline $50-60$ & algo difícil & preuniversitario \\
\hline $30-50$ & difícil & cursos selectivos \\
$0-30$ & muy difícil & universitario (especialización)
\end{tabular}

\begin{tabular}{|c|c|c|c|}
\hline \multicolumn{4}{|c|}{ Nivel de perspicuidad (P) } \\
\hline $\mathbf{P}$ & estilo & $\begin{array}{c}\text { tipo de } \\
\text { publicación }\end{array}$ & estudios \\
\hline 0 a 15 & muy difícil & científica, filosófica & titulados universitarios \\
\hline $\begin{array}{c}16 a \\
35\end{array}$ & árido & pedagógica, técnica & $\begin{array}{l}\text { selectividad y estudios } \\
\text { universitarios }\end{array}$ \\
\hline $\begin{array}{c}36 a \\
50\end{array}$ & $\begin{array}{l}\text { bastante } \\
\text { dificil }\end{array}$ & $\begin{array}{l}\text { literatura y } \\
\text { divulgación }\end{array}$ & cursos secundarios \\
\hline $\begin{array}{c}51 a \\
65\end{array}$ & normal & Los media & popular \\
\hline $\begin{array}{c}66 a \\
75\end{array}$ & $\begin{array}{l}\text { bastante } \\
\text { fácil }\end{array}$ & $\begin{array}{l}\text { novela, revista } \\
\text { femenina }\end{array}$ & 12 años \\
\hline $\begin{array}{c}76 a \\
85\end{array}$ & fácil & para quioscos & 11 años \\
\hline $\begin{array}{l}86 a \\
100\end{array}$ & muy fácil & $\begin{array}{l}\text { cómics, tebeos y } \\
\text { viñetas }\end{array}$ & 6 a 10 años \\
\hline
\end{tabular}

\begin{tabular}{|c|c|}
\hline \multicolumn{2}{|c|}{$\begin{array}{c}\text { Equivalencia Infiesz- } \\
\text { perspicuidad }\end{array}$} \\
\hline \begin{tabular}{c|c} 
Perspicuidad & Inflesz \\
\hline $0-40$ & muy difícil \\
$40-55$ & algo dificil \\
$55-65$ & normal \\
$65-80$ & bastante fácil \\
$80-100$ & muy fácil \\
\hline
\end{tabular}
\end{tabular}

\begin{tabular}{|c|c|}
\hline \multicolumn{2}{|c|}{ Legibilidad Mu $(\mu)$} \\
\hline$\mu$ & facilidad de lectura \\
\hline $91-100$ & muy fácil \\
\hline $81-90$ & fácil \\
$71-80$ & un poco fácil \\
$61-70$ & adecuado \\
$51-60$ & un poco dificil \\
$31-50$ & difícil \\
$0-30$ & muy difícil
\end{tabular}

Son interesantes los datos que arroja esta página (Figura 5), entre ellos, los resultados con las seis fórmulas que indican el número de caracteres, letras, palabras, signos de puntuación utilizados y las edades adecuadas para la comprensión del texto que, en este caso, proporcionó que fuese para niños de 7.4 años y que el tiempo estimado de lectura sería de 0.2 minutos.

\section{Figura 5}

Resultados obtenidos al someter un párrafo de este capítulo a evaluación de legibilidad

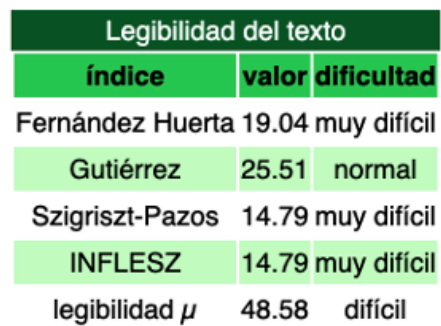

Estadisticas del texto

caracteres 321

letras 269

sílabas 114

palabras 50

frases

párrafos

letras por palabra 5.38

sílabas por palabra 2.28

palabras por frase 50.0

Número de palabras por su número de

sílabas

Número de sílabas Número de palabras

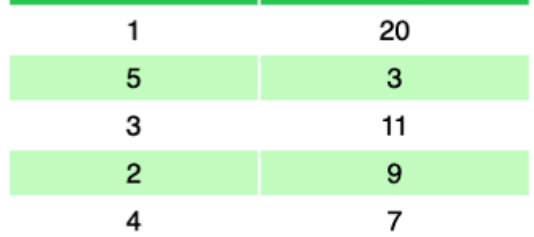

\begin{tabular}{|c|c|c|}
\hline \multicolumn{3}{|c|}{ Signos de puntuación } \\
\hline orden & Signos & frecuencia \\
\hline 1 & Comas (,) & 2 \\
\hline 2 & Puntos (.) & 1 \\
\hline 3 & Puntos y aparte & 1 \\
\hline 4 & Dos puntos (:) & 0 \\
\hline 5 & Punto y coma (;) & 0 \\
\hline 6 & Interrogación de cierre (?) & 0 \\
\hline 7 & Interrogación de apertura (¿) & 0 \\
\hline 8 & Exclamación de cierre (!) & 0 \\
\hline 9 & Exclamación de apertura (i) & 0 \\
\hline 10 & Guiones (-) & 0 \\
\hline 11 & Rayas (一) & 0 \\
\hline 12 & Apóstrofos (') & 0 \\
\hline 13 & Puntos suspensivos (...) & 0 \\
\hline 14 & Comillas ( $\propto, "$, ", " y demás) & 0 \\
\hline 15 & Paréntesis ( $\mathrm{y}$ ) & 0 \\
\hline 16 & Corchetes [] & 0 \\
\hline 17 & Llaves \{\} & 0 \\
\hline 18 & Diples $(>y<)$ & 0 \\
\hline 19 & Barras diagonales $(\Omega)$ & 0 \\
\hline 20 & Barras inversas $(N)$ & 0 \\
\hline 21 & Plecas (I) & 0 \\
\hline 22 & Asteriscos $\left({ }^{*}\right)$ & 0 \\
\hline 23 & Signos de párrafo (§) & 0 \\
\hline 24 & Calderones (ף) & 0 \\
\hline 25 & Flechas $(\rightarrow)$ & 0 \\
\hline 26 & Dos puntos y aparte & 0 \\
\hline
\end{tabular}


Este ejemplo es una muestra de cómo se puede calcular la legibilidad de acuerdo con seis diferentes fórmulas a las que se somete un material de lectura; es una teoría cuantificable que puede ayudar a crear mejores propuestas para facilitar la comprensión y que el diseñador puede utilizar como herramienta para determinar el grado de legibilidad que tiene el material con el que trabajará para diseñar algún mensaje de comunicación. Lo que es importante señalar es que cuando se habla de lecturabilidad habrá que considerar el aspecto de la dificultad de lectura.

\section{Conclusiones}

Son muchos los aspectos que se deben considerar para generar una comunicación que sea legible para los débiles visuales. La generación de un diseño de información que utilice algunos criterios para fortalecer los mensajes no dificulta la labor del diseñador, pero ayudará a muchísimas personas. Aspectos desde la elección de la fuente tipográfica, el largo de línea del texto, la jerarquía de los textos, los espaciados, así como algunas herramientas que se encuentran en la web pueden ayudar a identificar desde la construcción del texto su nivel de legibilidad; con base en la lógica de ese sitio, se puede determinar si un lenguaje es entendido y por quiénes puede ser entendido, lo cual ayuda a realizar toma de decisiones para el diseño de información que debe estar centrado en el usuario. En el caso de este estudio, la adaptación de la legibilidad tipográfica en conjunto con los lineamientos de accesibilidad marca la pauta para que en primera instancia pueda ser percibido para analizar si es comprensible.

Es importante para el diseño de información que cumpla con el objetivo de ser comprensible por el usuario, no solo en aspectos de forma sino de fondo; por lo tanto, es necesario que se apliquen las recomendaciones sugeridas en cuestiones de legibilidad en el texto de diseño de información, como las listas antes descritas. Existen otras consideraciones de composición en un diseño, pero en este capítulo solo se plantean los necesarios para cubrir las cualidades de ser legible; sin embargo, el diseñador puede generar otros enfoques de composición visual para aplicar estas reglas y cumplir con el propósito.

En el tema de lo comprensible, donde intervienen procesos mentales, el tema de la legibilidad simplifica las consecuencias inmediatas de haber percibido bien lo que se presenta ante el lector; por esta razón, se enlistan a lo largo del capítulo, 
factores que determinan la comprensión de la lectura, sin dejar a un lado la interpretación del receptor o su contexto en general.

Tener una sensibilidad por el entorno y sus habitantes imperfectos, favorece al aumento de personas que pueden percibir con mayor precisión la información que se desea comunicar. Estas consideraciones, tanto de diseño como del mensaje, requieren de un momento de reflexión, análisis y toma de decisiones, que a largo plazo ayudará a un mayor número de personas.

\section{Referencias}

Aceituno, M. (2010). Seminario de producción multimedia. Universidad Nacional de Quilmes. http://libros.uvq.edu.ar/spm/14_legibilidad.html

Adobe. (2021). Qué es el kerning y el tracking. https://helpx.adobe.com/la/indesign/ using/kerning-tracking.html

Ballesteros, S., \& Fernández, I. (2013). Análisis de la legibilidad lingüística de los prospectos de los medicamentos mediante el índice de Flesch-Szigriszt y la escala Inflesz. Anales del Sistema Sanitario de Navarra, 36(3), 397-406. https:// doi.org/10.4321/S1137-66272013000300005

Borràs, R., Peris, E., \& Ondategui, J. C. (2016). Efecte del contrast i color de fons en els moviments oculars ila responsa acomodativadurant la lectura (Tesis de Maestría). Univesitat Politécnica de Catalunya, Barcelona, España. https://www.acotv. org/media/com_lazypdf/pdf/TFM_deCastellarnauRoca.pdf

Centro Estatal de Vigilancia Epidemiológica y Control de Enfermedades. (2020) Visión CEVECESemana 43. https://salud.edomex.gob.mx/cevece/docs/tripticos/2020/ Semana43.pdf

Consejo Nacional para el Fomento Educativo. (2010). Discapacidad visual. Guía didáctica para la inclusión en educación inicial y básica. CONAFE. https://www. gob.mx/cms/uploads/attachment/file/106810/discapacidad-visual.pdf

De Buen, J. (2008). Manual de diseño editorial. Trea.

Maciá, F. (2021). ¿Qué es la accesibilidad web? Cómo cumplir con las directrices WCAG. Human Level. https://www.humanlevel.com/diccionario-marketingonline/pautas-de-accesibilidad-wcag\#Test_de_Accesibilidad_Web

Instituto Nacional de Estadística y Geografía. (2010). Perfil sociodemográfico de la población con discapacidad en el estado de Jalisco. http://internet.contenidos. inegi.org.mx/contenidos/Productos/prod_serv/contenidos/espanol/bvinegi/ productos/nueva_estruc/702825090258.pdf 
Instituto Nacional para Ciegos de Colombia. (2018). Materiales Accesibles para niños con Discapacidad Visual [Archivo de video]. https://www.youtube.com/ watch? $=$ =goKnLIOqljM\&ab_channel=INCIColombia

Kane, J. (2012). Manual de Tipografía (2a. ed.). Gustavo Gili.

Legible. (2016-2018a). Lecturabilidad de Hernández Huerta. https://legible.es/blog/ lecturabilidad-fernandez-huerta/

Legible. (2016-2018b). Fórmula de comprensibilidad de Gutiérrez de Polini. https:// legible.es/blog/comprensibilidad-gutierrez-de-polini/

Legible. (2016-2018c). Fórmula de Crawford. https://legible.es/blog/formula-decrawford/

Legible. (2016-2018d). Índice de perspicuidad de Szigriszt-Pazos. https://legible.es/ blog/perspicuidad-szigriszt-pazos/

Legible. (2016-2018e). Escala INFLESZ. https://legible.es/blog/escala-inflesz/

Legible. (2016-2018f). Legibilidad $\mu$. https://legible.es/blog/legibilidad-mu/

Legible. (2016-2018g). Analizador de legibilidad de texto. https://legible.es

Lupton, E. (2014). Tipografía en pantalla. Una guía para diseñadores, editores, tipógrafos, blogueros y estudiantes. Gustavo Gili.

Real Academia Española. (2020). Legibilidad. En Diccionario de la lengua española (23a. ed.). https://dle.rae.es/legibilidad

Rodríguez, A. (2015) Diseño editorial: el espaciado ideal para que un texto sea legible. Paredro. https://www.paredro.com/diseno-editorial-el-espaciado-ideal-paraque-un-texto-sea-legible/

W3C. (2021). Making Content Usable for People with Cognitive and Learning Disabilities. https://www.w3.org/TR/coga-usable/\#summary-understand 


\section{Capítulo 5}

\section{Design thinking para implementar buenas prácticas en accesibilidad web}

Angie Fernández Olimón y Elvia Luz González Muñoz

El término experiencia de usuario se ha desarrollado en los últimos años debido a que las personas ya no solo consumen servicios o productos por su calidad, ahora buscan que estos les proporcionen satisfacción personal. El diseño de experiencia de usuario no solo se basa en la estética, también se sustenta en lo que el usuario debe sentir y los resultados que obtenga de la interacción con un sitio web. Algunos de los factores que contribuyen a esa satisfacción son, por ejemplo, el tiempo que requiere el sitio web en cargar todos sus recursos. De acuerdo con la International Organization of Standardization:

La experiencia de usuario son las percepciones y respuestas de una persona como resultado del uso o de la anticipación del uso de un producto, sistema o servicio. [...] La experiencia de usuario incluye todas las emociones, creencias, preferencias, percepciones, respuestas físicas y fisiológicas, comportamientos y logros de los usuarios que ocurren antes, durante y después del uso. (ISO 9241-210:2010)

La experiencia de usuario o UX (por sus siglas en inglés) se basa en tres componentes: la usabilidad, el diseño y la accesibilidad. La usabilidad es definida por Traynor (2013) como la "medida empírica que califica qué tan fácil, rápido y agradable es un sitio web para un cierto tipo de usuario, evaluando tareas y contextos 
de uso" (p.375). El concepto puede ser visto esencialmente como el modo en que el usuario percibe la interacción con el contenido digital, la facilidad y la intuición para encontrar su objetivo de manera eficaz.

El segundo componente de la experiencia de usuario es el diseño; este va más allá del aspecto visual, está relacionado con la arquitectura de la información y el diseño responsivo o flexibilidad, que es la adaptación del diseño de un sitio web a diversos formatos para dispositivos móviles (González, 2020). El diseño aporta organización, orden y estructura a los contenidos del sitio.

El tercer componente es la accesibilidad, definida por Carreras (2013) como:

el arte de garantizar que un sitio o servicio web puede ser visitado y utilizado de forma satisfactoria por el mayor número posible de personas, independientemente de las limitaciones personales que tenga o de aquellas limitaciones que sean derivadas de su entorno. (p.183)

El acceso a la web puede considerarse algo sencillo y generalizado en esta época, sin embargo, para un sector de la población esto tiene un valor limitado, debido a las barreras que dificultan o imposibilitan el acceso. Estas barreras generan desventajas para las personas con discapacidad, porque no pueden beneficiarse de los servicios y la información disponible en línea. Tim Berners-Lee, creador de la WEB, creía que un aspecto esencial de esta era "el acceso de todos, independientemente de su discapacidad" (Accesibilidad Web, 2006).

Esta necesidad de lograr la accesibilidad, parte de la consideración de que todos los usuarios tienen características y capacidades diferentes, lo que influye en la forma como interactúan con el contenido de un sitio web. En el 2002, Lenhart informó que el $12 \%$ de los usuarios de la Web tenían discapacidades. Dado que el número total de personas con discapacidades está aumentando, en combinación con el hecho de que el número de personas que utilizan Internet ha aumentado enormemente, es más que probable que el porcentaje de usuarios con discapacidades en la actualidad es mayor (Kurt, 2017).

Las personas con ciertos tipos de discapacidades (visuales, auditivas, de movilidad, del habla, cognitivas y neurológicas) enfrentan mayores dificultades en el uso de la Web. Aunque existen tecnologías de asistencia disponibles, como el software de conversión de texto a voz o los lectores de pantalla, que pueden mejorar la acce- 
sibilidad, estas tecnologías solo pueden funcionar correctamente si el contenido se adhiere a los principios de diseño accesible que considera la forma como el usuario accede a una determinada página. En otras palabras, el criterio para garantizar la igualdad de accesibilidad para los usuarios con discapacidad debe ser que el usuario pueda navegar e interactuar con el contenido como lo pretendía el creador de la página web (Kurt, 2017). Al respecto, Mankoff et al. (2005) señalaron que "la accesibilidad web implica hacer que el contenido web esté disponible para todas las personas, independientemente de las discapacidades o limitaciones ambientales que experimenten" (p.41).

El desarrollador debe considerar estas variaciones en los usuarios y con el apoyo de metodologías que tengan como punto central el análisis del usuario, como es el caso del design thinking, que a lo largo de sus diferentes etapas busca optimizar el diseño para incluir a personas con algún tipo de limitación.

La asociación World Wide Web Consortium (W3C, 2021) desarrolló una serie de lineamientos aplicables a nivel internacional para lograr la accesibilidad web; actualmente son empleadas para evaluar si un sitio web es accesible o no, esto se logra revisando los criterios que cumple para ubicarlo en el nivel de accesibilidad alcanzado. En este punto, el diseño juega un papel primordial en el logro de la accesibilidad, al lograr que los sitios web sean lo suficientemente flexibles para satisfacer las diferentes necesidades, preferencias y situaciones de los usuarios. Un sitio web accesible y bien diseñado proporciona un acceso igual o equivalente a todos los usuarios y debe funcionar de manera compatible con las tecnologías de asistencia (Jaeger, 2006).

Según el Department of Health and Human Services (2006), los problemas más comunes, que presenta un sitio web que no es accesible, son: la falta de etiquetado textual en los elementos del sitio que no son textuales, información mal estructurada, textos con redacción rebuscada, falta de coherencia en el modo de redacción o que la estructura del contenido sea confusa y demasiado robusta. En estos casos, el equipo interdisciplinario juega un papel importante para lograr su mejora. Sin duda, es cierto que construir relaciones más íntimas con los usuarios de forma creativa, puede resultar en la mejora de procesos tecnológicos y facilitar la resolución de problemas que se presenten antes de la producción de un sitio web (W3C, 2021).

La metodología del design thinking contribuye a que todo el equipo de trabajo tenga acercamiento con el usuario, puede ser directo o indirecto, dependiendo 
de los roles y la etapa en la que se encuentre. La intervención de profesionales del desarrollo web (editores de texto, correctores de estilo) a cargo de la accesibilidad, permite identificar la problemática y clarificar el significado de las palabras inusuales, adecuar el contenido para todo tipo de usuario y homologar los contenidos en cada uno de los componentes del sitio. El uso del design thinking permite que, desde etapas tempranas, los profesionales consideren que el contenido debe ser claro, conciso y correcto para el usuario que cuente con algún tipo de limitación física. En este proceso, deben integrarse todos los actores, a fin de que comprendan la importancia de lograr la accesibilidad y que cada uno aporte desde su campo; incluyendo el área de sistemas, los desarrolladores backend y frontend, los administradores de servidores, bases de datos y especialistas en SEO hasta llegar a la parte gerencial de la empresa.

Asimismo, se debe incorporar el trabajo de otros profesionales, como los psicólogos, que con el uso de esta metodología podrán incorporar el análisis de otros efectos, como la carga de trabajo. Betti (2013) relacionó la carga mental a los recursos de procesamiento que una persona necesita para realizar una tarea dentro de un sitio web; de esta manera, "cuanto más alta es la carga de trabajo, más alta la probabilidad de cometer errores" (s.p.).

Existen metodologías que tienen fines muy relacionados con el diseño de información, su objetivo es "lograr que la información sea fácil de encontrar y entender por medio de estructuras informáticas que sirvan las necesidades de los seres humanos que las van a utilizar" (Arango, 2013, p.154). Esta similitud demuestra que estas metodologías pueden ser aplicadas de manera satisfactoria en cuestión de aplicación de nuevas tecnologías, para economizar tiempos y recursos humanos.

\section{Metodología de design thinking}

Como se mencionó, se propone incorporar la metodología de design thinking para lograr la accesibilidad web, por medio del reconocimiento de las características del usuario y de las mejoras que el equipo de trabajo integre para una resolución óptima de la accesibilidad. Esta metodología fue introducida por Herber Simon en 1969 y evolucionó con el trabajo de David Kelly y Tim Brown, en una agencia de diseño Ilamada IDEO en Palo Alto, California (Pinos, 2021). En un principio, se utilizaba para el ámbito económico como una estrategia viable para los negocios, pero al pasar 
del tiempo, se fue popularizando en la publicidad hasta convertirse en una metodología que se sigue como proceso de diseño y de reconocimiento para el usuario directo, en casi cualquier disciplina.

El concepto que acogió Mootee (2019) sobre esta metodología es que "constituye su propio modo analítico, que se centra en las formas, las relaciones, la conducta y las interacciones y emociones humanas reales" (p.39), esto da como resultado la mejora en el conocimiento pleno del usuario y su entendimiento. También, da la ventaja de que el equipo de trabajo identifica los problemas de accesibilidad de manera pronta antes de llegar a la etapa de desarrollo de un sitio web.

Con la metodología de design thinking, puede desarrollarse la intuición de los líderes de proyecto y equipo de trabajo involucrados en la implementación de la accesibilidad de un sitio web. De acuerdo con Mootee (2019), la intuición "tiene la notable capacidad de aportar claridad a la toma de decisiones estratégicas" (p.59), lo que suma al desarrollo de un proyecto de diseño de un sitio web accesible, ya que contribuye a la interacción sensible y responsable con el usuario.

Para el equipo de trabajo que desarrolla un sitio web accesible es importante fomentar la inclusión, comunicarse con sus usuarios reconociendo sus características y capacidades, demostrar que la responsabilidad social es parte esencial de los valores que se tiene en la institución o empresa. El design thinking contribuye a resolver la problemática que se presente para el desarrollo de un sitio web accesible de manera empática con el usuario y con creatividad para el equipo de trabajo (Cañas, 2021).

El propósito de esta metodología es reconocer a partir del estudio del usuario las variantes existentes y desarrollar la divergencia en las visiones del equipo de trabajo. La Real Academia Española (RAE, 2020b) define la divergencia como "la diversidad de opiniones o pareceres." Este proceso tiene un segundo momento, convergente, donde se busca seleccionar las mejores opciones y propuestas para lograr una solución. La RAE (2020a) define la convergencia como "coincidir en la misma posición ante algo controvertido", lo que permite que las etapas vayan evolucionando para llegar al objetivo final.

Durante este proceso, los participantes explorarán muchas ideas y regresarán a buscar una solución las veces que sea necesario, deben poder entrar y regresar a cada etapa hasta conseguir el resultado deseado (Brown, 2018). 
En la Universidad de Stanford, Bob Mckim, creativo en los años 60 y 70, desarrolló este modelo de cinco etapas, que en la actualidad es el más utilizado y considerado como el estándar; sin embargo, algunos autores y empresas lo modifican según sus necesidades (Brown, 2018).

En la Figura 1, se muestra este modelo a seguir para llegar a la solución probable deseada. Es un proceso experimental e iterativo que por lo regular se desarrolla de manera colaborativa.

\section{Figura 1}

Fases de proceso del design thinking

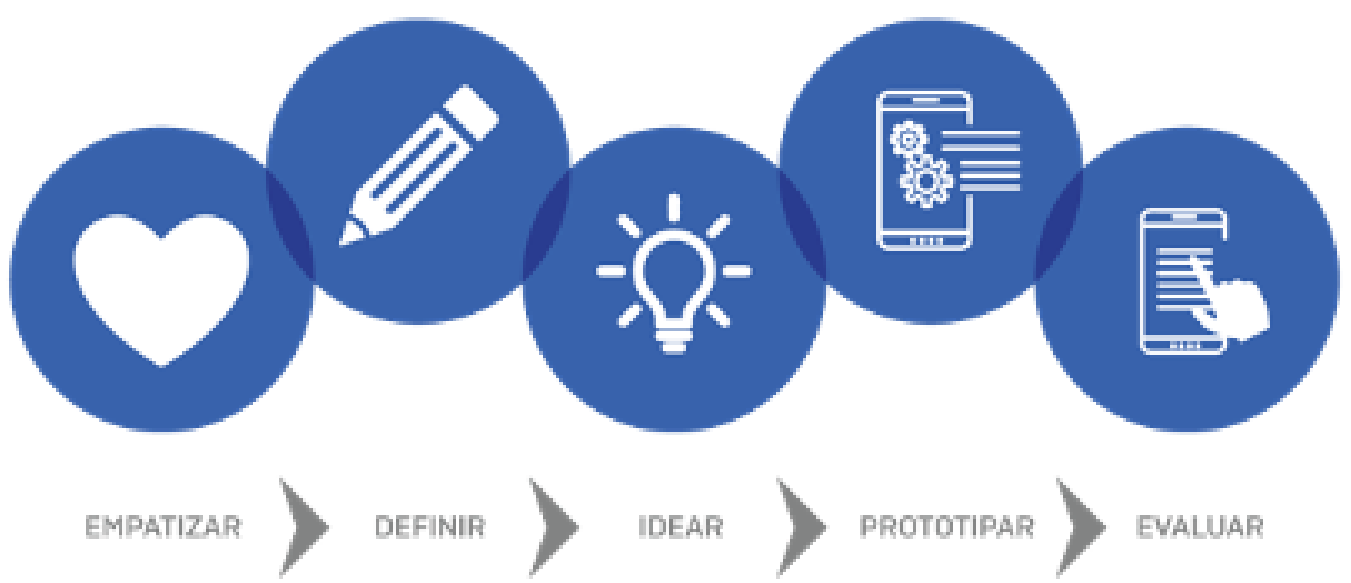

Las cinco etapas son empatizar, definir, idear, prototipar y evaluar. Los lineamientos para su aplicación son en torno a cinco principios: la definición de roles en el equipo de trabajo, la delimitación de trabajo en las diferentes etapas, la definición del comportamiento, centrarse siempre en el usuario y la repetición de los ciclos las veces que sea necesario. Esta iteración permite que cada vez mejoren los resultados, según los ciclos que sean necesarios para llegar al resultado deseado (Duarte, 2019).

La colaboración del equipo de trabajo es fundamental, se abonan al proyecto todos los puntos de vista, la experiencia y los conocimientos para dar soluciones integrales a la problemática detectada en los usuarios, para esto se enlistan las etapas a desarrollar.

\section{Etapa 1. Empatizar}

La primera etapa es la de empatizar con el usuario al que va dirigido el sitio web, es acercarse a los usuarios. El objetivo de esta etapa es descubrir cuánto sabe el usua- 
rio acerca del producto o servicio, identificar las necesidades psicológicas y emocionales del usuario; esto mediante mapas de empatía que permiten mirar desde su perspectiva, para lograr un conocimiento más profundo sobre su personalidad, su entorno, sus necesidades y sus deseos.

Para hacer tangible este conocimiento se propone que el equipo de trabajo realice un mapa de empatía que, de acuerdo con Duarte (2019), consiste en cuatro fases:

- Segmentación. Se agrupa a los usuarios en función de sus características físicas; en este caso, personas con algún tipo de limitación física, de esta forma se tendrán dos grupos específicos para evaluar.

- Personalización. Dentro de esta fase, es de suma importancia identificar plenamente a los usuarios, por lo que se recomienda hacer una ficha de todos y cada uno de los participantes; en estas se describirán sus datos personales, un poco de su biografía, fotografía, metas, frustraciones, tipo de personalidad, sus necesidades al interactuar con el producto o servicio y, en específico, se documentará qué tipo de limitación presenta cada uno de los usuarios.

- Empatizar. En esta fase, el equipo de trabajo se sensibiliza ante las respuestas de los usuarios; se busca entablar una conexión emocional con sus sentimientos, emociones y pensamientos. Se recomienda hacer un mapa de empatía (Figura 2). Con este mapa se logrará descubrir cuál es su entorno y cómo lo vive en compañía de familiares y amigos; se reconoce al usuario mediante su lenguaje corporal, su modo de actuar y hablar. También se identifica la clase de información que recibe el usuario de parte de la gente que lo rodea y cuáles son sus mayores preocupaciones e inquietudes. Se le solicitará que reconozca cuáles son los principales obstáculos en su entorno, tanto materiales como emocionales. Por último, se le cuestionará cuáles son las expectativas del sitio en el cual planea navegar y obtener interacción; es decir, cómo será un sitio al que califique como usable (Duarte, 2019).

- Validación. En esta fase se crean las hipótesis, el equipo crea predicciones y suposiciones de posibles resultados para lograr la accesibilidad del sitio web. Es aquí en donde se implementa el mapa de empatía. 
Figura 2

Mapa de empatía

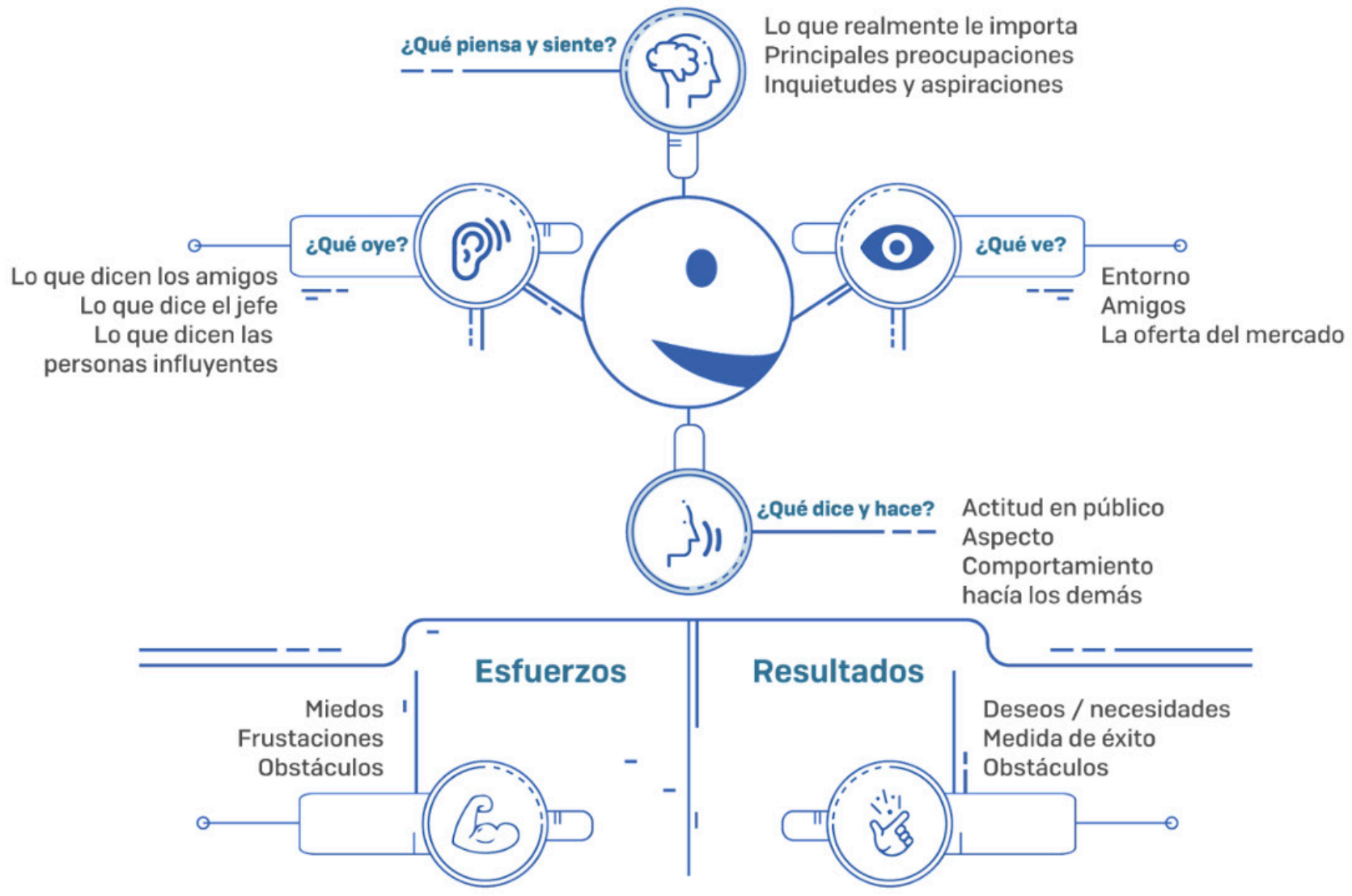

Nota. Elaborado con base en Iglesias (2019).

También se recomienda hacer uso del Customer Journey Map (CJM) como parte de la etapa de empatizar, como un medio para identificar las sensaciones que tienen los usuarios cuando tienen contacto con los diferentes puntos de navegación de un sitio, donde se marca la interacción directa del usuario con el sitio y se califica por medio de su experiencia de manera positiva o negativa (Figura 3). Este mapa sirve para definir las experiencias que ha tenido el usuario con el sitio web; con precisión se descubre el antes, durante y después de la experiencia. Se deben plasmar, en papel o en formato digital, estas sensaciones para poder identificar gráficamente los puntos donde se tiene mayor dificultad para que fluya la navegación.

En esta etapa intervienen todos los integrantes del grupo de trabajo. Se deben plantear varias hipótesis, dar solución a esas dificultades y obstáculos que el usuario con algún tipo de limitación señaló enfrentar al interactuar con un sitio web; en la navegación, la búsqueda de contenido y hasta las dificultades técnicas que impiden una navegación fluida. Responder a la pregunta "¿cómo podemos hacer para...?" permitirá crear escenarios con posibles soluciones al problema (Duarte, 2019). 


\section{Figura 3}

Plantilla de Mapa de Experiencia del Cliente

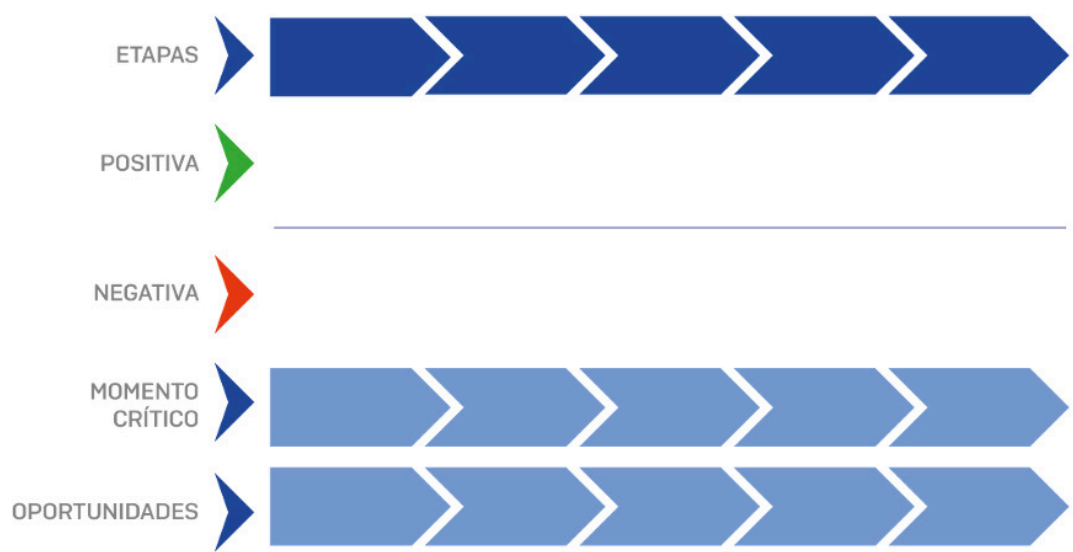

Nota. Elaborado con base en Espinoza (2019).

Para conseguir estos datos se puede elaborar una guía de entrevistas, en donde se plantean preguntas específicas para crear narrativas de parte del usuario que permitan obtener información relevante.

La implementación de esta etapa permitirá que el usuario con algún tipo de limitación comparta las dificultades que tiene para acceder a un sitio web; desde sus emociones hasta la problemática de no contar con un dispositivo móvil adecuado o no contar con acceso a la red y todos sus contenidos. Se debe estudiar la reacción que tienen ante la falta de equidad en cuanto acceso a la información. Por lo tanto, el equipo de trabajo debe ponerse en la piel del usuario, para mejorar su experiencia y la satisfacción que obtenga al interactuar con el sitio web.

\section{Etapa 2. Definir}

En este punto se construye el análisis con base en el punto de vista de las necesidades del usuario; aquellas evidentes y aquellas que no reconoce como tal. En esta etapa se busca sintetizar e identificar los problemas clave que tiene el usuario cuando navega e interactúa con el sitio web.

La recolección de toda la información y conocimiento sobre el usuario beneficiará profundamente al reconocimiento de sus necesidades. Se deben filtrar los temas que se desean indagar para que la narrativa sea detallada; tratar que el usuario comparta sus historias de vida, llevará al equipo de trabajo a un aprendizaje sobre su persona; con esto se podrá elaborar una síntesis de los mayores obstáculos con los que se enfrenta al hacer uso del sitio. 
Para el equipo de trabajo involucrado en esta etapa, es importante definir la problemática de los usuarios con alguna limitación; esto facilitará la implementación de normas y estándares de manera técnica y la construcción de la arquitectura de información; con estas buenas prácticas, el sitio web puede ser calificado con un mayor nivel de accesibilidad.

\section{Etapa 3. Identificar}

En esta etapa se implementa la divergencia; todos los integrantes del equipo de trabajo expresan sus pensamientos de manera abierta, todas las ideas son válidas en esta etapa, el pensamiento en conjunto servirá para identificar las posibles soluciones. Trabajar con el método de lluvia de ideas ayuda a tener pensamientos abiertos, escuchar y documentar las ideas de todos los miembros del equipo involucrados en el proyecto, esto servirá para abrir el panorama a la solución más viable (Langenfeld, 2019).

En este ejercicio, es importante la participación de todos los profesionales involucrados; se requiere la aportación de ideas prácticas y frescas. Suele pasar que, en su mayoría, las ideas son técnicas; por ejemplo, el equipo que tiene actividades relacionadas con el desarrollo de software podrá opinar acerca de soluciones como la colocación de un botón en el sitio web para que el usuario pueda hacer zoom a la pantalla; los diseñadores gráficos podrán proponer la utilización de colores de alto contraste para la forma y el fondo; y los creadores de contenido multimedia podrán sugerir la aplicación de subtítulos a los videos (Revilla, 2018). Estas soluciones, si bien deben ser creativas, deben basarse en datos objetivos acerca de las capacidades y necesidades del grupo de usuarios con limitaciones. Esto permitirá que las propuestas faciliten la accesibilidad de los usuarios.

Después, es importante hacer un filtro de ideas y considerar cuáles tienen mayor potencial; el número puede ser de tres a cuatro, para después refinarlas. En esta etapa se estudia el impacto que tienen las ideas más relevantes y las que el equipo considera tienen más viabilidad de ser desarrolladas y un mayor impacto en la experiencia del usuario.

\section{Etapa 4. Prototipar}

La tercera etapa de esta metodología es prototipar; en esta se marca pauta para definir el rumbo que lleva el sitio y su interacción con el usuario. El objetivo principal es 
hacer tangibles las ideas, construir de manera muy cercana a la realidad el sitio web que se desea evaluar con el usuario directo. Esta etapa es resultado de la selección de las mejores ideas generadas por el equipo con base en el estudio recabado sobre el usuario.

Para esta etapa se recomienda aplicar las pruebas de análisis en un ambiente relajado, donde el usuario con alguna limitación no tenga ningún obstáculo físico externo, sin distracciones, como celulares o interacción con otras personas que los acompañen. La intervención de profesionales en esta etapa puede ser muy robusta y sumamente importante, ya que definirá la implementación real del sitio a nivel producción. Los resultados que se obtengan de esta etapa serán muy cercanos a la precisión de un resultado real. Para probar el prototipo se debe indicar claramente a los usuarios la tarea que se espera realice en tres fases:

1. Fase física: en donde se utilizan materiales básicos para simular las características del sitio; en este caso, puede ser un celular o una tableta con acceso a Internet, con las herramientas de software necesarias para lograr la navegación.

2. Fase de entorno: consiste en desarrollar la prueba en un ambiente muy parecido al real.

3. Fase de experiencia: donde se descubre el nivel de facilidad con el que el usuario logra navegar y cómo califica la satisfacción al interactuar con el sitio.

Para la elaboración de los prototipos se pueden utilizar diversas herramientas y aplicaciones en diferentes formatos: bocetos y diagramas, interfaces de papel, maquetas, storyboards, prototipos digitales, entre otros. Con estas técnicas pueden lograrse prototipos que van desde lo básico hasta los más complejos. En el prototipo se define la viabilidad, el presupuesto y el tiempo que el sitio requiere para lograr ser accesible; para esto se recomienda la elaboración de un mapa de esfuerzo o impacto, donde se identifican visiblemente las ideas de mayor impacto y menor esfuerzo; su implementación es importante para la toma de decisiones (Figura 4).

En esta etapa se evalúa directamente en el prototipo la interacción que tendrá el usuario final con el diseño de información, la usabilidad, la navegación y el contenido. Lo mejor es señalar pocas tareas al usuario y una a la vez, para no abrumarlo con indicaciones y que su narrativa al momento de la navegación sea natural, esto permitirá que se puedan identificar todos los errores posibles. 
Figura 4

Mapa de esfuerzo

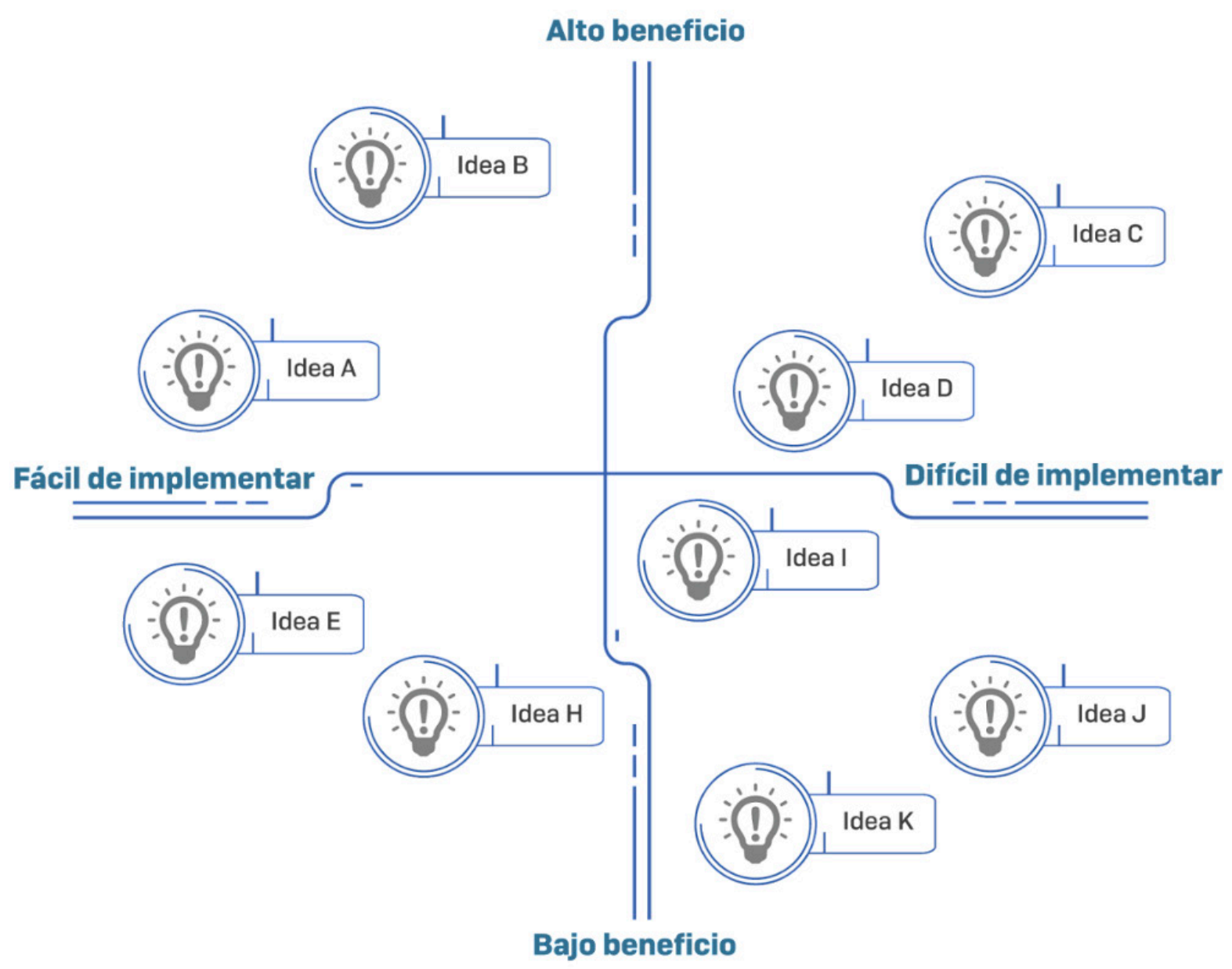

Nota. Elaborado con base en Duarte (2019).

La etapa de prototipo proporciona las herramientas necesarias para evaluar, no solo la interacción del usuario con el sitio, sino también el nivel de accesibilidad que este puede alcanzar, cuando se evalúa con base en las guías de la WCAG 2.1 para alcanzar un nivel de conformidad (Revilla, 2018). Estas guías se basan en cuatro principios y 14 lineamientos (Tabla 1); en su implementación solo se ven involucrados los desarrolladores back-end y front-end (Web Accessibility Initiative, 2019).

A partir de estos lineamientos, se puede evaluar el cumplimiento de alguno de los tres niveles de conformidad: el nivel " $A$ " es el más bajo; " $A A$ " es el nivel medio y "AAA" es el más alto (W3C, 2021). Por ejemplo, el nivel " $A$ " se basa en que cualquiera pueda acceder al sitio, mientras que en un nivel "AAA" el sitio mejora su usabilidad e incrementa la cantidad de usuarios (Revilla, 2018).

La accesibilidad de un sitio web se basa y es evaluada por cuatro principios fundamentales: (a) debe ser perceptible para las personas y buscadores; (b) debe 


\section{Tabla 1}

\section{Lineamientos de accesibilidad}

\section{Lineamientos}

1. Proporcionar alternativas equivalentes al contenido visual y auditivo.

2. No confiar solo en el color.

3. Utilizar hojas de estilo y de marcado y hágalo correctamente.

4. Aclarar el uso del lenguaje natural.

5. Crear tablas que se transformen con gracia.

6. Asegurarse que las páginas con nuevas tecnologías se transformen con elegancia.

7. Asegurar el control del usuario de los cambios de contenido urgentes.

8. Garantizar la accesibilidad directa de las interfaces de usuario integradas.

9. Diseño para la independencia del dispositivo.

10. Utilizar soluciones provisionales.

11. Utilizar tecnologías y pautas del W3C.

12. Proporcionar información de contexto y orientación.

13. Proporcionar mecanismos de navegación claros.

14. Asegurarse de que los documentos sean claros y sencillos.

Nota. Elaborado con base en W3C (2021).

ser operable, el equipo de trabajo debe otorgar todos los elementos necesarios para la interacción de cualquier usuario con el sitio; (c) debe ser comprensible, el usuario debe tener claro el modo de navegación y debe encontrar fácilmente lo que busca; (d) debe ser robusto, hacer uso de nuevas tecnologías y herramientas de apoyo como los lectores de pantalla (Revilla, 2018).

La accesibilidad permite jerarquizar información; por medio de criterios técnicos se pueden indicar títulos o resaltar contenido importante en el sitio, con base en encabezados y marcado semántico; por ejemplo, por medio de etiquetas HTML para definir un título $\mathrm{H} 1$, para un subtítulo $\mathrm{H} 2$ o etiquetas con hojas de estilos para dar importancia a un enlace dentro del contenido del sitio. También es canal para la arquitectura de la información y permite hacer uso del contenido conforme a la relevancia que busca el usuario. 


\section{Etapa 5. Evaluar}

En esta etapa se vuelve al usuario con las observaciones realizadas y resueltas a su favor; se busca la retroalimentación con base en los resultados obtenidos de la interacción con los prototipos desarrollados, se identifican las carencias y se logra evolucionar la idea para llegar a la resolución de los problemas.

Así, existe la posibilidad de que, con el resultado de su interacción, el usuario incite a regresar a cualquiera de las etapas anteriores. En dicho caso, se realizan nuevamente las tareas de la etapa de prototipo, con esto se descubre mediante un proceso iterativo la solución que satisfaga todas las necesidades. Este proceso se puede repetir las veces que sea necesario, siempre y cuando se tenga identificado el avance para evitar estancarse y ralentizar el proceso (Langenfeld, 2019).

La implementación de la accesibilidad, por medio de metodologías como el design thinking, permite desarrollar mejores ideas; esto aporta la oportunidad de presentar al usuario productos de calidad, factibles de navegar por cualquier persona y en cualquier situación. Contar con el entendimiento del usuario, mediante las diferentes etapas del proceso, tiene como objetivo explorar y materializar las ideas del equipo de trabajo. Identificar las soluciones para ofrecer acceso a todos los usuarios sin importar su condición física, motora o mental es un trabajo de todos y que en varios países se ha dictaminado como norma.

La aplicación de esta metodología permite establecer metas y tiempos que se espera cumplir para generar soluciones satisfactorias. Puede ser utilizada por cualquier persona y sus tiempos de aplicación son muy rápidos y cercanos a los usuarios del sitio.

La arquitecta Sheila Pontis, experta en diseño de información, señala que "La esencia del diseño de información es analizar, organizar, entender, solucionar y diseñar, y su principal objetivo es la traducción de información compleja, datos no organizados ni estructurados, en información con sentido y de fácil acceso" (Pontis, 2012, párr.1). Ahora conocemos que la metodología de design thinking tiene los mismos fines y que su principal objetivo es contribuir a resolver problemas de comunicación, transmisión de información y organización.

\section{Conclusiones}

La accesibilidad web es un concepto muy amplio que engloba una serie de aspectos éticos, técnicos y sociales. Uno de los principales objetivos del equipo de tra- 
bajo interdisciplinario debe ser el garantizar la accesibilidad a la web para todos los usuarios, sin importar sus limitaciones. Se requiere la eliminación de barreras y obstáculos para que todas las personas puedan participar por igual en la red.

La igualdad de acceso significa, entonces, que todas las personas que deseen aprovechar todo lo que Internet tiene para ofrecer pueden hacerlo, independientemente de sus circunstancias, necesidades y preferencias particulares (nivel de capacidad/discapacidad, edad, nivel de educación, equipamiento disponible), plataforma utilizada y preferida, ya sea de escritorio, teléfono móvil o tableta. Si no se cumple la promesa de universalidad del acceso, tan integral a la visión de Tim Berners-Lee, un número incalculable de personas puede verse privado de la oportunidad de perseguir sus metas educativas y aspiraciones profesionales.

Es inminente la aplicación de nuevos recursos y metodologías para estar a la vanguardia y cumplir con la meta anterior. Esto se logrará a partir de generar resultados innovadores basados en estrategias, recursos y, sobre todo, en el conocimiento y talento humano para identificar puntualmente las necesidades, actitudes y comportamientos de los usuarios.

El design thinking proporciona las herramientas necesarias para que un sitio web pueda ser desarrollado y mejore la experiencia del usuario, lo que conlleva la aplicación correcta de sus tres componentes: la usabilidad, el diseño y la accesibilidad.

Las ventajas que aporta esta metodología son varias; en primer lugar, su proceso no lineal pone en el centro del proceso al usuario, se toman en cuenta sus necesidades y satisfacción para aportar un verdadero valor a la usabilidad del sitio web y lograr la accesibilidad de este, permite volver a cada una de las etapas para redefinir el rumbo de la problemática y buscar la mejor solución. Segundo, se promueve la creatividad, la capacidad de sensibilización del equipo de trabajo, la buena disposición para colaborar y el desapego a ideas propias sobre el sitio, así como la elaboración de hipótesis de posibles soluciones sin tener miedo al rechazo de ideas o críticas.

Usar como base las etapas del design thinking favorece la eficacia en la resolución de problemas más acertados para la interacción óptima con el usuario. La implementación de estas herramientas facilita al equipo de trabajo la toma de decisiones antes de comenzar a producir un producto; en este caso, la implementación de un sitio web con todos los requerimientos básicos para que sea accesible. 
En términos prácticos, en la aplicación e implementación de la accesibilidad web se recomienda hacer el proceso desde cero, ya que hacerlo cuando un sitio ya es productivo aumenta los costos y dificulta reparar los lineamientos marcados a nivel internacional; con esta metodología y sus técnicas se simplifica la estrategia, lo que resulta en la mejora de la jerarquización de la información, la implementación de nuevas tecnologías, el desarrollo de código limpio, herramientas de software y, sobre todo, la responsabilidad social que resulta para el usuario con algún tipo de limitación física o tecnológica.

El design thinking puede tener consecuencias favorables para todo el equipo de trabajo que pretenda la implementación de accesibilidad web, como resultado de sus diversas etapas en las que se logra reconocer a profundidad al usuario y la problemática con la que se enfrenta cuando interactúa con el sitio.

\section{Referencias}

Accesibilidad Web. (2006). ¿Qué es la Accesibilidad web? http://accesibilidadweb.dlsi. ua.es/

Allende. (2019). Design Thinking, una metodología para innovar en cinco pasos. Creatividad Cloud. https://www.creatividad.cloud/design-thinking-unametodologia-para-innovar-en-cinco-pasos/

Arango, J. (2013). Entre la Arquitectura y la Información. En S. Betti, \& L. Paz (Ed.). Pioneros y hacedores. Fundamentos y casos de diseño de interacción con estándares de Accesibilidad y usabilidad. Godot.

Betti, S. (2013). Ergonomía física y cognitiva: los sistemas sensoriales humanos y la evaluación ergonómica de interfaces. En S. Betti \& L. Paz (Ed.), Pioneros y hacedores. Fundamentos y casos de diseño de interacción con estándares de Accesibilidad y usabilidad. Godot.

Brown, T. (2008). Tim Brown: Tales of creativity [Video]. TED Conferences. https:// www.ted.com/talks/tim_brown_tales_of_creativity_and_play\#t-43097

Cañas, J. (2021). Diseño UX: experiencia de usuario UX/UI + Figma [Video]. Udemy. https://www.udemy.com/course/ux-design-disenador-ux-de-cero-aprofesional-2021/learn/lecture/21531106\#overview

Carreras, O. (2013). Accesibilidad Web y SEO. En S. Betti \& L. Paz. (Ed.), Pioneros y hacedores. Fundamentos y casos de diseño de interacción con estándares de Accesibilidad y usabilidad. Godot. 
Duarte, L. (2019). Prototipado y user testing con Design Thinking [Video]. Crehana. https://www.crehana.com/clases/v2/9396/player/25269/?source_ page $=$ Course $\% 20$ Dashboard\&source_detail=Content\%20section

Espinoza, R. (2019). ¿Qué es el customer journey map? RobertoEspinosa.es https:// robertoespinosa.es/2021/02/20/customer-journey-map/

González, S. (2020). Cyberclick. https://www.cyberclick.es/que-es/experiencia-deusuario

Iglesias, Y. (2019). Designthinking Gal. https://designthinking.gal/el-mapa-deempatia/

International Organization of Standardization (ISO 9241-210:2010). (2010). Ergonomics of human-system interaction - Part 210: Human-centred design for interactive systems.

Kurt, S. (2017). Moving toward a universally accessible web: Web accessibility and education. Assistive Technology, 13(4), 1-11. https://doi.org/10.1080/10400435 .2017 .1414086

Langenfeld, K. (2019). Design Thinking para principiantes. Independiente.

Mankiff, J., Fait, H., \& Tran, T. (2005). Is you web page accessible? A comparative study of methods for assessing web page accessibility for the blind. Proceedings of the SIGCHI Conference on Human Factors in Computing Systems. http://sonify. psych.gatech.edu/ walkerb/classes/assisttech/pdf/Mankoff(2005).pdf

Mootee, I. (2019). Design Thinking para la innovación estratégica. Empresa Activa.

Pinos, D. (2021). Design Thinking: del origen de la metodología a un MINDSET. https:// dianapinos.com/2021/05/03/design-thinking-del-origen-de-la-metodologiaa-un-mindset/

Pontis, S. (2012). Qué es el diseño de información. Foro Alfa. https://foroalfa.org/ articulos/que-es-el-diseno-de-informacion

Real Academia Española. (2020a). Converger. https://dle.rae.es/converger

Real Academia Española. (2020b). Divergente. https://dle.rae.es/divergente

Revilla, O. (2018). Accesibilidad Web. WCAG 2.1 de forma sencilla. Itákora Press.

Traynor, V. (2013). Elaboración de una normativa de Usabilidad y Accesibilidad Web: El caso de la web de la Ciudad de Buenos Aires. En S. Betti \& L. Paz. (Ed.), Pioneros y hacedores. Fundamentos y casos de diseño de interacción con estándares de Accesibilidad y usabilidad. Godot. 
Web Accessibility Initiative, W. (2019). Principios de accesibilidad. Web Accessibility Initiative (WAl). https://www.w3.org/WAl/fundamentals/accessibilityprinciples/es

World Wide Web Consortium. (2021). Web Content Accessibility Guidelines 1.0. https:// www.w3.org/TR/1999/WAI-WEBCONTENT-19990505/\#Conformance 


\section{Capítulo 6}

\section{El wayfinding y su incidencia en las estrategias de movilidad urbana Caso de estudio: ciclovías del centro de Puebla}

Mariel García Hernández y Juan Eduardo López Morales

Desde tiempos inmemoriales, una de las necesidades básicas del ser humano ha sido desplazarse de un lugar a otro con fines sociales, políticos, religiosos, laborales, culturales o por la propia inmersión de la rutina diaria del individuo. Actualmente, de acuerdo con Ibañez (2018), "vivimos en un mundo complejo, donde cada día las personas se desplazan, circulan, transitan e interactúan con diferentes espacios" (p.21); sin embargo, más allá de un tema de desplazamiento, las personas requieren encontrar el camino que los lleve a donde desean llegar y, además, tener la mejor experiencia de movilidad en esta tarea fundamental.

Cuando hablamos de una experiencia de movilidad nos referimos a qué tanto las necesidades prácticas y emocionales del usuario son resueltas o cubiertas a través del espacio en el cual está interactuando. Por ello, es importante desarroIlar estrategias de movilidad considerando la legibilidad urbana, es decir, no solo centrarse en analizar el entorno, el contexto físico y los requerimientos del propio espacio, sino establecer bases empáticas con los usuarios de los espacios urbanos y sus expectativas al respecto; esto a través de un análisis del comportamiento de los usuarios, sus necesidades con respecto al objeto de diseño a desarrollar, su perfil tanto demográfico como psicográfico, sus deseos y necesidades a cubrir con base al espacio urbano.

A raíz de esto, el wayfinding juega un papel relevante en lograr comunicar las diferentes necesidades y planteamientos a usar en la movilidad urbana; este debería ser considerado dentro de dichas estrategias, implementadas por los gobiernos 
en turno, quienes tienen la posibilidad de ejecutar acciones en beneficio de la ciudadanía y de los propios usuarios. Como objeto de estudio para poder ejemplificar esta tesis inicial, se tomó el caso de las ciclovías, ya que estas son un ejemplo de movilidad urbana que, en teoría, ayudan a tener mejores formas de desplazamiento de los habitantes (Ramos, 2017). Sin embargo, en la ciudad de Puebla durante el mes abril del 2021 se hicieron mediáticos una serie de eventos en donde se reportaban caídas de usuarios en torno a la ciclovía que se encuentra en la Calle 7 Sur, esquina con 13 Poniente del Centro Histórico de dicha ciudad, dando pauta a desarrollar el siguiente análisis del wayfinding y la incidencia que podría tener en el desarrollo de estrategias urbanas de movilidad.

\section{El wayfinding como generador de experiencias de movilidad urbana}

Como hemos planteado en el apartado anterior, para poder generar bases empáticas con los usuarios que interactúan con el espacio urbano podemos auxiliarnos del wayfinding; este juega un papel importante en el desarrollo de estrategias de comunicación visual que abonan a la legibilidad urbana del propio espacio y a la estrategia de movilidad pública, siendo esto posible gracias a uno de los enfoques de esta disciplina.

De acuerdo con Frascara (2015), el wayfinding es definido como el diseño de sistemas de orientación en espacios arquitectónicos, urbanos y naturales. Dalton et al. (2019) señalaron que el wayfinding se encarga de la planificación de la navegación del usuario en un espacio. Calori y Vanden-Eynden (2015) argumentaron que el wayfinding tiene como objetivo ayudar a las personas a encontrar su camino a través de un entorno, en donde a menudo esto implica algo más que la mera señalización. Por otra parte, los autores señalan que el wayfinding encuentran su quehacer en seis grandes áreas:

1. Diseño urbano (señalización de la ciudad): calles, avenidas, etc.

2. Arquitectura del paisaje: parques, espacios públicos, etc.

3. Arquitectura: edificios comerciales, de gobiernos, etc.

4. Diseño de interiores: conceptualización de ambientes, museos, etc.

5. Diseño Industrial: quioscos de información, numeración y placas de materiales, sistemas de ensamblaje de piezas, su fijación y anclaje, procesos de fabricación e implementación de gráficas.

6. Diseño gráfico: señalética, características cromáticas, tipografía, etc. 
En un contexto que se enfoca en el diseño urbano, según Hunter et al. (2018), el wayfinding es un proceso que conlleva una interacción dinámica entre las personas y su entorno (lugar). Los autores establecen un modelo que plantea el contexto en que este proceso tiene lugar (Figura 1), en donde podemos observar los elementos que se relacionan: el ambiente comunitario, que vendría siendo la esfera donde están se encuentra las personas (peatones, conductores de algún tipo de vehículo y usuarios de tránsito), las herramientas tecnológicas, como GPS o sistemas de navegación y las condiciones propias que conforman el ambiente del viaje que realizan estos usuarios, como los lugares que están en el camino, los sonidos, los olores, la iluminación y el propio camino planteado a través de señalización urbana.

\section{Figura 1}

Modelo del wayfinding

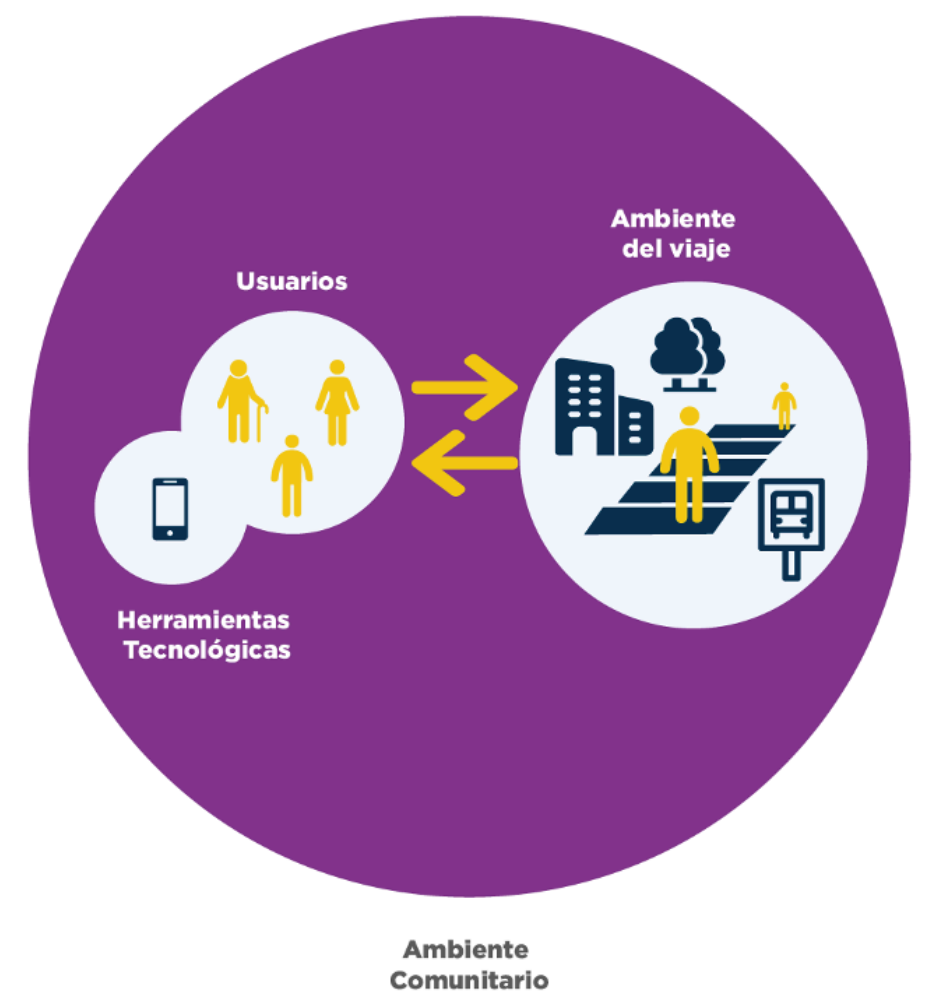

Nota. Elaborado con base en Hunter et al. (2018).

Cabe señalar que un sistema de wayfinding en un contexto urbano se vale de herramientas de señalización para hacer de la experiencia de usuario más efectiva y eficiente (e. g., señalética, mapas, indicaciones visuales en aceras, borlados, flechas de continuidad de movilidad). Estas herramientas, según la Secretaría de Comunicaciones y Transportes (2014), tienen el objetivo de "reglamentar, informar y advertir de las condiciones prevalecientes y eventualidades acerca de rutas, di- 
recciones, destinos y lugares de interés donde transitan los usuarios" (p.3). Este tipo de herramientas ayudan a establecer puntos de referencia espaciales que hacen de la imagen urbana más legible; para poder desarrollar este tipo de instrumentos se debe tomar en consideración lo que plantean Calori y Vanden-Eynden (2015):

- Restricciones de tiempo y presupuesto.

- Objetivos para la construcción de la identidad cultural que se desea establecer o reforzar a través del diseño urbano y arquitectónico.

- Contexto formal y temático del sitio. Al respecto, Chong et al. (2012) señalaron que se debe "identificar al sitio o al emplazamiento de un proyecto arquitectónico o urbano y a su entorno como parte de un sistema natural y social, en el que se interrelacionan diferentes procesos y factores" (p.25). Estos factores son de índole sociocultural, como antecedentes sociales-económicos e históricos-culturales, localización del sitio, estructura urbana, usos del suelo urbano (habitacional, industrial, comercial, áreas verdes, entre otros), estructura urbana, infraestructura, servicios urbanos, presiones y restricciones (ductos de gas, líneas de tensión, vestigios arqueológicos, entre otros), imagen urbana, tenencia del suelo (asentamientos irregulares y propiedad ejidal, entre otros), riesgos y vulnerabilidad (químico-tecnológicos, ecológicos-sanitarios, socio-organizativos, entre otros) y normativo (estatal, nacional e internacional).

- Perfiles de usuario del espacio a trabajar. En este punto nos referimos a las personas que habitan e interactúan con el espacio.

- Características físicas del sitio. De acuerdo con Chong et al. (2012), estos rasgos son de índole física-biológica, como lo son el relieve, el tipo de suelo, el clima, la hidrología y la vegetación.

- Vías de circulación y puntos de decisión. Según el Ayuntamiento de la Ciudad de Puebla (2018), en la Norma Técnica de Diseño e Imagen Urbana del Municipio de Puebla, estos son banquetas, esquinas, rampas peatonales, infraestructura ciclista, zona de espera de transporte público, zonas de seguridad, estacionamiento para bicicletas y automóviles, cruces e intersecciones, camellones e islas de refugio y puentes peatonales.

- Códigos aplicables que afectan a la señalización. Por ejemplo, la nomenclatura de conducción peatonal, de información turística y de identificación de vialidades y sus elementos, así como de la zona de monumentos o vestigios arqueológicos. 
A partir de la definición de Hunter et al. (2018), podemos observar que el wayfinding es un sistema complejo que está ligado directamente al desarrollo de perspectivas de movilidad urbana. Es por esto, que podemos decir, que el wayfinding debe plantearse dentro de una estrategia urbana, ya que el espacio urbano es "el lugar más representativo del modo de vida urbano" (Bodnar, 2015 como se citó en Cevallos \& Parrado, 2018). Por ende, podríamos plantear la siguiente pregunta: ¿Cómo se relaciona el wayfinding con este modo de vida urbano?

Retomando las definiciones señaladas al inicio de este apartado, sostenemos que el wayfinding es un sistema que incide directamente en temas de movilidad urbana, en la forma en que los usuarios se mueven a través del entorno urbano que los rodea. Dado este enfoque, es inherente estudiar los sistemas de orientación que son comprendidos como uno de los quehaceres del wayfinding y la forma en que el usuario comprende este sistema e interactúa con él.

\section{Caso de estudio: ciclovías del centro de Puebla}

Para poder ejemplificar la propuesta de este trabajo de investigación, nos valemos del caso de estudio que aborda el acontecimiento acerca de las caídas de peatones en ciclovías en la Calle 7 Sur, esquina con 13 Poniente del Centro Histórico de la ciudad de Puebla.

Dicho evento se viralizó a través de redes sociales en el mes de abril del 2021, teniendo cobertura incluso en medios periodísticos como Aristegui Noticias (2021), El Heraldo de México (2021), El Universal (2021), entre otros. Los hechos radicaban en que a través de la cámara de seguridad número 8 de la Dirección de Emergencias y Respuesta Inmediata (DERI) de Puebla, fueron captadas numerosas caídas de peatones que intentaban cruzar al otro lado de la calle (Figura 2).

A partir de este hecho mediático, que notablemente representa un peligro latente para el peatón en tránsito, nos llevó a plantear la siguiente pregunta: ¿Por qué los peatones sufrían caídas en las mediaciones de la ciclovía?

\section{Metodología}

Para poder responder la pregunta que gira en torno a este caso de estudio, se implementó una estrategia de naturaleza cualitativa para obtener información relativa a aspectos del diseño urbano del espacio en donde se presentaba este fenómeno 


\section{Figura 2}

Recopilación de imágenes de las caídas de peatones en la Calle 7 Sur esquina con 13 Poniente

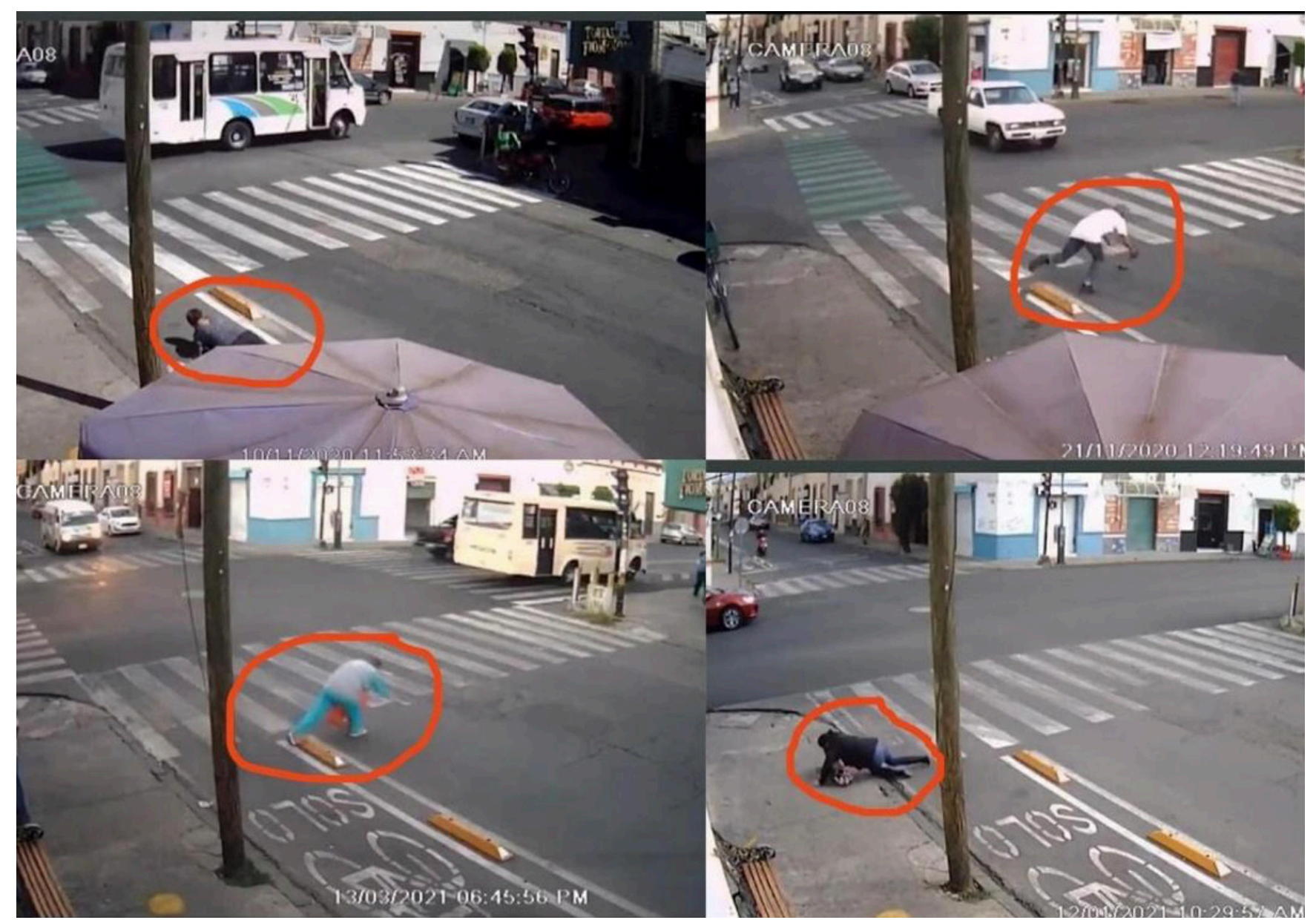

Nota. Tomado de El Heranldo de México (2021).

y la experiencia del usuario que se suscita al ejercer la acción de cruzar la calle. Se implementaron dos instrumentos de investigación: recolección de datos espaciales y observación sistemática del usuario al interactuar con el entorno.

La unidad de estudio elegida fue la intersección de la esquina de la Calle 3 sur y la Calle 13 Poniente del Centro Histórico de Puebla, debido que esta era la ubicación en donde tenía lugar el evento. Como variables espaciales se eligieron la ciclovía, los borlados que son parte de esta, el cruce peatonal y las banquetas de la intersección vial mencionada anteriormente; dichas variables fueron elegidas ya que eran las características propias del espacio urbano en donde se presenta el fenómeno.

En cuanto a la obtención de los datos relacionados con el espacio, se hizo un estudio a partir de las unidades de análisis que plantean Cevallos y Parrado (2018), como parte del levantamiento de características del entorno urbano (Tabla 1). 


\section{Tabla 1}

Dimensiones de análisis del entorno urbano

\begin{tabular}{|c|c|c|}
\hline Dimensión & Definición & Indicadores \\
\hline Diseño & Aspectos generales de la unidad de estudio. & Tipo de vía \\
\hline Accesibilidad & $\begin{array}{l}\text { Aspectos esenciales para una movilidad peatonal } \\
\text { inclusiva y caminable. }\end{array}$ & $\begin{array}{l}\text { Accesos preferenciales. } \\
\text { Barreras arquitectónica. Límites }\end{array}$ \\
\hline Confort & $\begin{array}{l}\text { Sensaciones de agrado físico y psicológico que } \\
\text { ofrece el diseño. }\end{array}$ & Sensaciones. Iluminación. Mobiliario. \\
\hline Seguridad & Protección existente para el peatón. & $\begin{array}{l}\text { Medios motorizados. Contaminación. } \\
\text { Factores ambientales. Presencia de } \\
\text { autoridad policiaca. }\end{array}$ \\
\hline Usos & Tipo de población y usos sociales existentes. & $\begin{array}{l}\text { Actores. Presencia caminos alternos. } \\
\text { Tiempo de uso. Destino. }\end{array}$ \\
\hline
\end{tabular}

Nota. Elaborado con base en Cevallos y Parrado (2018).

Los usuarios que se analizaron fueron únicamente peatones en estado de tránsito. No se tomaron en cuenta otro tipo de actores como comerciantes o ciclistas, debido a que los peatones eran los protagonistas del evento estudiado.

\section{Hallazgos}

Retomando el modelo de análisis propuesto por Cevallos y Parrado (2018), se obtuvo la siguiente información cualitativa:

- Diseño: el tipo de vía es pública y encontramos avenidas que son usadas como rutas de transporte público (microbuses y modelos Urvan generalmente de la marca Nissan).

- Accesibilidad: no existen rampas peatonales y las áreas de seguridad en las esquinas son inexistentes.

- Confort: se encuentra al aire libre en un espacio público. No existe mobiliario en las paradas de espera del transporte público ni para el descanso del peatón (bancas).

- Seguridad: aunque pasan patrullas de seguridad municipal, no es un área de concentración exclusiva para estas. Sin embargo, se encuentra la cámara de seguridad número 8 que pertenece a la Dirección de Emergencias y Respuesta Inmediata (DERI) de la ciudad de Puebla, la cual enfoca en dirección a la Calle 3 Sur y esquina de la Calle 13 Poniente. 
- Usos: esta ubicación es usada principalmente para el comercio formal e informal, aunque con una tendencia mayor al informal. En su mayoría se pueden observar adultos y adultos mayores en esta zona.

El instrumento de observación planteado en el apartado anterior implicó observar los videos de la cámara número 8 de la DERI de la ciudad de Puebla, compartidos por El Heraldo de México (2021) en su portal en línea, en donde se registraban las caídas de los peatones. A través de estos videos, se pudo observar el camino que el peatón ejecuta para cruzar la esquina contraria en la Calle 13 Poniente, el cual conlleva que estos pasaran por los borlados de seguridad, que forman parte de la sección de la ciclovía que se encuentra en esta vialidad; esto es el resultado de que el paso peatonal está bloqueado por un poste de luz y un registro de telefonía por cable, lo cual obliga al usuario a cruzar por un patrón distinto a las indicaciones de acceso peatonal establecido por la estrategia de wayfinding urbana (Figura 3).

\section{Figura 3}

Camino ejecutado por el peatón de Sur a Norte

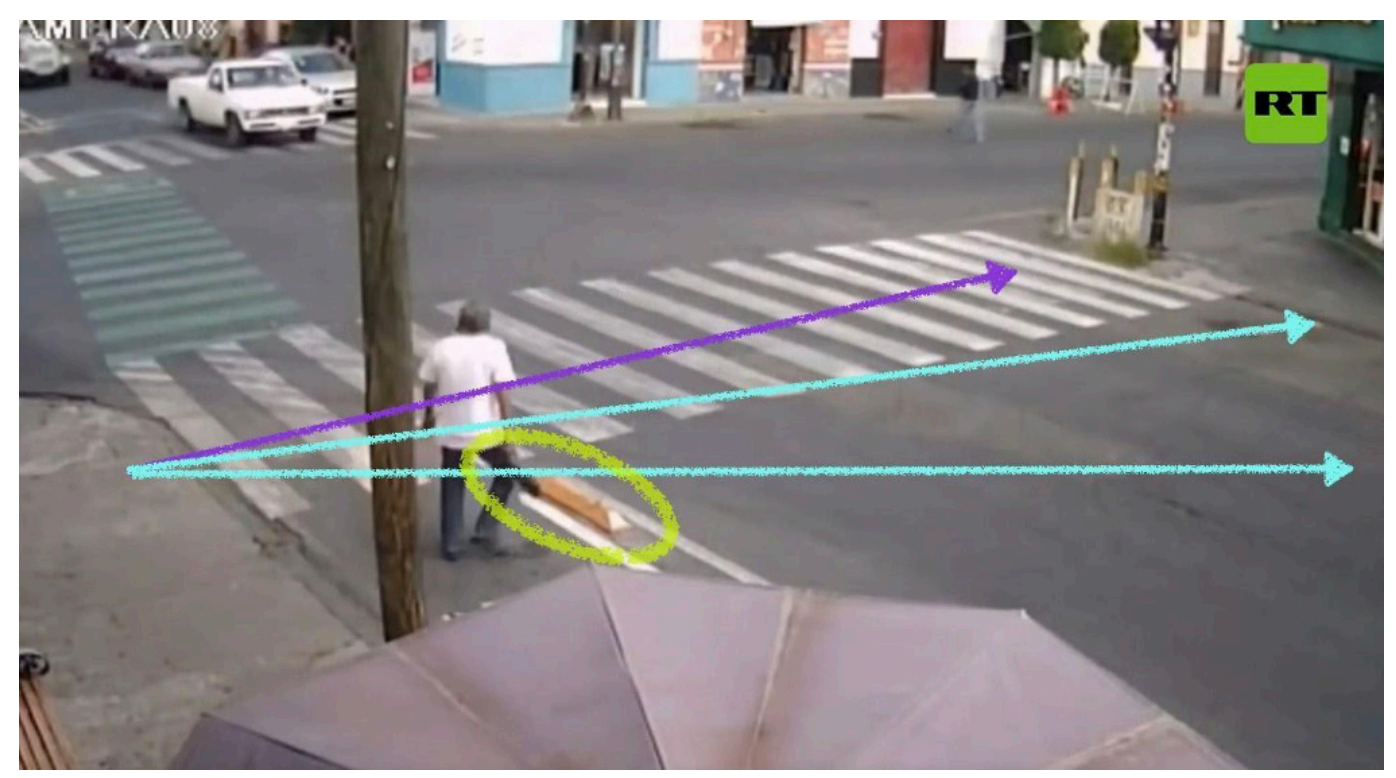

Nota. Tomado de El Heranldo de México (2021).

La misma situación se presenta al ejecutar la acción, pero a la esquina contraria que se planteaba en el apartado anterior; ya que el paso peatonal está bloqueado por los objetos previamente descritos (inclusive en esta toma se observa una motocicleta estacionada en el paso peatonal); el peatón se ve obligado a crear su propia solución a este problema de movilidad (Figura 4). 


\section{Figura 4}

Camino ejecutado por el peatón de Norte a Sur

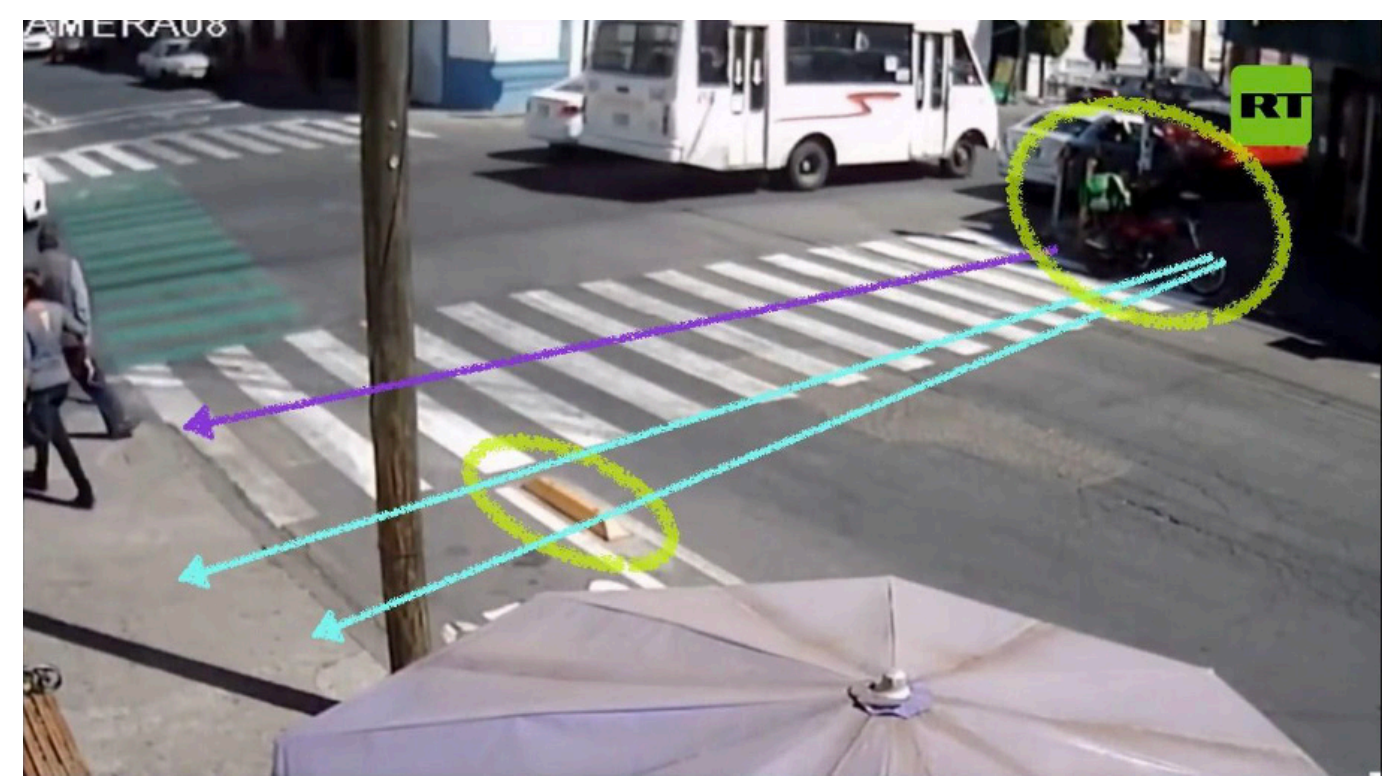

Nota. Tomado de El Heranldo de México (2021).

Esta maniobra está motivada por el sentido común, según establece Colville-Andersen (2018), la cual es Ilamada línea del deseo. Cevallos y Parrado (2018) indicaron que "la trayectoria de estas líneas ocurre a través del espacio urbano y se transforman en una ruta evidente que representa la forma de deambular la ciudad por las personas" (p.212). Las líneas de deseo son patrones de movilidad que el usuario crea con base en su necesidad de "abrirse paso" entre los posibles obstáculos que puede haber en el camino, aunque a veces este no es el más seguro. Según Cevallos y Parrado (2018), se entiende por líneas del deseo a "aquellos caminos alternos que los peatones prefieren tomar para ir de un lugar a otro en vez de usar los impuestos por manuales de movilidad pública" (p.212). El hablar de caminos democráticos que son trazados por los propios usuarios es hablar de un wayfinding comunitario, el cual puede ser repetido por varias generaciones hasta que se haga la intervención o modificación pertinente, tomando en cuenta este patrón que se desprende de la experiencia de usuario.

Englobando lo previamente observado de cómo el usuario ha trazado su propio camino a través de líneas del deseo, podemos resaltar que las caídas de estos en dichas calles responden a las siguientes razones: (1) el paso peatonal está obstruido; (2) la falta de atención del peatón al cruzar la calle, ya que la ubicación se encuentra localizada en el centro de la ciudad de Puebla, en donde pasan diversas unidades de transporte público y es un lugar concurrido para ser usado por vende- 
dores ambulantes, por lo que el usuario tiene que dividir su atención en evitar un arrollamiento al cruzar la calle; y (3) no existe la señalización suficiente ni adecuada para hacer énfasis en que existe la ciclovía.

\section{Las políticas públicas en movilidad y su incidencia en la movilidad urbana en Puebla}

Siguiendo con las reflexiones, resulta importante conocer diversos puntos de vista y parte del proceso de elaboración de la ejecución de las ciclovías en el centro de Puebla, para saber cuáles son los objetivos que se persiguen al implementar ciertas estrategias del diseño de información a la movilidad urbana de esta ciudad y específicamente a esta forma de movilidad.

De acuerdo con el Instituto Municipal de Planeación Puebla (2021):

[EI] Programa de Movilidad Urbana Sustentable (PMUS) busca replantear la manera en que la movilidad ha sido abordada en el municipio de Puebla, mediante el establecimiento de una visión de largo plazo que permita orientar los esfuerzos institucionales del Gobierno Municipal en la construcción de un modelo de movilidad urbana accesible, segura y sustentable, que incide de manera positiva en la calidad de vida de las personas. (p.7)

En el diseño, ejecución e implementación de una política pública es importante no caer solamente en los procesos de escritorio; en México, es común tener programas, proyectos o ideas que en teoría son viables, pero en la práctica no lo son o al compartir la información a los ciudadanos-usuarios no se genera esa comunicación que logre incidir en los resultados esperados.

Como mencionó Aguilar (1992):

Las políticas se han vuelto también un lugar densamente administrativo. La complejidad, escala, variabilidad e interdependencia de los asuntos públicos requieren cada vez más información confiable, conocimiento especializado, cálculos precisos de costos y consecuencias para decisiones que se adoptan casi siempre en condiciones de riesgo y bajo escasez. Sin el soporte de un riguroso ejercicio lógico, científico y técnico, las deci- 
siones de gobierno podrían caer en peores equivocaciones, dispendios, imprevisiones, que por la magnitud de su impacto acarrearía males y sufrimientos sociales. (pp.20-21)

Al realizar una política pública, en el caso de esta ciudad, con necesidades como la mayoría de las zonas urbanas con alta densidad de población, debemos ver que la estructura, el contexto y la utilidad de estas ideas deben enfocarse en las necesidades propias de los usuarios; ante estas áreas de oportunidad de realizar acciones en beneficio de la ciudadanía, no se debe dejar de lado la posibilidad de emitir un diseño de información que sea útil para el propio conocimiento de la apropiación de la idea con los usuarios.

La infraestructura ciclista en la Ciudad de Puebla, en el año 2021, la podemos observar en la Figura 5.

\section{Figura 5}

Infraestructura Ciclista en Puebla en 2021

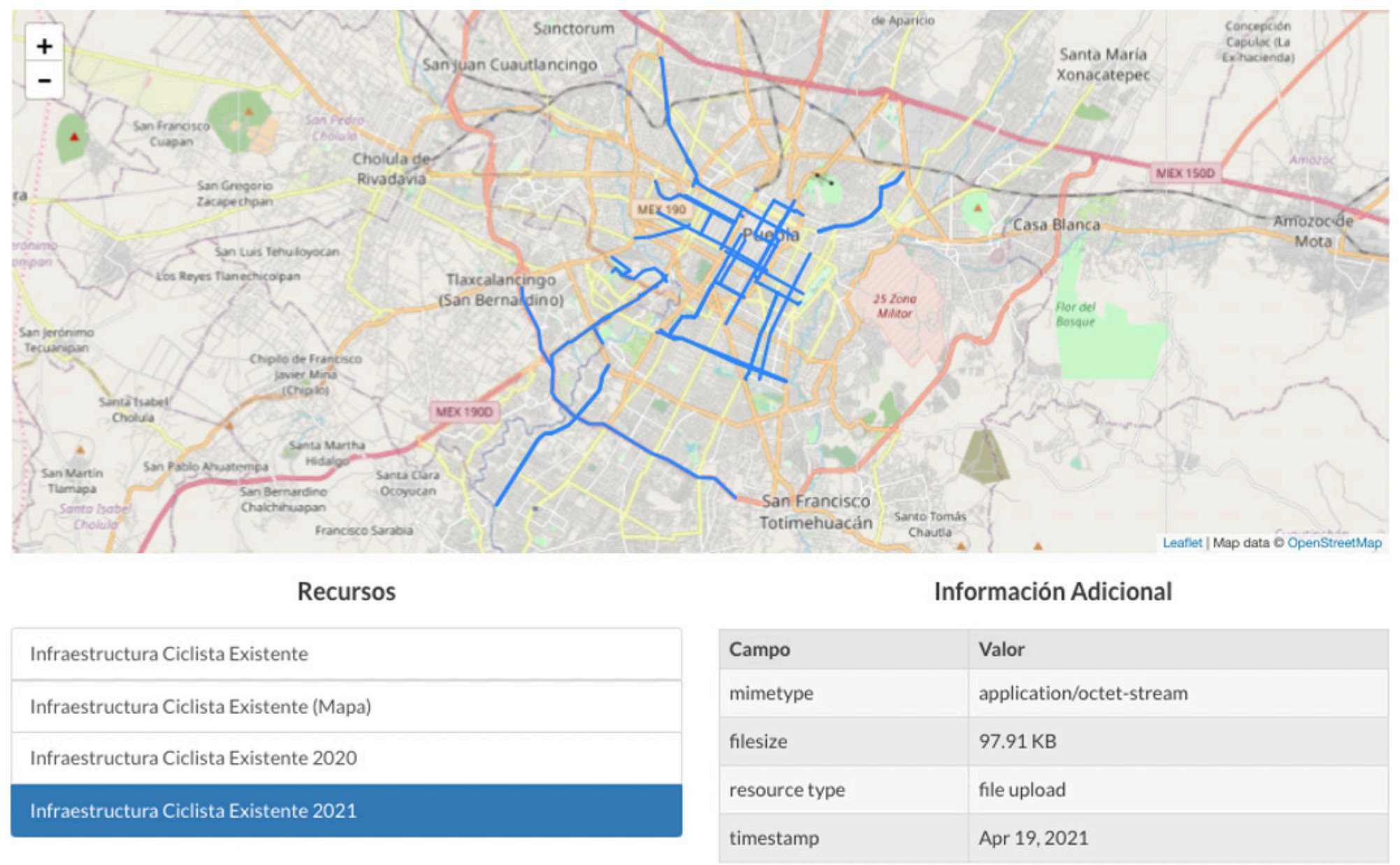

Nota. Tomado de Municipio de Puebla (2021). 
Es importante conocer dónde se encuentran las 66 rutas posibles, donde los ciclistas pueden utilizar una movilidad para su propio beneficio. Asimismo, es importante identificar las razones de las caídas y de las eventualidades presentadas con los usuarios.

Al realizar una política pública de movilidad, se debe tener en cuenta que se encuentra sujeta a la evaluación y retroalimentación de la idea o acción realizada; se deben considerar las recomendaciones de las posibles mejoras en todos los sentidos, para el beneficio de los ciclistas y de la sociedad en general. Las decisiones gubernamentales deben ser evaluadas para permitir posibles cambios en aquellos casos que así lo requieran.

\section{Conclusiones}

Con base en lo que se ha planteado a lo largo del capítulo, retomamos la idea de que es importante generar espacios que se adapten a las necesidades del usuario; como pudimos observar en el caso de estudio, queda evidenciado que se pretende que los usuarios sean quienes se adapten a estos espacios, dejando fuera las expectativas y necesidades de uso que los usuarios necesitan cumplir con base en estos.

Asimismo, podemos decir que queda evidenciada la idea de que "se privilegia la rentabilidad capital y la aprobación exclusiva del espacio por algunos sujetos particulares que profesan posiciones de poder" (Cevallos \& Parrado, 2018, p.211), omitiendo las necesidades y el propio sistema espacial creado por el usuario escrito en su caminar diario a través de la ciudad; es el propio usuario quien va marcando discursos normativos y democráticos de sistemas de wayfinding, los cuales deberían ser pauta para generar una estrategia de movilidad urbana para quienes ejecutan esta tarea, a través de los lugares de encuentro y desplazamiento pautado por el comportamiento de movilidad de los usuarios en la ciudad.

A través de esta consciencia de los itinerarios del peatón, el entorno y las propias características urbanas del espacio, se podrían generar estrategias de movilidad que respondan a las necesidades y expectativas de los habitantes; las cuales sean mediadas por la disposición de edificios, la actividad comercial en las aceras, el entorno construido por los grupos sociales que habitan el espacio y la accesibilidad (Cevallos \& Parrado, 2018). Por lo tanto, el desarrollo de estas estrategias de movilidad puede tomar como base el planteamiento del concepto de wayfinding dentro de lo que establece el diseño de información, es decir, como un sistema democrático 
que es consciente del usuario, dando buenas condiciones (seguras y caminables) de movilidad y de experiencia del peatón.

Dichas estrategias deberían buscar una efectividad comunicacional en beneficio de toda la comunidad, para visualizar las posibles pautas a utilizar en los programas y acciones de la administración pública, de manera que ayuden a compartir información con más precisión y con elementos de elegibilidad y entendimiento al propio usuario y a la ciudadanía en general. El wayfinding y el diseño de información, ambos utilizados de forma proactiva, pueden ser de utilidad para muchas decisiones públicas en nuestro país, al tener áreas de oportunidad, ligadas al conocimiento y entendimiento global de lo planteado en dichos programas, acciones o decisiones a desarrollar por parte de las entidades públicas.

\section{Referencias}

Aguilar, L. F. (1992). La hechura de las políticas (1a. ed.). Porrúa. http://www. fundacionhenrydunant.org/images/stories/biblioteca/Politicas-Publicas/QLvT7L41Vk.pdf.pdf

Aristegui Noticias. (2021). Se vuelve tendencia ciclovía en la que «todos caen» en Puebla. Aristegui Noticias. https://aristeguinoticias.com/0604/mexico/sevuelve-tendencia-ciclovia-en-la-que-todos-caen-en-puebla/

Ayuntamiento de la Ciudad de Puebla. (2018). Norma Técnica de Diseño e Imagen Urbana del Municipio de Puebla. H. Ayuntamiento de Puebla 2018-2021. https:// www.pueblacapital.gob.mx/images/transparencia/obl/24relevante/15/dicta. norma.dis.imag.urb.pdf

Calori, C., \& Vanden-Eynden, D. (2015). Signage and wayfinding design: a complete guide to creating environmental graphic design systems. Wiley.

Cevallos, A., \& Parrado, C. (2018). Cartografía del deseo: Diseño, caminabilidad y peatones en la ciudad de Quito. Quid 16, (10), 210-229.

Chong, M. A., Carmona, A., \& Pérez, M. A. (2012). El análisis de sitio y su entorno en el desarrollo de proyectos arquitectónicos y urbanos. Revista Universitaria de Aprendizaje, 7. https://cdigital.uv.mx/bitstream/handle/123456789/40119/ RUA8p15.pdf

Ciudad Autónoma de Ceuta. (s.f.). Patrimonio edificado. http://web.ceuta.es:8080/ patrimoniocultural/edificios/controlador?cmd=inicio 
Colville-Andersen, M. (2018). Copenhagenize: The Definitive Guide to Global Bicycle Urbanism. Island Press.

Datos Puebla Capital. (2021). Infraestructura Ciclista Existente 2021. https:// datos.pueblacapital.gob.mx/dataset/infraestructura-ciclista-existente/ resource/53598bb2-e370-4cd5-b4ab-42e868ab26cd

Dalton, R. C., Hölscher, C., \& Montello, D. R. (2019). Wayfinding as a social activity. Frontiers in psychology, 10, 142.

El Heraldo de México. (2021). Personas tropiezan en calles de Puebla; ¿dónde se ubica la accidentada ciclovía? El Heraldo de México. https://heraldodemexico. com.mx/nacional/2021/4/1/video-personas-tropiezan-en-calles-de-puebladonde-se-ubic\%20a-la-accidentada-ciclovia-278455.html

El Universal. (2021). Ciclovía Puebla: mucha risa y memes, pero ¿qué hay detrás de las caídas? El Universal. https://www.eluniversal.com.mx/estados/ciclovia-pueblamucha-risa-y-memes-pero-que-hay-detras-de-las-caidas

Frascara, J. (2015). Information design as principled action: making information accessible, relevant, understandable, and usable. Common Group.

Hunter, R. H., Anderson, L. A., \& Belza, B. L. (2018). Community Wayfinding: Pathways to Understanding. Springer.

Ibañez, G. P. (2018). De los métodos en señalética, wayfinding y diseño gráfico experiencial. En J. I. G. Garmendia Ramírez (Ed.), De los métodos y las maneras, número 3 (pp. 21-29). Universidad Autónoma Metropolitana.

Instituto Municipal de Planeación Puebla. (2021). Programa de Movilidad Urbana Sustentable. https://gobiernoabierto.pueblacapital.gob.mx/transparencia_ file/informacion-complementaria/dictamenes.otros/dicta.prog.movilidad. urb17.pdf

Municipio de Puebla (2021). Datos abiertos. Infraestructura ciclista existente 2021. https://datos.pueblacapital.gob.mx/dataset/infraestructura-ciclista-existente/ resource/53598bb2-e370-4cd5-b4ab-42e868ab26cd

Ramos, O. (2015). El uso de la bicicleta como medio de transporte en la ciudad de Puebla (Tesis de maestría). Benemérita Universidad Autónoma de Puebla, México. https://repositorioinstitucional.buap.mx/handle/20.500.12371/637

Secretaría de Comunicaciones y Transportes (2014). Manual de señalización vial y dispositivos de seguridad. Capítulo I. Generalidades del señalamiento. http:// www.sct.gob.mx/fileadmin/DireccionesGrales/DGST/Manuales/NUEVOSENALAMIENTO/04-Capiitulol-Genesdelse\%C3\%B1ala.pdf 


\section{Capítulo 7}

Tipografías Web para uso informativo

Tannia Edisa Flores Raffta y Jorge Campos Sánchez

La comunicación a través de medios masivos ha sido una de las herramientas que gobiernos, instituciones educativas y empresas han empleado, a lo largo de los años, para mantener informada a la sociedad de los acontecimientos de interés para su población; desde los medios impresos hasta la era digital en la que el mundo se encuentra en la actualidad. Sin duda, la contingencia sanitaria provocada por la pandemia de COVID-19 ha acelerado la migración a los medios digitales. Las instituciones educativas no son la excepción, en cuestión de unas pocas semanas tuvieron que trasladar una gran parte de sus actividades sustanciales y la comunicación con sus integrantes a medios como las redes sociales.

Una gran cantidad de personas utilizan las redes sociales y acceden a ellas a través de dispositivos móviles como teléfonos inteligentes y tabletas, que le hacen más cómodo al usuario la conexión a nivel de portabilidad, pero les obligan a sacrificar otro tipo de comodidad, la de la lectura. Según Sarmiento (2014), "Los fabricantes saben que tabletas y celulares son el medio más común de lectura actual, y por eso hacen que sus pantallas no cansen los ojos, ni mucho menos los afecten" (como se citó en Semana, 2014, párr.5), sin embargo, existen otros factores además de las capacidades tecnológicas de las pantallas de los dispositivos, que pueden ocasionar cansancio físico o mental en los lectores. Las pantallas de estos equipos son considerablemente menores que las de un monitor convencional de una computadora de escritorio o portátil, lo que provocará que las piezas de información se visualicen, inevitablemente, en un tamaño más pequeño. Al respecto, la selección tipográfica para el diseño de las piezas de información juega un papel fundamental. 
El objetivo de este capítulo es analizar factores formales y criterios de selección y aplicación tipográfica para las piezas de información publicadas por el Centro Universitario de Arte, Arquitectura y Diseño (CUAAD) de la Universidad de Guadalajara, en el periodo del 15 de julio al 15 de agosto de 2021.

Antes de comenzar a evaluar la tipografía en piezas de información, es importante conocer algunas definiciones del término. Según Martínez (1990), la "Tipografía es el término utilizado para imprimir por medio de tipos de metal, móviles, independientes y reciclables, cada uno de los cuales tiene una letra en relieve en su parte superior" (p.37).

Rubén Fontana, uno de los principales referentes en el estudio de la tipografía en América Latina, indicó que:

La tipografía es uno de los códigos culturales que utilizamos para comunicarnos, probablemente una de las convenciones más masificadas. Podríamos decir que el alfabeto es uno de los mayores acuerdos entre los hombres de una cultura. Las formas, los colores, los gestos y los sonidos conforman las bases de la comunicación humana y la tipografía, de alguna manera, resume esas formas culturales y las expresa a través de signos gráficos. (como se citó en Cosgaya, 2003, párr.2)

Por su parte, Calles (2003), en el ensayo sobre diseño tipográfico en México, mencionó que "La tipografía convierte a la palabra en una mercancía. Nada es tan habitual y ordinario en nuestra vida cotidiana, tan presente y obvio, como la tipografía" (p.33). Mientras que Poblete (2008) indicó que:

La tipografía es el oficio que trata el tema de las letras, símbolos y números que están en un texto impreso que puede ser físico o electromagnético, la tipografía estudia el tamaño, la forma, el diseño y cómo se relacionan unos tipos con los otros, cómo se relacionan visualmente entre ellos, cómo influye la tipografía en la sociedad. (como se citó en Cadena, 2003, s.p.)

Como se puede observar en las definiciones anteriores, se utilizan diversos términos; la primera definición recuerda el origen de la tipografía, en el cual se realizaban moldes de metal mecánicamente funcionales, los cuales contenían el alfabeto 
o letras a utilizar; la segunda definición hace alusión a la cultura y la comunicación a través de signos gráficos; dentro de la tercera se hace notar que desde el inicio de la disciplina su utilidad ha sido incuestionable, esto debido a que se ha hecho presente en la vida cotidiana, ya que nos encontramos rodeados de ella; y la cuarta definición hace alusión al ámbito académico en donde la tipografía se ha convertido en un objeto de estudio y una herramienta intrínsecamente relacionada al diseño gráfico y, por ende, al diseño de información.

La forma de las letras se ha visto siempre relacionada a los avances tecnológicos; desde los tipos móviles con los que Gutenberg imprimió su famosa biblia de 42 líneas hasta el desarrollo de tipografía variable en los últimos años. Es importante recordar que la era de la tipografía digital comenzó hace apenas algunas décadas, sus albores se pueden encontrar a principios de los años 80 , con la llegada de los equipos de cómputo de autoedición, pero su desarrollo más importante se dio a partir de mediados de la década de los 90 , cuando los profesionales del diseño adoptaron la computadora como la herramienta de trabajo más importante en su práctica. Sin embargo, aunque el diseño de fuentes tipográficas se realizaba en equipos de cómputo, un número importante de ellas fueron pensadas y creadas para funcionar en un entorno impreso. No es sino hasta principios del nuevo milenio cuando se comienza a desarrollar tipografía específicamente pensada para funcionar de una forma correcta en pantallas digitales.

La evolución tecnológica ha dictado la forma de las letras a lo largo de la historia, el mejoramiento de las pantallas de los dispositivos móviles también ha permitido una mejor calidad en la visualización de los textos que se despliegan en ellas. No es lo mismo leer en un teléfono móvil de principios de siglo que en una pantalla de última generación, con una resolución mucho mejor. Se puede pensar que, en un futuro, cuando la calidad de las pantallas sea aún mayor, no se tendrán limitantes en las formas tipográficas seleccionadas, pero nos encontramos aún alejados de esta utopía.

Si bien, no existen reglas generales, es importante considerar algunos aspectos relevantes para que las formas se reproduzcan satisfactoriamente en el entorno digital: (a) carencia de detalles pequeños o muy finos, pues los pixeles que componen las pantallas, muy posiblemente no permitirán su despliegue de manera correcta; (b) proporción de la altura de la equis amplia, para abrir espacios internos y evitar emplastamientos de los textos; y (c) estructuras con contraformas amplias 
y regulares, para evitar los espacios con formas intrincadas que favorezcan que se junten elementos. Por lo anterior, en la mayoría de las plataformas digitales se han seleccionado (o desarrollado a la medida) sistemas tipográficos sans serif con estructuras abiertas y proporciones verticales amplias.

Una vez seleccionadas las fuentes tipográficas para la publicación, es importante considerar la composición de la pieza de información y las jerarquías internas que se marquen en ella. Esto facilitará al lector comprender la estructura del mensaje y dividirlo por bloques de texto coherentes. Para ello, se pueden utilizar diferentes recursos como el tamaño de la letra, su grosor e inclinación, así como ubicación en el espacio.

\section{Consideraciones previas}

Antes de comenzar a analizar las piezas, consideramos importante conocer algunas recomendaciones que emite la plataforma Facebook a los creadores de contenido para diseñar sus publicaciones; aunque no son obligatorias, son sugerencias que la empresa realiza para aumentar el interés por parte de los lectores: (a) que el título no exceda los 40 caracteres; (b) que el texto principal contenga una cantidad de 125 caracteres; y (c) que se realice una breve descripción de no más de 30 (Meta, 2021). Estos aspectos podrían ayudar a que el lector comprenda de mejor manera el mensaje principal, pues le será simple y fácil de recordar.

\section{Análisis de casos}

Desde la cuenta de Facebook del CUAAD, en el periodo comprendido entre el 15 de julio y el 15 de agosto de 2021, se han publicado una serie de piezas de información con diferentes objetivos; todas dirigidas a la comunidad universitaria. Aunque existen muchos criterios para seleccionar las fuentes tipográficas a utilizar, como pueden ser aspectos conceptuales, filosóficos, ergonómicos, económicos y legales, en este capítulo nos centraremos en los aspectos técnico-formales para conseguir un buen rendimiento de las formas tipográficas en dispositivos móviles; entorno en el que una buena parte de la comunidad universitaria accede a la red social.

En total, se han analizado ocho piezas de información, con diferentes mensajes dirigidos a públicos diferenciados; algunos han sido desarrollados desde la administración central y otros desde el propio centro universitario. La selección tipográfica en todas las comunicaciones es muy similar, una familia tipográfica de 
estilo sans serif, de formas geométricas y contraformas amplias, con una proporción vertical de altura de las equis generosa y trazo poco modulado. Todos estos aspectos, teóricamente funcionan de manera correcta; sin embargo, la utilización de dichas fuentes tipográficas es la que puede generar algunos conflictos de lectura en las piezas, sobre todo, cuando se despliegan en dispositivos móviles de resolución estándar, en tamaños muy pequeños.

En la Figura 1, se observa una pieza con poca información, que se adapta a las recomendaciones iniciales que hace la plataforma en el número de caracteres en los mensajes. Tiene poco texto y un enlace en el que los interesados pueden obtener más información. Las formas tipográficas son grandes y el contraste cromático con el fondo es alto.

\section{Figura 1}

Pieza de comunicación sobre dictamen de ingreso en $2021 B$

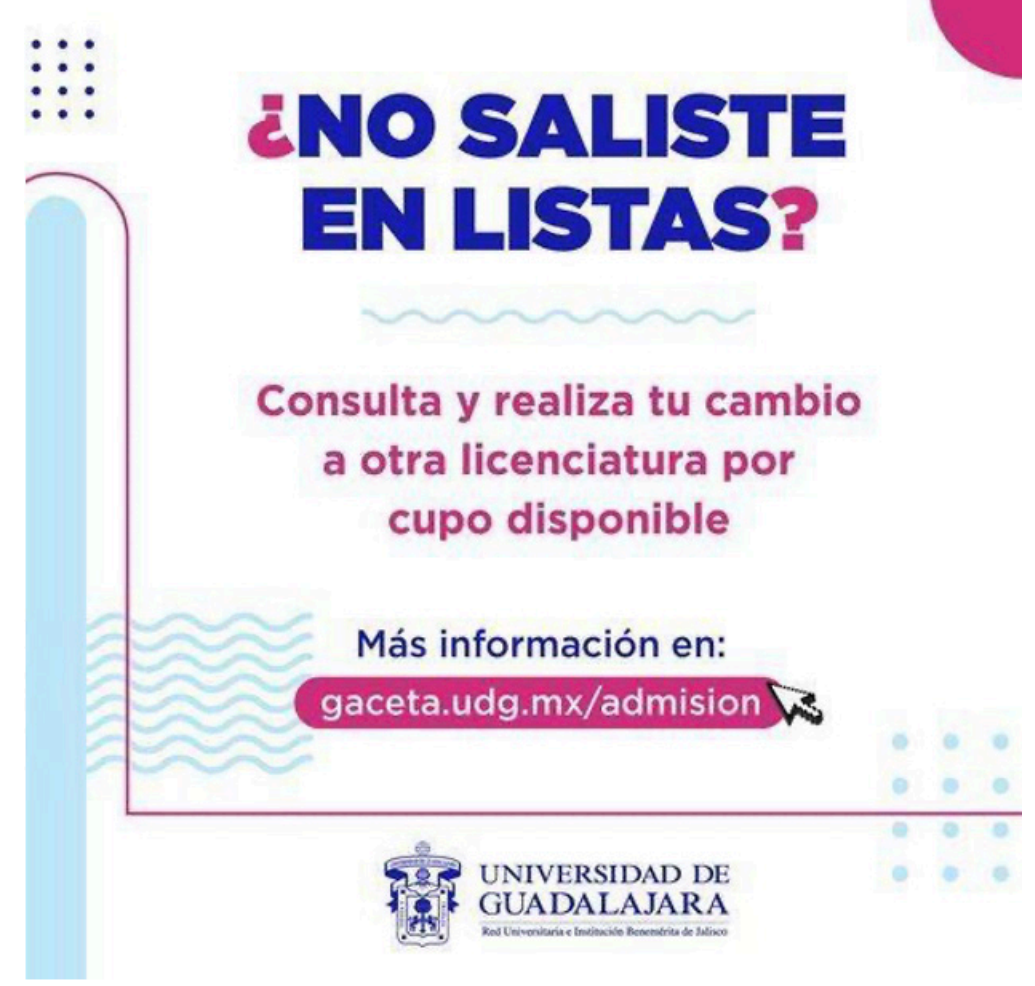

Nota. Tomado de Universidad de Guadalajara (2021a).

En la Figura 2, se puede observar una cantidad de información mayor que en la Figura 1; sin embargo, el tamaño de los textos sigue siendo grande y la composición cuenta con un espaciado amplio entre renglones. El número de caracteres por línea no supera los 25 , por lo que es fácil que el usuario lea el mensaje. De igual forma que en la Figura 1, se cuenta con un enlace para obtener más información, lo que evita 
saturar de texto la pieza. El contraste cromático entre el texto y el fondo es alto, esto facilita el reconocimiento de los caracteres. Sin embargo, el contraste existente en el identificador de la Universidad de Guadalajara y el fondo es bajo, por lo que no es fácil reconocer sus formas.

\section{Figura 2}

Pieza de comunicación sobre el uso de la vitamina D como aliado contra el COVID-19

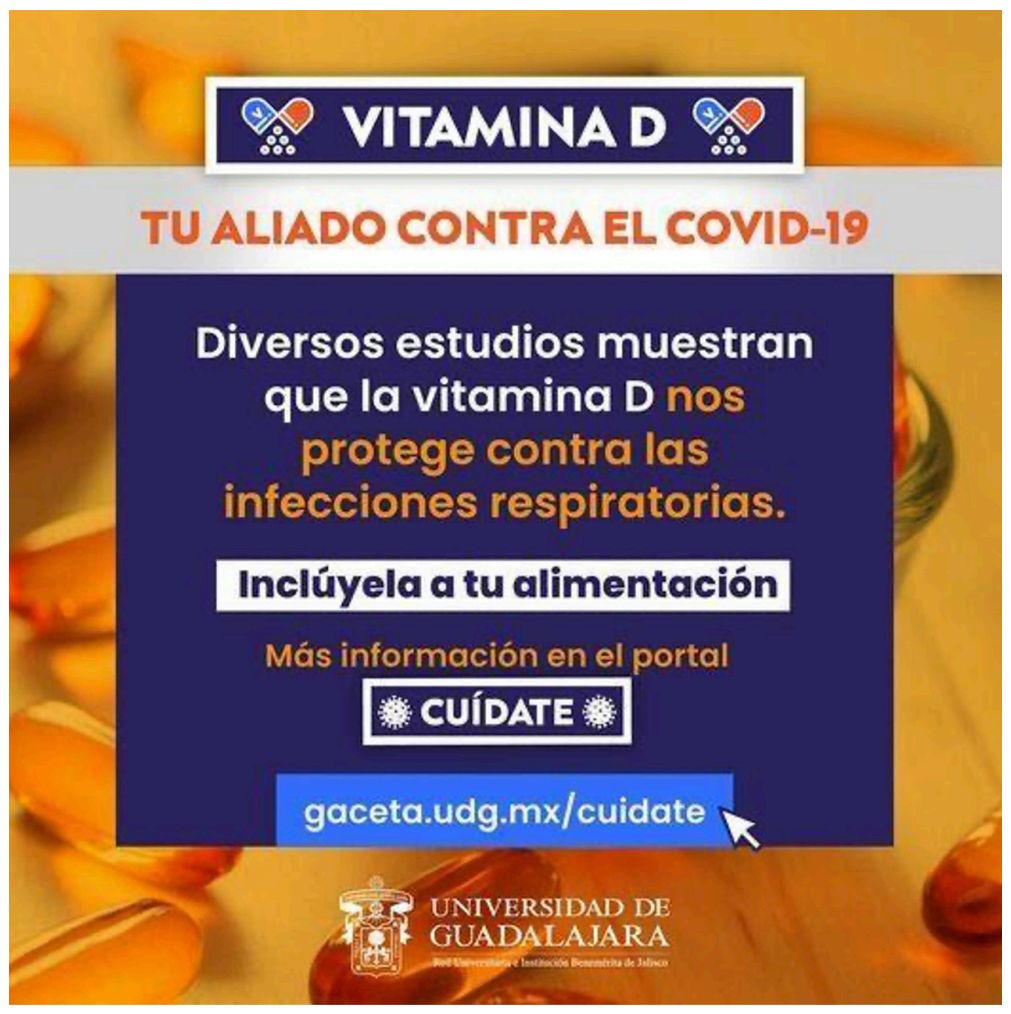

Nota. Tomado de Universidad de Guadalajara (2021b).

En la Figura 3, al igual que en las anteriores, la cantidad de texto es poca y el tamaño de las letras es grande, por lo que soportan ser reproducidos en tamaños de pantalla pequeños. Asimismo, cuenta con un llamado a visitar un enlace externo para obtener más información. El contraste cromático entre fondo y texto es bajo en algunas líneas, esto no facilita su lectura, sin embargo, en la información trascendental que son los plazos para aplicar a la beca, se utiliza un envolvente de color obscuro y el texto blanco, con un peso visual importante, lo que hace que sea el elemento dominante en la composición. El signo identificador de la Universidad de Guadalajara tiene un alto contraste con el fondo, lo que facilita su reconocimiento.

Las Figuras 4 y 5 serán analizadas en conjunto, debido a la similitud en el sistema gráfico empleado. Ambas cuentan con un marco en color naranja sobre el que se ubican los signos identificadores institucionales, tanto de la Universidad 


\section{Figura 3}

Pieza de comunicación sobre becas para estudiantes

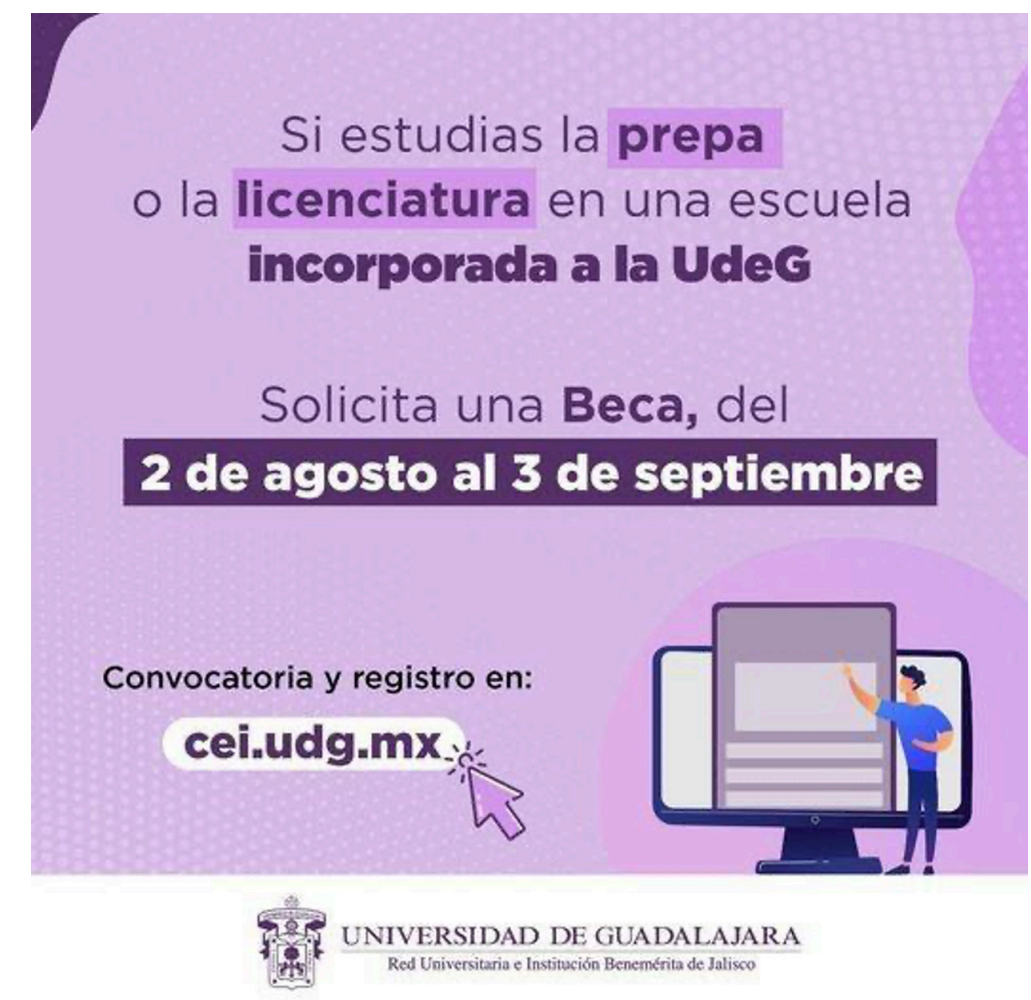

Nota. Tomado de Universidad de Guadalajara (2021c).

de Guadalajara, como del CUAAD; parece ser que el objetivo de ese elemento es generar un alto contraste cromático y que sean fáciles de reconocer. Se puede apreciar claramente que, cuando las formas tipográficas son pequeñas, delgadas y con una modulación importante entre gruesos y finos es mucho más complicado de visualizar que cuando, como en el caso del logotipo del CUAAD, son de mayor tamaño, carecen de remates y son de un grosor superior. Este mismo efecto se puede observar en el cabezal de las piezas.

Mientras que en la Figura 4 se utiliza un tamaño y un grosor grandes, y se encuentra con un contraste importante entre fondo y figura, en la Figura 5 se hace lo contrario. Claramente se puede observar que es más fácil de reconocer, tanto a nivel formal como a nivel de jerarquía, el titular de la pieza. En ambos casos, a diferencia de las Figuras 1, 2 y 3, se tiene una cantidad mayor de caracteres, que se encuentran en un puntaje menor y en un estilo más ligero y con espacio entre líneas reducido, lo que provoca que sea más complicado de leer y estimula que el usuario abandone la lectura; todo esto, aunado a que el texto es acompañado de una ilustración que compite por el espacio dentro de la pieza. 
Figura 4

Pieza de comunicación sobre periodo vacacional

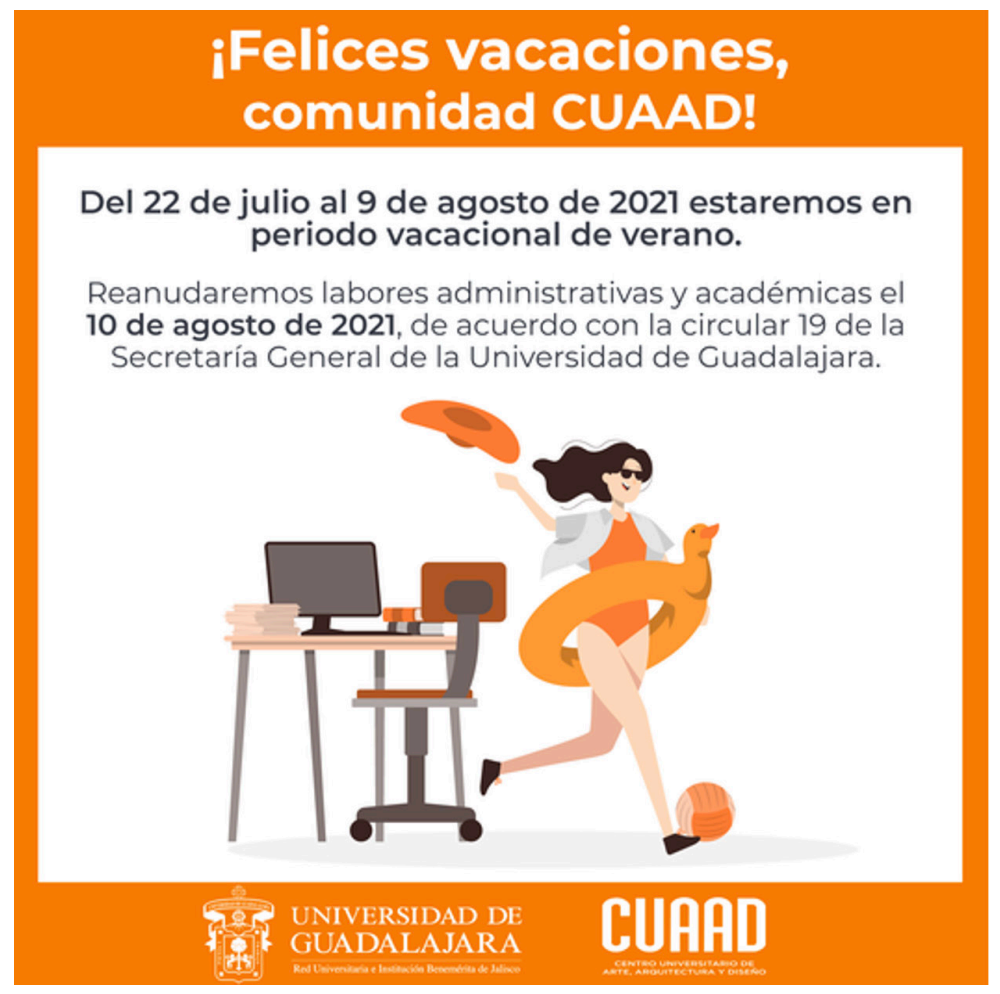

Nota. Tomado de CUAAD (2021a).
Figura 5

Pieza de comunicación sobre atención de Control Escolar del CUAAD

Las ventanillas de la Coordinación de Control Escolar continúan con atención a la distancia.

Servicios para aspirantes, estudiantes,egresados, graduados y titulados (de pregrado y posgrado)

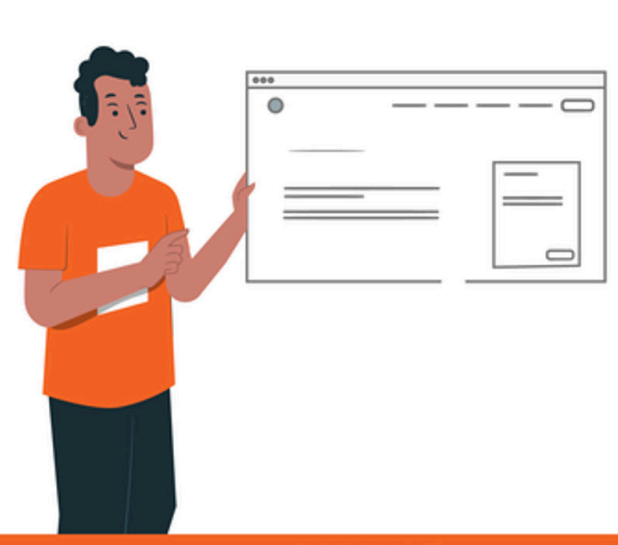

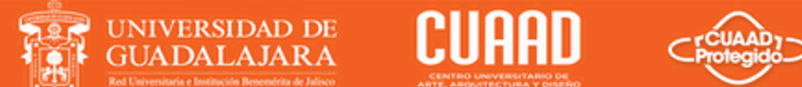

Nota. Tomado de CUAAD (2021b).

En la Figura 6, se puede observar un estilo de diseño diferente a las anteriores. Comparte el estilo tipográfico seleccionado, pero carece de los mismos elementos identitarios en la parte inferior. Si bien, la cantidad de palabras es pequeña, al igual que en la Figura 5, carece de una jerarquía en el texto. Aunque el segundo bloque de texto es un poco mayor en puntaje, la diferencia no es notoria, lo que provoca que exista una competencia entre los primeros bloques de texto. En toda la pieza se utiliza la versión ligera de la fuente, aún en el texto que se encuentra sobre el envolvente de color verde, lo que hace que el texto, en esa zona, sea aún mas complicado de reconocer.

Las piezas de la Figura 7 y 8 forman parte de la misma serie de piezas de comunicación; en estas se emiten instrucciones a los estudiantes admitidos a los diferentes programas educativos del CUAAD. En los cabezales, se utiliza la versión bold de la fuente tipográfica, en un puntaje alto y tienen un contraste cromático importante con el fondo, lo que los hace muy legibles, a pesar de la cantidad de texto que se encuentra en el cabezal de la pieza de la Figura 8. En el cuerpo del texto se ha colocado una gran cantidad de información que, aunque se está jerarquizando a 


\section{Figura 6}

Pieza de comunicación sobre el Doctorado en Innovación para el Hábitat Sustentable

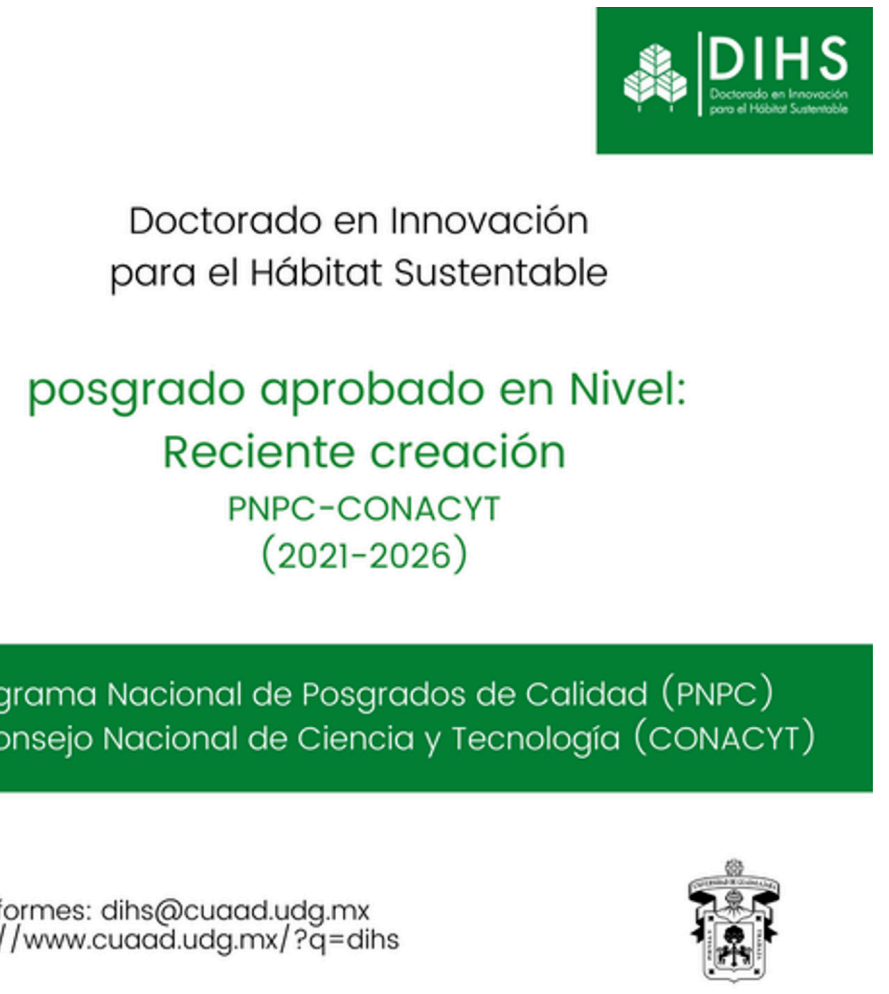

Nota. Tomado de Doctorado en Innovación para el Hábitat Sustentable (2021).

través del color y el peso visual en las palabras clave y que cuenta con alto contraste cromático con el fondo, el tamaño al que se despliega, la cantidad de caracteres por línea y el poco espacio que existe entre los renglones hacen que sea una pieza muy poco legible. Es importante recordar que las pantallas de los dispositivos móviles son pequeñas y que los textos serán desplegados en un tamaño muy reducido. En la parte inferior se encuentran los signos identitarios en color oscuro sobre fondo claro; lo que facilita su reconocimiento.

\section{Conclusiones}

A partir del análisis realizado a las ocho piezas descritas se puede decir que:

- Aunque la selección tipográfica es un elemento crucial en el diseño de información para medios digitales, como lo son las piezas analizadas en este capítulo, no es suficiente para lograr la legibilidad y captar el interés de los usuarios. El uso que se le dé a la tipografía será fundamental para conseguir estos anhelados objetivos.

- Facebook acierta en las recomendaciones que emite a los creadores de contenido con respecto a la cantidad de texto en un banner o anuncio. A menor 


\section{Figura 7}

Pieza de comunicación para

estudiantes admitidos al CUAAD

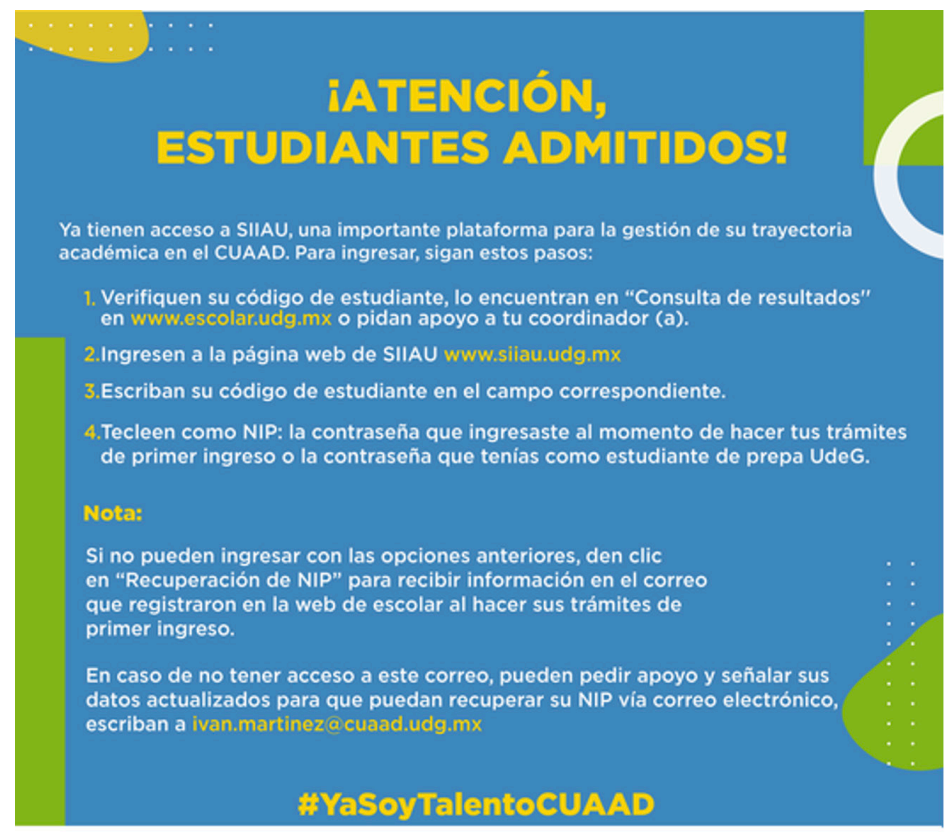

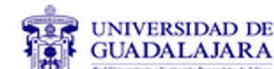

CUARD
Figura 8

Piezas de comunicación para estudiantes admitidos al CUAAD de la Licenciatura en Artes escénicas

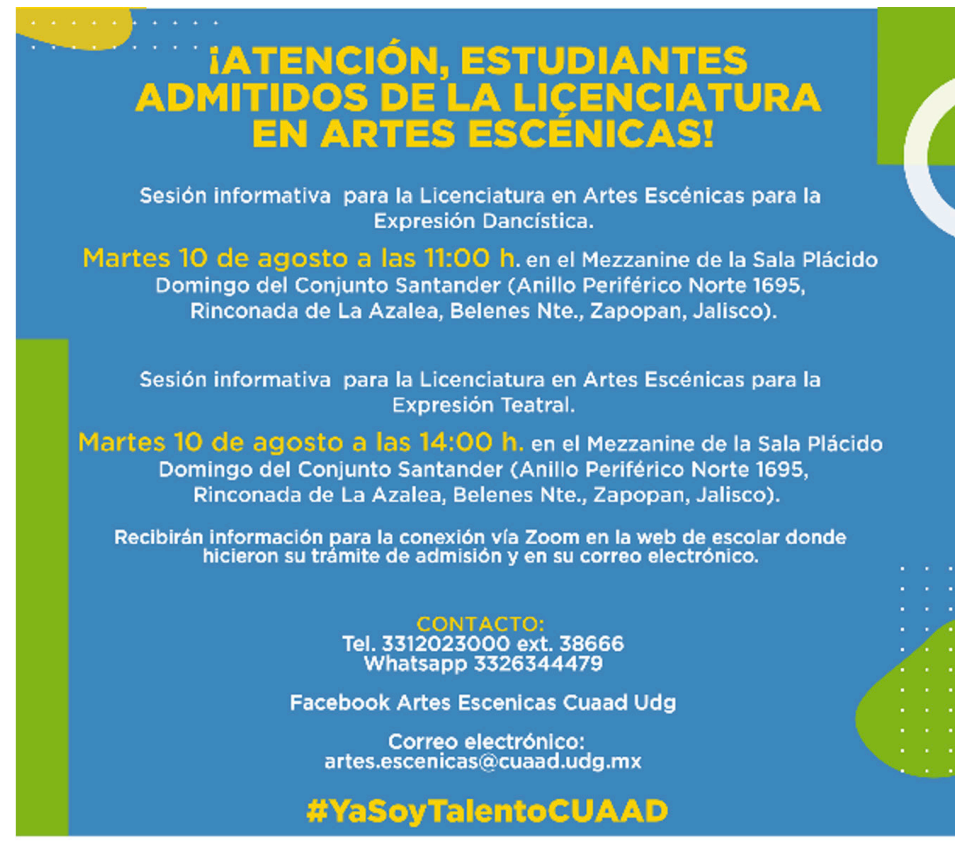

The UNIVIRSIIAAD DE

CUARD

Nota. Tomado de CUAAD (2021d)

cantidad de texto, será más fácil de leer, por lo que será muy importante la selección cuidadosa de las palabras a utilizar; un tema que, sin duda, podrá ser muy interesante para futuras investigaciones con respecto al diseño de información para redes sociales.

- El tamaño sí importa. Mientras más pequeñas sean las letras, tendrán mayor dificultad para desplegarse en la matriz de pixeles que las conforman. Un tema de interés para futuras investigaciones podría ser el desarrollo de fuentes tipográficas diseñadas específicamente para funcionar en entornos digitales y la programación que se les incluya con instrucciones de comportamiento en pixeles, llamada hinting.

- El uso de variantes tipográficas para jerarquizar los elementos es de suma importancia para facilitar al lector la creación de bloques de información.

- El contraste cromático entre letras y fondo es muy importante para facilitar la lectura. En formas pequeñas, usar fondos blancos o claros con letras oscuras es de mucha ayuda. 
Es importante mencionar que estas conclusiones parten de la observación de las piezas analizadas y no constituyen reglas inamovibles para el diseño de información, pero puede ser un punto de partida para realizar investigaciones más exhaustivas al respecto.

\section{Referencias}

Cadena, S. I. (2007). La tipografía y su complejidad creativa. Diseño en Palermo. Encuentro Latinoamericano de Diseño. https://fido.palermo.edu/servicios_ dyc/encuentro2007/02_auspicios_publicaciones/actas_diseno/articulos_pdf/ ADC080.pdf

Calles, F. (2003). Tipografílicos vs tipografóbicos "Ensayos sobre diseño tipográfico en México". Designio.

Centro Universitario de Arte, Arquitectura y Diseño. (2021a). ¡Felices vacaciones! [Post Facebook]. https://www.facebook.com/CUAAD/ photos/a.544664782278444/4314585568619661/

Centro Universitario de Arte, Arquitectura y Diseño. (2021b). Comunidad CUAAD, les recordamos que este nuevo ciclo 2021-B los servicios de Control Escolar continúan a la distancia. [Post Facebook]. https://www.facebook.com/CUAAD/ photos/a.544664782278444/4383049185106632/

Centro Universitario de Arte, Arquitectura y Diseño. (2021c). Estudiantes admitidos al ciclo 2021-B, les recordamos que ya tienen acceso a SIIAU, una plataforma que utilizarán por el resto de su estancia académica. [Post Facebook]. https://www. facebook.com/CUAAD/photos/a.544664782278444/4311520958926122/

Centro Universitario de Arte, Arquitectura y Diseño. (2021d). jAtención, estudiantes admitidos de la Licenciatura en Artes escénicas! [Post Facebook]. https://www. facebook.com/CUAAD/photos/pcb.4311454275599457/4311494512262100/

Cosgaya, P. (2003). Entrevista: Rubén Fontana. https://www.cosgaya.com.ar/ articuloPrint.php?a=14

Doctorado en Innovación para el Hábitat Sustentable. (2021). Buenas noticias!!! Felicidades a todo el equipo del DIHS. [Post Facebook]. https://www.facebook. com/DIHS.UDG/photos/a.104394715100587/156909753182416/

Martínez, L. (1990). Treinta siglos de tipos y letras. Tilde. https://ikosweb.com/ tipografia/lectura_01.pdf 
Meta. (2021). Guía de anuncios de Facebook. https://www.facebook.com/business/ ads-guide/image

Semana. (2014). ¿Leer libros en papel o en un dispositivo digital? https://www.semana. com/tecnologia/tips/articulo/leer-libros-papel-dispositivo-digital/373988-3/

Universidad de Guadalajara. (2021a). ¡Aún puedes estudiar una licenciatura en el calendario 2021-B! [Post Facebook]. https://www.facebook.com/udg.mx/ photos/a.228812161541/10158712328006542/

Universidad de Guadalajara. (2021b). La vitamina D actúa como protector de enfermedades respiratorias como la influenza y contra COVID-19 [Post Facebook]. https://www.facebook.com/udg.mx/ photos/a.228812161541/10158729507936542/

Universidad de Guadalajara. (2021c). iSolicita una beca! [Post Facebook]. https:// www.facebook.com/udg.mx/photos/a.228812161541/10158773305991542/ 


\section{Capítulo 8}

\section{Las variables visuales como herramienta para la configuración del mensaje visual de artefactos de diseño de información}

Mariel García Hernández y Adrián Antonio Cisneros Hernández

La finalidad de este capítulo es describir las variables visuales como herramientas que facilitan la configuración del mensaje visual, al permitir la buena transmisión de la información y propiciar el entendimiento para el buen acceso por parte del usuario. Es importante contemplar el concepto de diseño de información como disciplina desarrolladora de artefactos, que favorezcan la transmisión de la información de manera eficaz; esto a través de la transferencia de datos complejos a información de fácil comprensión, en donde las variables visuales perceptivas y diferenciales actúan como recurso para la configuración correcta de la pieza, al ofrecer refuerzos visuales en la intención y objetivo del mensaje.

Se realiza un análisis exploratorio en tres piezas infográficas, en tres niveles de complejidad (bajo, intermedio y alto), que evidencian la aplicación de las variables, al identificar el orden de la información, agrupación y jerarquización; asimismo, deja al descubierto la asequibilidad para los usuarios que interactúa con la pieza.

\section{El diseño de información para el buen acceso a la información}

Hoy en día, la sociedad se encuentra hiperinformada e hiperconectada, debido a la accesibilidad que brindan las tecnologías de la información y la comunicación (TIC). Estas herramientas permiten la creación, distribución y manipulación de la información, sin embargo, esto no garantiza que dicha información sea comprendida y asimilada de forma eficiente por el usuario. Es en este punto que interviene el diseño de información. 
El diseño de Información, de acuerdo con Horn (1999), es el arte y ciencia que alista la información para ser utilizada de manera eficiente y eficaz; por su parte, Baer y Vacarra (2008) describieron a la disciplina como la traducción de datos complejos en información significativa, que permitirá la comprensión a las personas para lograr sus objetivos de forma rápida; por ello, es importante definir las necesidades del usuario (Black et al., 2017). Esto no es hacer que la información solo sea estéticamente atractiva, sino brindar las características que permitan claridad y significado de la información.

Horn (1999) estableció tres objetivos principales del diseño de información:

1. Elaborar documentos que sean comprensibles, asimilables con rapidez y precisión, y de fácil traducción en acciones eficaces.

2. Diseñar interacciones con equipos que sean fáciles de usar, naturales y lo más agradables posible. Esto implica resolver muchos de los problemas en el diseño de la interfaz humano-computador.

3. Permitir que las personas encuentren su camino en el espacio tridimensional con comodidad y facilidad, especialmente el espacio urbano, pero también, dados los recientes avances, en el espacio virtual. (p.15)

Asimismo, Horn (1999) determinó las cualidades que sobresalen del diseño de información: (a) la eficacia, que es la capacidad de lograr el efecto que se desea o se espera y (b) la eficiencia, que es la facultad de disponer de algo para conseguir un efecto determinado, esto en el cumplimiento de los propósitos comunicativos. Con respecto al trabajo del diseñador de información, en cualquier tipo de proyecto debe buscar que la información sea comprensible; para ello, debe transformarla y presentarla, adaptándose a los propósitos, competencias, experiencias, prioridades y condición de los usuarios, sin importar el medio, es decir, "desde el papel hasta en dispositivos digitales, indistintamente del contexto o proyecto" (Pontis, 2018, p.3).

Sin olvidar el compromiso adquirido con el usuario, como mencionaron Black et al. (2017), al incluir "un enfoque iterativo de diseño, prueba y modificación en función de sus aportes, al ofrecer resultados que se adaptan a las necesidades de las personas" (p.xi). Los recursos utilizados por el diseñador "son imágenes, símbolos, colores y palabras, para comunicar ideas, ilustrar información o expresar relaciones visualmente" (Heckman, 2009, p.10). Todo esto bajo una visión del diseño centrado en el usuario, que permite reconocer la serie de habilidades, conocimientos o 
acciones de los usuarios y, al mismo tiempo, aprender de ellos como seres diferentes, independientes del diseñador.

Es de suma importancia hacer referencia a las áreas de trabajo en diseño de información (Frascara, 2011) o artefactos posibles a crear por el diseño de información (Pontis, 2018; Visocky \& Visocky, 2008), desde diseño de textos (documentos), tablas alfanuméricas, materiales didácticos, iconos y símbolos, incluyendo las visualizaciones de datos e infografías, siendo estos últimos los productos más representativos de la disciplina.

Existen principios de diseño de información que contribuyen al diseño y al desarrollo del mensaje, estos son la base o las fuentes fundamentales dentro de la disciplina. Ronnie Lipton (como se citó en Pettersson, 2016) planteó que los principios del diseño de información son independientes a las características propias de un idioma o cultura, estableciendo ocho principios: (1) Coherencia, es el mantenimiento del estilo en los elementos; (2) Proximidad, es la composición que accede a la relación entre los recursos visuales; (3) Fragmentación, es la agrupación por relación y la separación para permitir una asimilación adecuada de la información; (4) Alineación, los elementos se alinea con otro elemento; (5) Jerarquía, es enfatizar la información importante o elementos de acuerdo con la composición, color o peso visual; (6) Estructura, es la secuencia que muestra un sentido a la información para los usuarios; (7) Equilibrio y flujo ocular, es la identificación claro del punto de partida de la información, así como secuencia ocular ideal en el material; y (8) Claridad, es referente a la redacción si es clara y concisa, de acuerdo al nivel alfabetización de los usuarios.

Asimismo, para Visocky y Visocky (2008), se pueden definir tres grupos de principios. Los primeros son los cognitivos, que están basados en la forma que los usuarios interpretan y adquieren nuevos conocimientos mediante los procesos cognitivos implicados en la comunicación visual (i. e., percepción, memoria y atención). Los segundos son los de comunicación, se enfocan en la estructuración del mensaje, referente al idioma, audiencia y expectativas, con un enfoque en la organización, la familiaridad y la alfabetización. Los terceros son los principios estéticos, que hacen referencia a la forma de presentar el mensaje; estos tienen dos categorías: estructura (retícula, jerarquía) y legibilidad (color, contraste, tipografía).

Los principios son los lineamientos que se siguen en cierta medida, conforme a las necesidades del problema y requisitos del artefacto al diseñarse, teniendo en 
cuenta las características, habilidades y necesidades de los usuarios; sin olvidar que son perceptibles a posibles ajustes, de acuerdo con el resultado de las etapas iterativas durante el desarrollo. Es por ello, que los principios se apoyan en atributos o variables visuales para favorecer la buena transmisión de la información y propiciar el entendimiento para el buen acceso.

\section{Las variables visuales como herramientas de configuración del mensaje visual}

El lenguaje visual es definido por Acaso (2006) como "el código usado para la creación del mensaje visual" (p.49). Este mensaje se configura "con base a herramientas con las que organizamos, ordenamos y jerarquizamos" (p.49) los elementos que conforman el propio mensaje visual. Estas herramientas de configuración fueron nombradas variables visuales por Jacques Bertin, considerado como el primer autor en proponer este tipo de instrumentos de configuración visual, en 1987, en su libro Semiology of Graphics (Meirelles, 2014).

De acuerdo con Olaya (2020):

Los elementos básicos de la representación son aquellos objetos geométricos de los cuales se compone ésta. Las variables visuales permiten diferenciar unos de otros y asignarles ciertas características, susceptibles a su vez de ser interpretadas junto al propio significado que el objeto pueda tener. (p.540)

Se puede decir que las variables visuales constituyen un elemento importante dentro del diseño de información, debido a que ayudan al diseñador a ordenar la información, agruparla y jerarquizarla y, a su vez, hacerla accesible para el usuario que interactúa con esta. De acuerdo con Ware (2019), se puede lograr optimizar el proceso de pensamiento visual a través de una estrategia que aluda al orden y la jerarquización de la información representada; por ello, es importante implementar una estrategia que ayude al usuario a procesar de la mejor manera posible el contenido del propio mensaje visual. Según Meirelles (2014), estas características pueden "aumentar el rendimiento de las tareas asignadas al artefacto de diseño que se está desarrollando" (p.128). 


\section{Categorías de las variables visuales}

A lo largo del tiempo y conforme se ha avanzado en el estudio de la configuración del mensaje visual, se han identificado diversas propuestas de estas herramientas; las más destacadas son las realizadas por Bertin (1983) y Meirelles (2014), estos autores presentan una serie de variables visuales que responden a diferentes características con relación a la propia configuración de la pieza de diseño que se esté trabajando.

Por su parte, Bertin (1983) definió siete variables visuales: posición, forma, tamaño, color, valor de color, textura y orientación, las cuales las categorizamos como variables visuales diferenciales; por otro lado, Meirelles (2014) señaló como variables visuales perceptivas: nitidez, resolución, transparencia y saturación.

\section{Variables visuales diferenciales}

Estas variables centran su objetivo en organizar los elementos de información dentro de la configuración del mensaje visual del objeto de diseño de información. Como ya se mencionó, estas son: posición, forma, tamaño, color, intensidad o valor de color, textura y orientación; las cuales son definidas por Olaya (2020) de la siguiente manera:

- Posición. Es la situación de localización que ocupa un símbolo en particular en el espacio. En un mapa, esto sería traducido como la posición del símbolo en algún valor de " $x$ " o " $y$ " (Figura 1).

\section{Figura 1}

Variable visual: posición

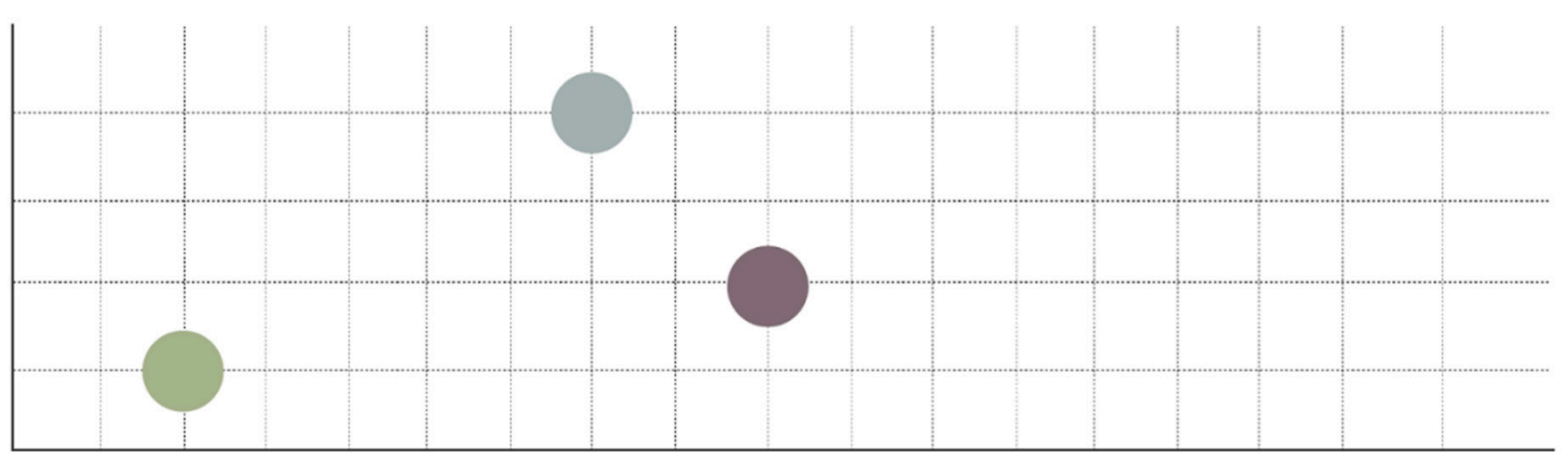

- Forma. Es la figura o determinación exterior que la distingue. Esta puede ser pictográfica o geométrica. La forma es definida por el perímetro exterior del objeto (Figura 2). 
Figura 2

Variable visual: forma
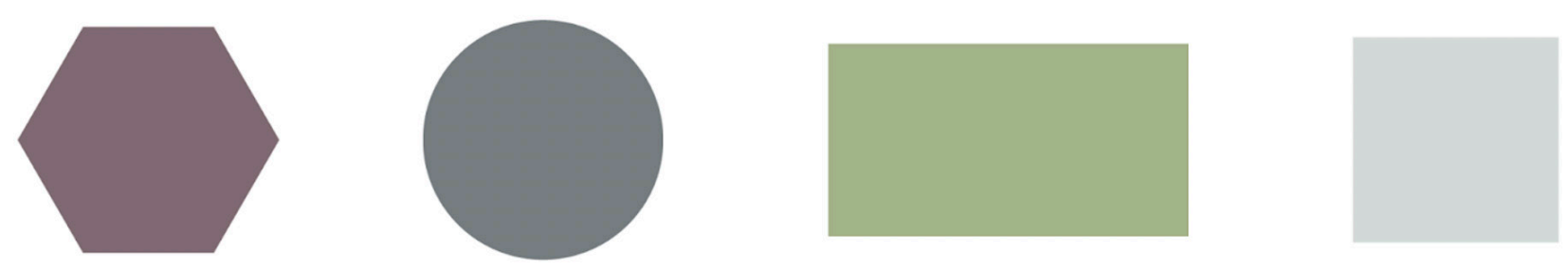

- Tamaño. Esta variable visual hace alusión a la proporción del objeto o del símbolo a representar (Figura 3). Los signos varían en tamaño en función de las dimensiones que presentan (diámetro, área, anchura, altura).

\section{Figura 3}

Variable visual: tamaño
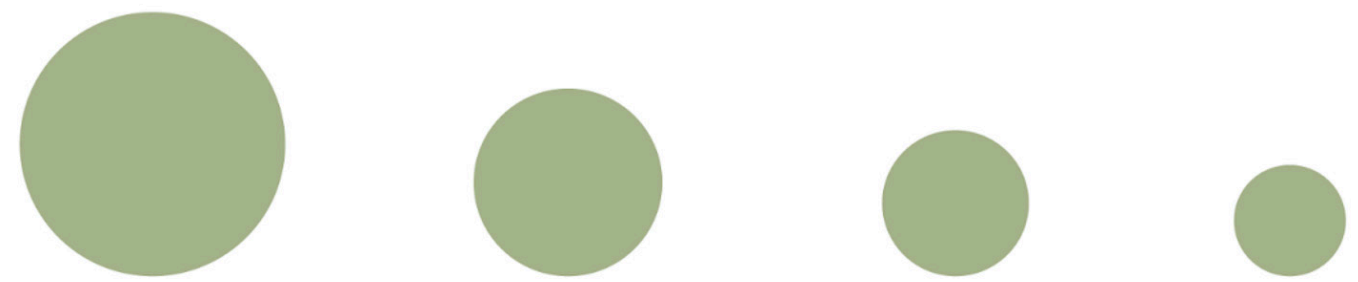

- Color. Esta variable visual es de la más usada y compleja. El color responde a la longitud de onda de la luz, a esto se le llama tono, a lo cual denominamos como rojo, azul, amarillo (Figura 4).

\section{Figura 4}

Variable visual: color
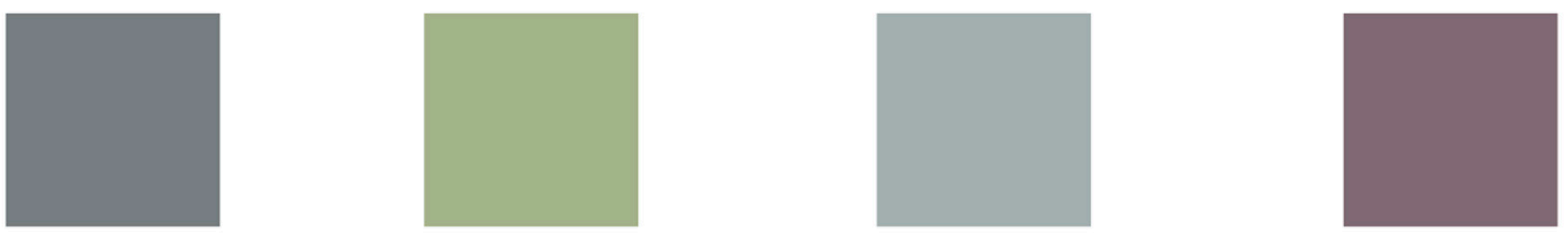

- Valor de color. Hace referencia a la claridad u oscuridad de un símbolo, ya sea este negro o de cualquier color. Se puede decir que esta variable hace referencia a la oscuridad relativa de un relleno (Figura 5). 


\section{Figura 5}

Variable visual: valor de color
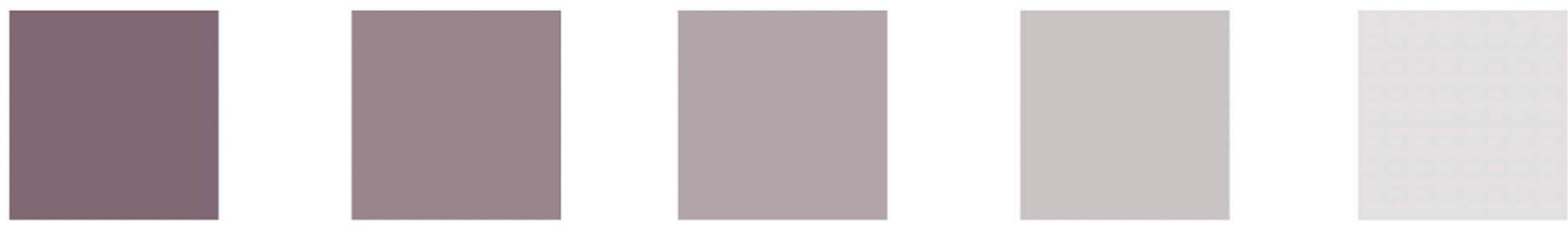

- Textura. Hace referencia al relleno de un símbolo mediante algún patrón. Al emplear patrones distintos se produce una diferenciación en los símbolos correspondientes (Figura 6).

\section{Figura 6}

Variable visual: textura
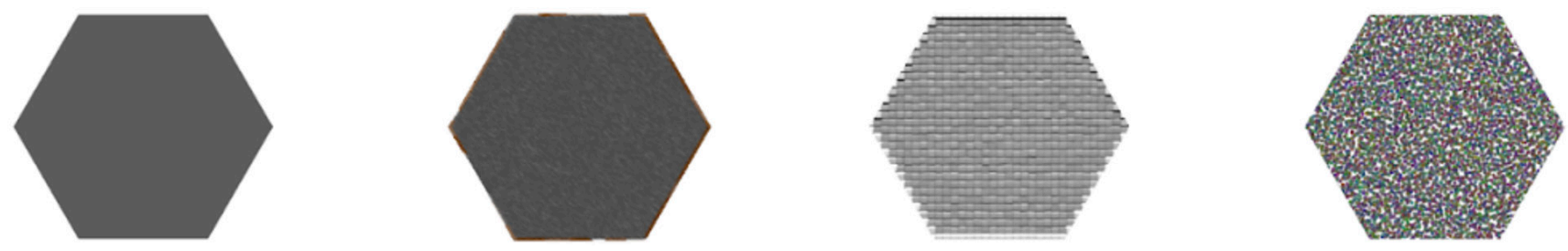

- Orientación. Es la variación de un símbolo al hacerla girar sobre el eje perpendicular del lienzo o soporte en donde el símbolo se encuentra (Figura 7).

\section{Figura 7}

Variable visual: orientación
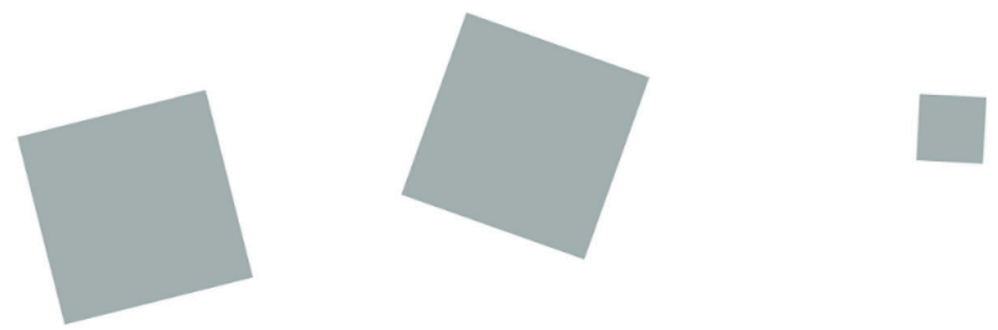

Variables visuales perceptivas

Las variables visuales perceptivas son aquellas relacionadas directamente con modificaciones de percepción visual ocular. Las variables visuales perceptivas son definidas de la siguiente manera: 
- Nitidez. Es el nivel de claridad con el que se perciben los detalles (Figura 8).

Figura 8

Variable visual: nitidez
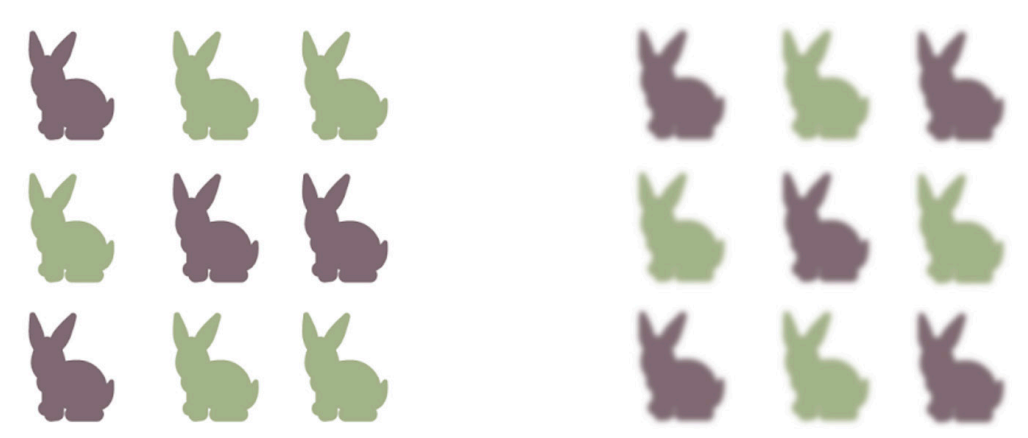

- Resolución. De acuerdo con Adobe (2021a), es "la precisión del detalle en las imágenes de mapa de bits, la cual se mide en píxeles por pulgada (ppp)" (párr.1) (Figura 9).

\section{Figura 9}

Variable visual: resolución
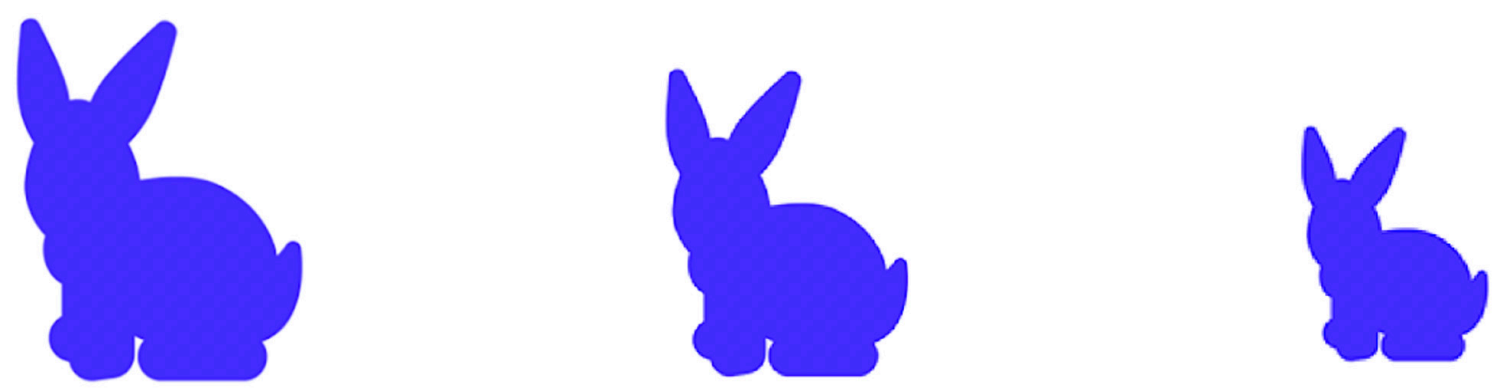

- Transparencia. Se refiere a las áreas transparentes en una imagen (Adobe, 2021b) (Figura 10).

Figura 10

Variable visual: transparencia

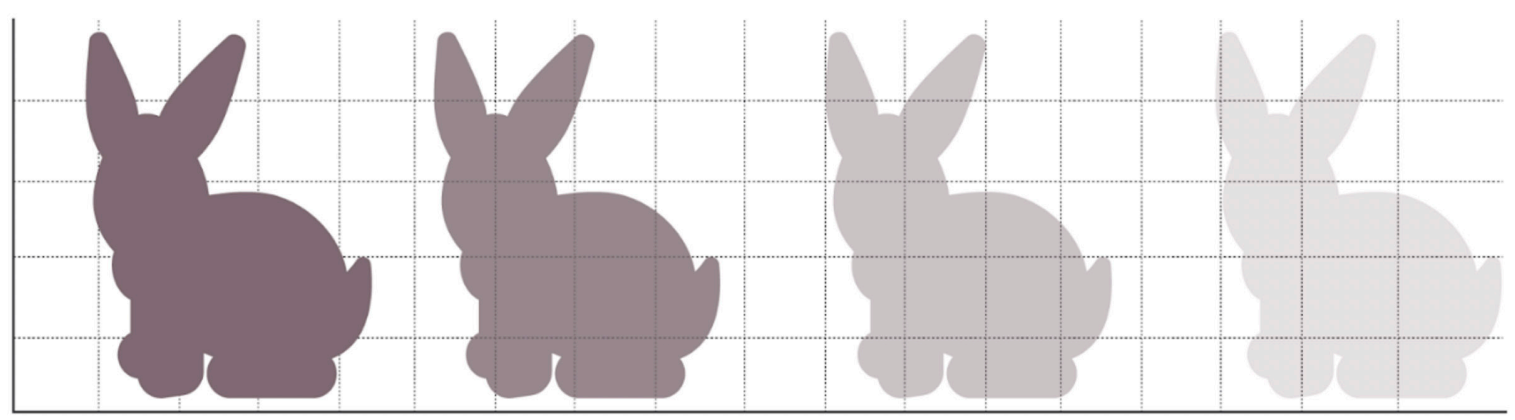


- Saturación. Propiedad relacionada con la pureza del color en la imagen, es decir, qué tan vivo es o no el color (Adobe, 2021c) (Figura 11).

\section{Figura 11}

Variable visual: saturación
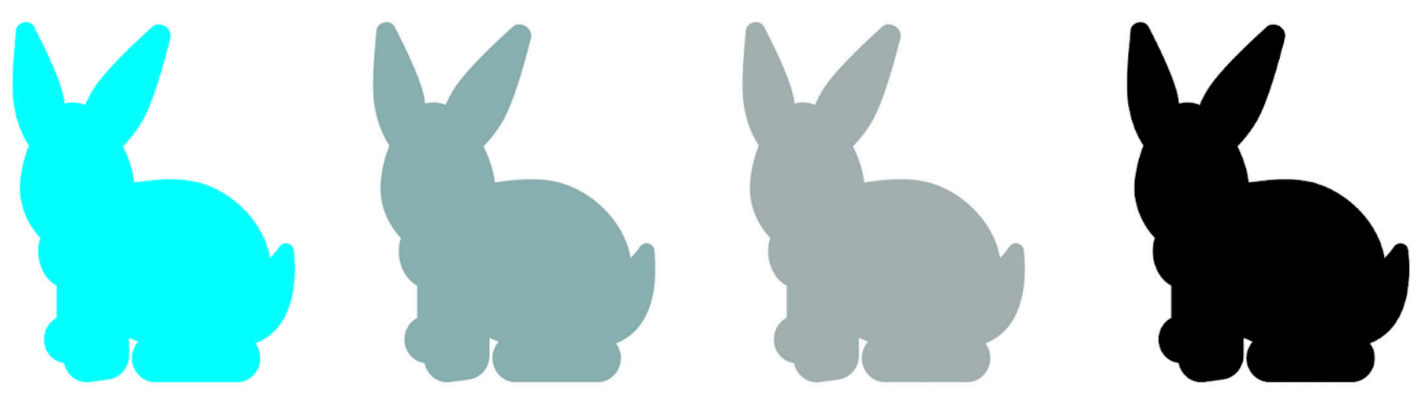

\section{Niveles o propiedades de las variables visuales}

Según Bertin (1983) y Meirelles (2014), las variables visuales presentan ciertas características; estos autores distinguen cuatro categorías, las cuales son definidas de la siguiente manera:

1. Asociativa. Es el nivel en donde las variables visuales permiten agrupar información (Bertin, 1983).

2. Selectiva. Es el nivel que permite hacer una distinción marcada entre la información.

3. Ordenada. En este nivel se genera una jerarquía en la información (Olaya, 2020).

4. Cuantitativa. En este nivel "cuando, además del orden, una variable puede mostrar cantidades o proporciones, entonces se dice que posee la propiedad cuantitativa (Olaya, 2020, p.544).

Al analizar la postura de Meirelles (2014), se presenta en la Tabla 1, una clasificación de la correlación entre las variables visuales y su nivel.

A partir de lo que se observa, la naturaleza de las variables visuales condiciona para lo que pueden ser implementadas; por lo tanto, se recomienda para la toma de diseño, que se haga de una manera consciente y estratégica, con el fin de aprovechar el potencial de cada una de estas variables y la forma en que estas son utilizadas para diseñar. 


\section{Tabla 1}

Dimensiones de análisis del entorno urbano

\begin{tabular}{|c|c|c|c|c|}
\hline $\begin{array}{l}\text { Variables visuales } \\
\text { diferenciales }\end{array}$ & Asociativa & Selectiva & Ordenada & Cuantitativa \\
\hline Posición & - & & $\bullet$ & - \\
\hline Forma & - & & & \\
\hline Tamaño & • & • & • & - \\
\hline Color & - & $\bullet$ & $\bullet$ & $\bullet$ \\
\hline Valor de color & - & • & $\bullet$ & - \\
\hline Textura & • & • & • & \\
\hline Orientación & - & & - & - \\
\hline $\begin{array}{l}\text { Variables visuales } \\
\text { perceptivas }\end{array}$ & Asociativa & Selectiva & Ordenada & Cuantitativa \\
\hline Nitidez & - & - & - & \\
\hline Resolución & - & & $\bullet$ & \\
\hline Transparencia & - & - & $\bullet$ & $\bullet$ \\
\hline Saturación & - & - & - & - \\
\hline
\end{tabular}

Nota. Elabora con base en Meirelles (2014).

\section{La configuración del mensaje visual a través de las variables visuales}

Las variables visuales son usadas como herramientas que pueden ser implementada por el encargado de configuración del mensaje visual en el producto de diseño de información que se trabaje; por ello, es importante conocer cada una de las bondades de las variables visuales, no se puede omitir que está condicionado a la naturaleza de la información, el objetivo y el usuario.

Cabe destacar que, dentro del quehacer de la configuración del mensaje visual, las variables visuales pueden servir de una clase de contenedor de más variables visuales; el diseñador puede generar un juego visual de composición complejo de información sin comprometer la claridad de esta y generar mensajes más significativos y puntuales. A continuación, se analizan las siguientes piezas de diseño de información para ejemplificar el uso de las variables visuales. Cada una de estas piezas se presenta con base a un incremento en su complejidad, relacionado directamente con el uso de la cantidad de variables visuales entre sí. 
En la Figura 12, se observa el uso de dos variables: tamaño y color; la variable visual tamaño está relacionada con cantidad (porcentaje), denotando directamente que el segmento del gráfico de pastel más grande representa un mayor porcentaje. La variable visual color hace una distinción entre dos conceptos, en este caso, hombre y mujer; se asigna el color naranja a hombre y el color azul a mujer. Debido al número de variables visuales, se puede decir que, el grado de complejidad de esta pieza de diseño de información es poca.

\section{Figura 12}

Pieza de diseño de información con uso de variables: tamaño y color

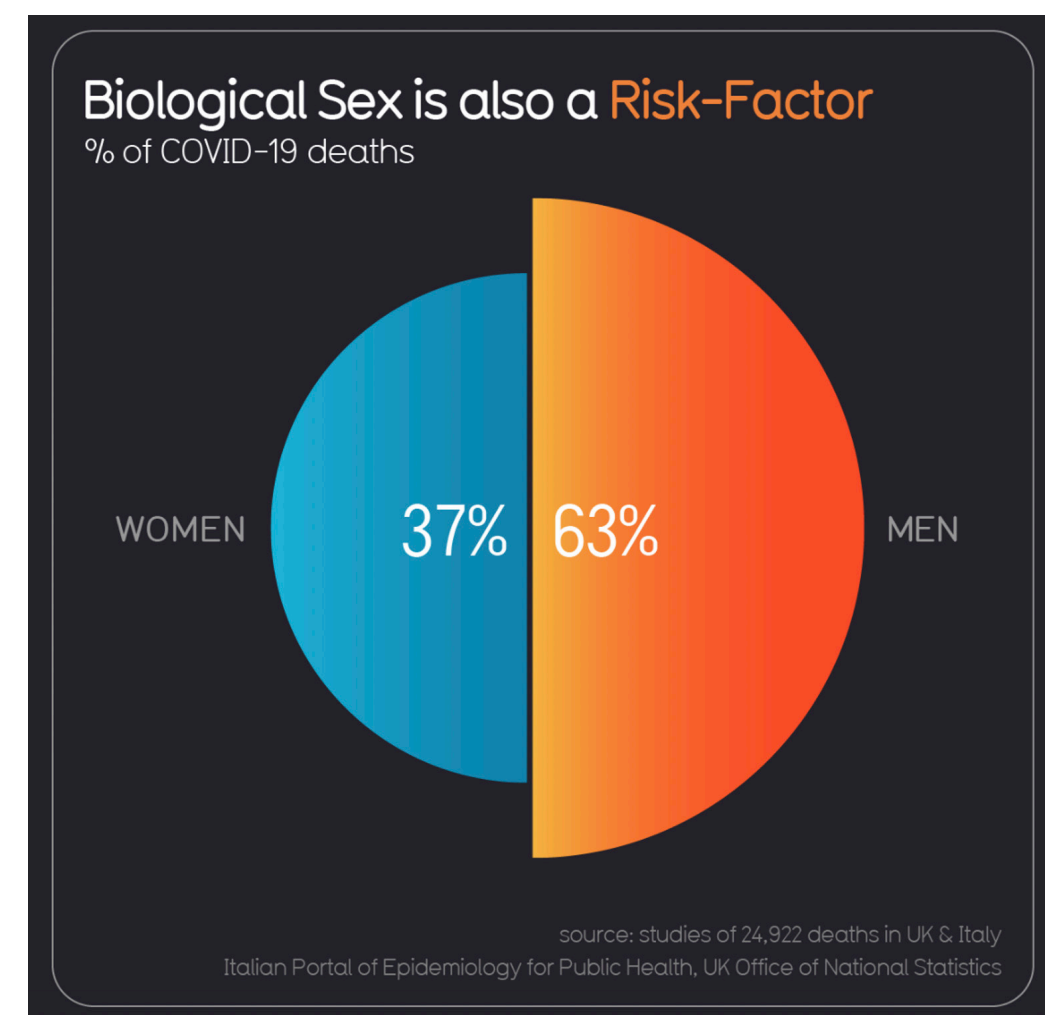

Nota. Tomado de Information is beautiful (2021a).

En la pieza de diseño de información (Figura 13), podemos observar la implementación de las variables visuales color, orientación y tamaño. Respecto a la variable visual color, se puede ver cómo en cada país un concepto es relacionado con un color; por ejemplo, en Japón, el color negro está relacionado con la infelicidad. En cuanto a la variable visual orientación, se observa que está intencionalmente en una inclinación que ayuda a generar la ilusión óptica de un círculo, lo que está relacionado con dar un juego visual de movimiento y hacer alusión al mundo. La variable visual tamaño está relacionada con la repetición de relación del lugar geográfico 
descrito, el color y el concepto relacionado a este, haciendo que el usuario pueda generar la conexión de dicho color; está relacionado con el mismo concepto en más de un país y, a su vez, cobra más fuerza semántica. Por la cantidad de variables usadas en la configuración de esta pieza, se puede decir que se presenta una complejidad media.

\section{Figura 13}

Pieza de diseño de información con uso de variables: color, orientación y tamaño

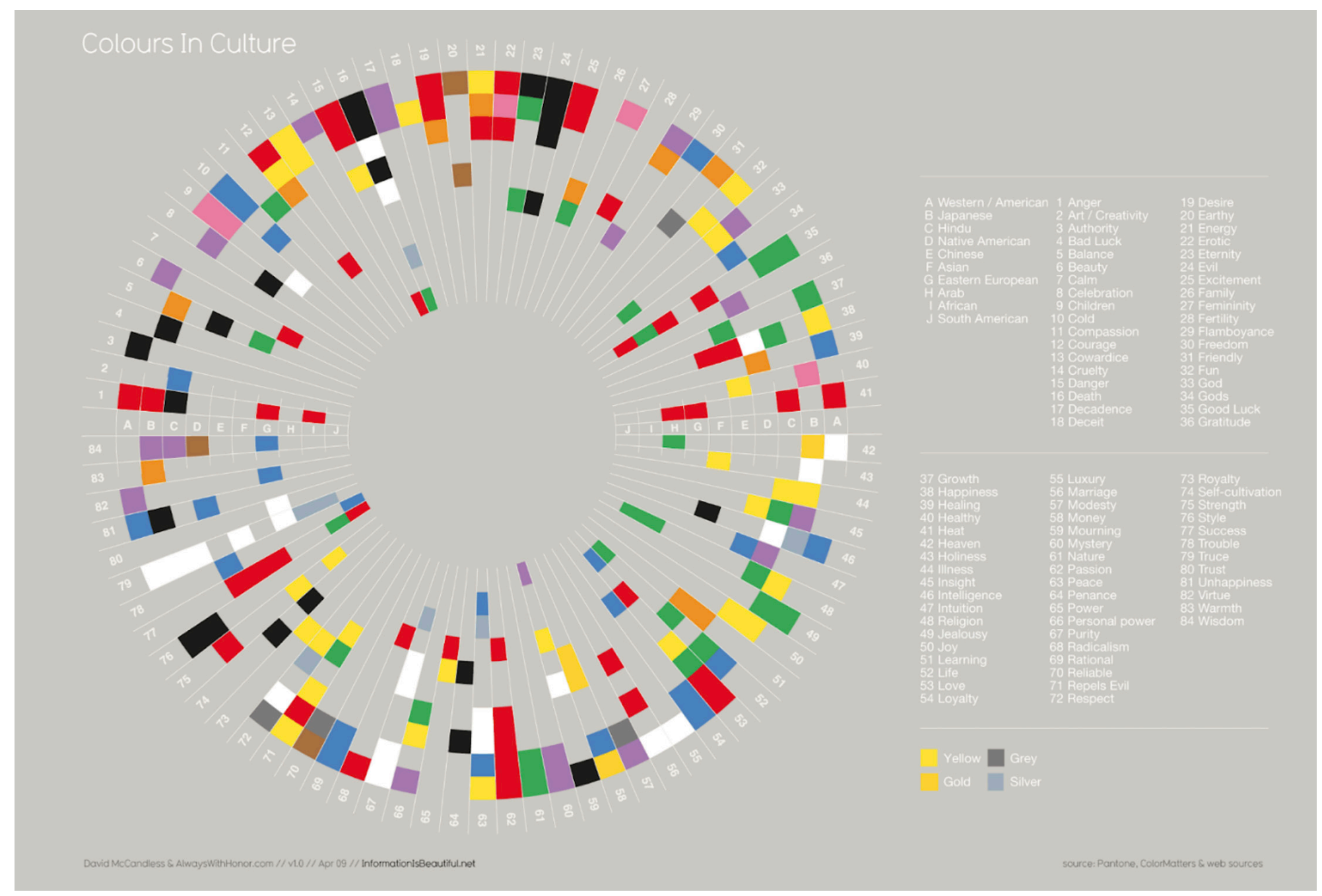

Nota. Tomado de Information is beautiful (2021b).

En la Figura 14, se observa la implementación de cinco variables visuales: saturación, color, tamaño, posición y orientación. Respecto a la variable saturación, se ve una evolución en la pureza del color amarillo (que a la vez es la variable color); a partir de estas dos variables se relaciona el nivel de riesgo para contraer coronavirus con respecto a cada una de las actividades presentadas en la pieza de diseño. Respecto a la variable visual tamaño, se aprecia que dicha característica del círculo va creciendo conforme se vuelve más alto el riesgo de la actividad que cada uno de 
estos representan. En cuanto a la variable posición, es empleada para agrupar los conceptos correspondientes a las actividades de bajo, medio y alto riesgo para contraer el virus. Respecto a la variable visual correspondiente a la orientación, vemos cómo las actividades parten de izquierda a derecha en correlación al crecimiento del riesgo que estas implican para el contagio de la enfermedad.

Debido al número de variables y la forma en que una puede servir como contenedor de otra variable en sí, podemos establecer un grado de complejidad alto de la configuración del mensaje visual de dicha pieza de diseño de información.

\section{Figura 14}

Pieza de diseño de información con uso de variables: saturación, color, tamaño, posición y orientación

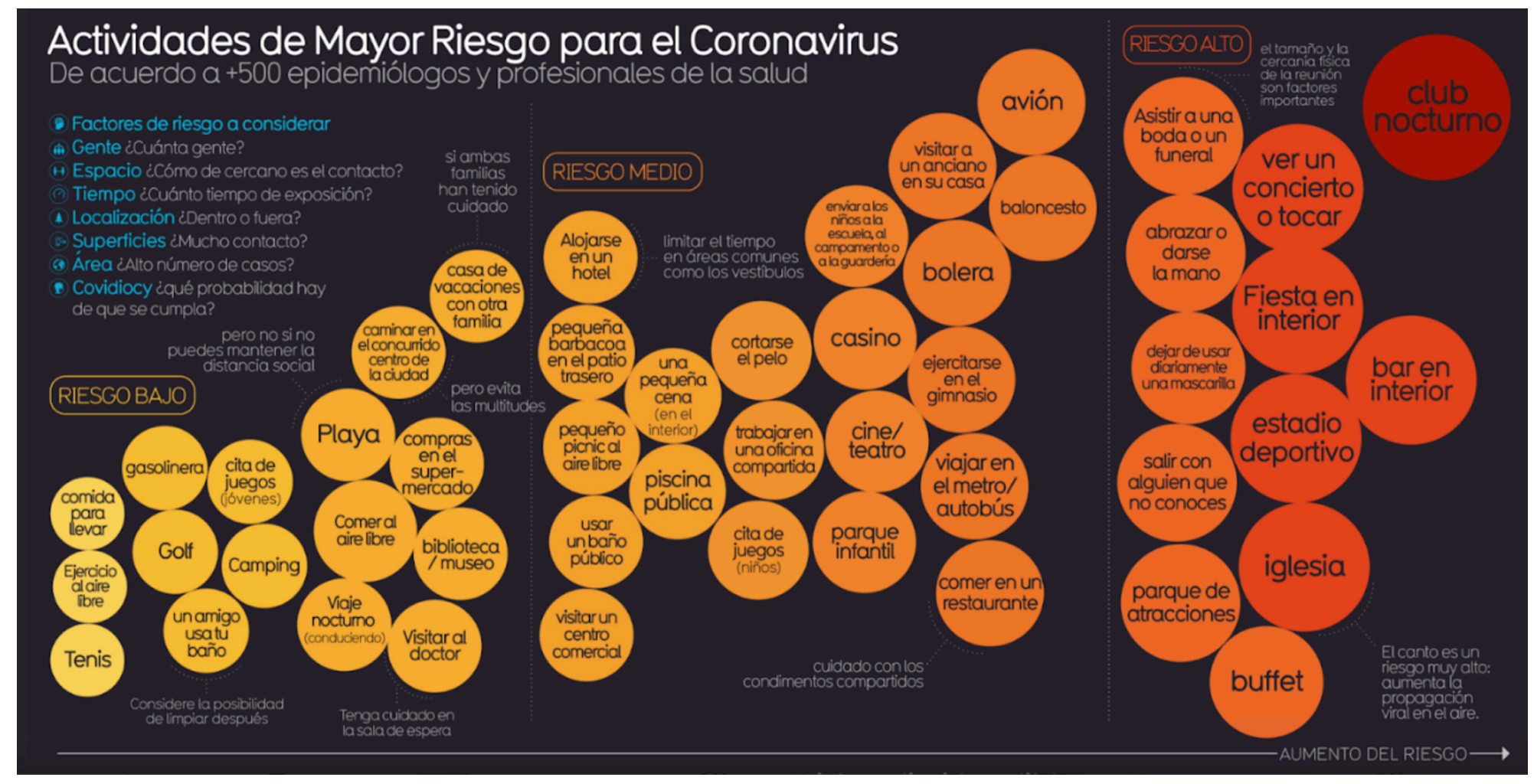

Nota. Tomado de Information is beautiful (2021c).

Como se observa en los ejemplos presentados, es viable la idea de que las variables visuales pueden estar una dentro de otra; este juego visual ayuda a generar piezas de información más puntuales, simples y significativas para el usuario. Además, estas fungen como herramientas de configuración importante para el diseñador encargado de la pieza de diseño de información a desarrollar. 


\section{Conclusiones}

A partir de este capítulo se puede identificar la determinación de las cualidades, eficacia y eficiencia en el cumplimiento de los propósitos comunicativos que sobresalen del diseño de información.

El diseñador debe propiciar en todo momento la comprensión a través de la transformación de los datos, de acuerdo con las características cognitivas del usuario y presentarla adaptándose al medio. Por lo tanto, al utilizar los principios de diseño de información, se facilitará el soporte en los atributos o variables visuales que facilitan la transmisión del mensaje.

En definitiva, las variables visuales son recursos que permiten al diseñador de información la construcción de un mensaje, bajo una estrategia consciente y objetiva; esto se logra por el potencial que otorgan las variables visuales diferenciales, las cuales brindan una organización en los elementos que participan en configuración del mensaje, y las variables visuales perceptivas, que ofrecen la posibilidad de modificar la percepción visual ocular en la construcción del artefacto.

Las variables visuales poseen características asociativas, selectivas, ordenadas y cuantitativas, las cuales confieren la oportunidad de presentar refuerzos visuales en la intención y objetivo del mensaje. Por tanto, el empleo de estas se demuestra en las piezas infográficas presentadas y se puede concluir que la aplicación de las variables visuales confiere atributos que refuerzan y orientan la percepción visual del usuario.

\section{Referencias}

Acaso, M. (2009). El lenguaje visual. Paidós.

Adobe. (2021a). Tamaño y resolución de imágenes. https://helpx.adobe.com/es/ photoshop/using/image-size-resolution.html

Adobe. (2021b). Transparencia y opacidad. https://helpx.adobe.com/es/photoshopelements/key-concepts/transparency-opacity.html

Adobe. (2021c). Saturación y desaturación. https://helpx.adobe.com/es/photoshopelements/key-concepts/saturation-desaturation.html

Baer, K., \& Vacarra, J. (2008). Information design workbook: Graphic approaches, solutions, and inspiration+ 30 case studies. Rockport Publishers.

Bertin, J. (1983). Semiology of Graphics: diagrams, networks, maps. University of Wisconsin. 
Black, A., Luna, P., Lund, O., \& Walker, S. (Eds.). (2017). Information design: research and practice. Taylor \& Francis.

Frascara, J. (2011). ¿Qué es el diseño de información? Ediciones infinito.

Heckman, D. (2009). Visualizing Information for Advocacy: An Introduction to Information Design, by John Emerson. Design and Culture, 1(3), 377-378. https:// doi.org/10.1080/17547075.2009.11643300

Horn, R. E. (1999). Information design: The emergence of a new profession. En R. Jacobson (Ed.), Information design (pp. 15-33). MIT Press.

Information is beautiful. (2021a). COVID 19 Coronavirus Data Pack. [Imagen]. https:// informationisbeautiful.net/visualizations/covid-19-coronavirus-infographicdatapack/

Information is beautiful. (2021b). Colours in culture. https://informationisbeautiful. net/visualizations/colours-in-cultures/

Meirelles, I. (2014). La información en el diseño: introducción a las historias, las teorías y las mejores prácticas para la visualización eficaz de información. Parramón.

Olaya, V. (2020). Sistemas de Información Geográfica. https://volaya.github.io/librosig/

Pettersson, R. (2016). Information Design Theories. https://www.iiid.net/runepettersson-information-design-theories/

Pontis, S. (2018). Making sense of field research: a practical guide for information designers. Routledge.

Visocky O'Grady, J., \& Visocky O'Grady, K. (2008). The information design handbook. How Books.

Ware, C. (2019). Information visualization: perception for design. Morgan Kaufmann. 
123 
Qartuppi, S. de R.L. de C.V. está inscrita de forma definitiva en el Registro Nacional de Instituciones y Empresas Científicas y Tecnológicas (RENIECYT) con el número 1600052.

Qartuppi, S. de R.L. de C.V. es miembro activo de la Cámara Nacional de la Industria Editorial Mexicana (CANIEM) con número de registro 3751.

Diseño de información en escenarios comerciales y sociales Un acercamiento a la teoría, aplicación y análisis

Esta obra se terminó de producir en diciembre de 2021. Su edición y diseño estuvieron a cargo de:

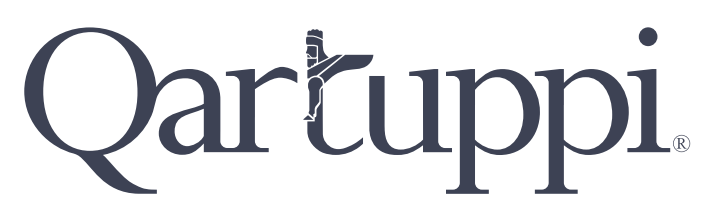

Qartuppi, S. de R.L. de C.V. https://qartuppi.com 


\section{(c) (i) $\$$}

BY NC SA

Esta obra se edita bajo una Licencia Creative Commons

Atribución-NoComercial-Compartirlgual 4.0 Internacional. 


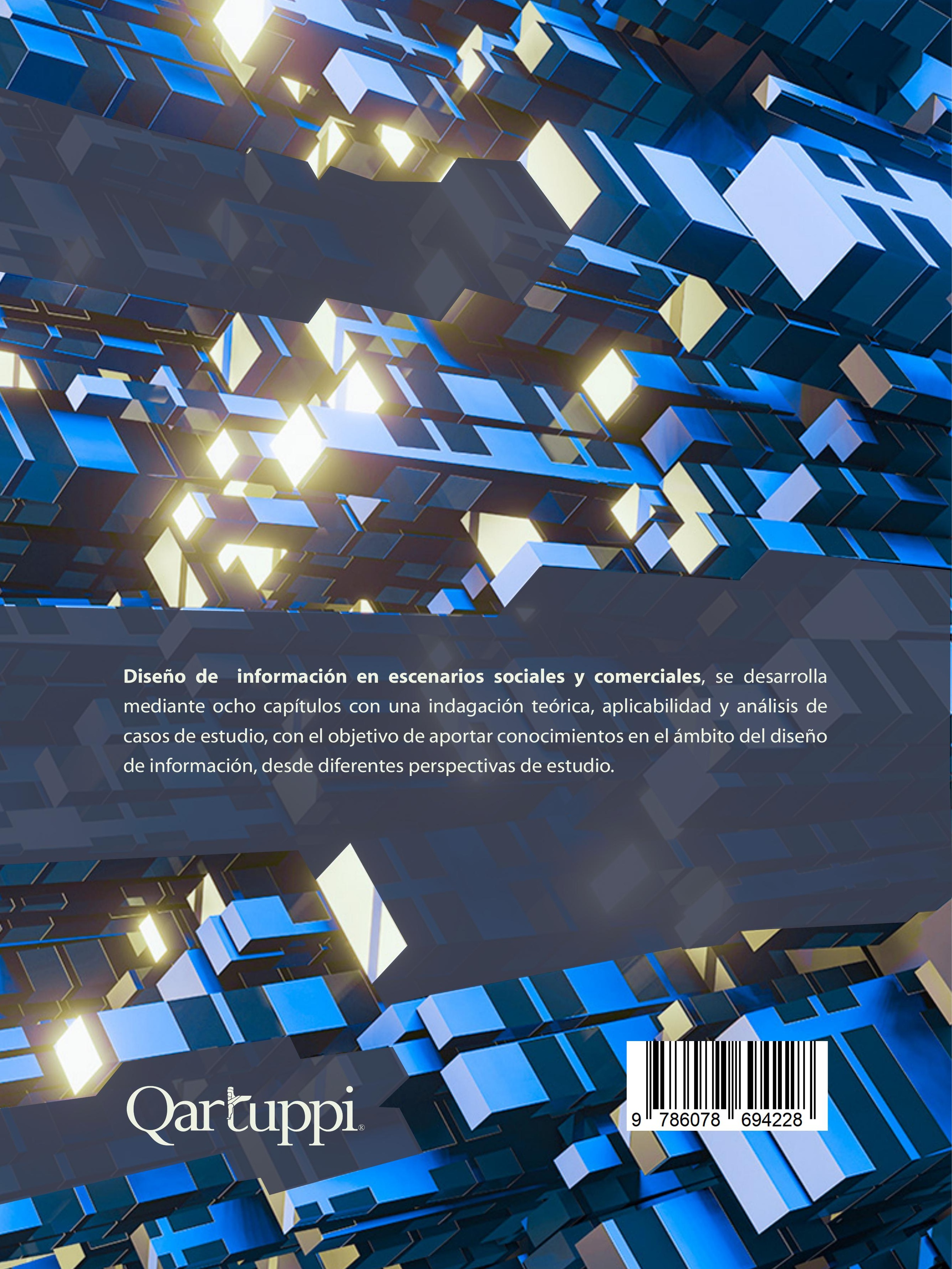

